\title{
Cost-Effective Net-Zero Energy Houses Through Optimization
}

by

Austin Selvig

A thesis submitted to the Faculty of Graduate and Postdoctoral Affairs in partial fulfillment of the requirements for the degree of

\author{
Master of Applied Science \\ in \\ Sustainable Energy Engineering
}

Carleton University

Ottawa, Ontario

(C) 2015 Austin Selvig 


\begin{abstract}
Development of net-zero energy house (NZEH) optimization has resulted in NZEHs with much lower building costs. However, a viable pathway to cost-effective NZEHs has not yet been made evident. This study uses the Non-domination Sorting Genetic Algorithm II with active Pareto-archiving (aNSGA-II) and Iterated Sequential Search (ISS) algorithms connected with EnergyPlus to perform energy and cost optimizations on seventeen scenarios to determine how NZEHs can become more cost-effective and what is necessary to make them as or more cost-effective than code-built houses. Three house types are optimized in Ottawa, Ontario: a single detached house, an end unit townhouse and a middle unit townhouse. This research finds that a single detached NZEH can be cost-effective if occupant engagement is pursued, if the price of solar photovoltaics decreases to $\$ 1.434 / \mathrm{W}$ installed, and if the construction costs are similar to that of a large-scale developer.
\end{abstract}




\section{Acknowledgements}

Most importantly I thank my supervisors, William (Liam) O’Brien, Craig G. Merrett, and Derek Hickson for their time, guidance and patience to help make this thesis a reality.

I thank the individuals within my sponsoring organization, Minto Communities, as well as within Minto Corporate Services and the Minto Sustainability Team, for their constant support on this project. I am very grateful to have been given an opportunity to work on a real net-zero energy housing project.

I thank Scott Horowitz and Craig Christensen at the National Renewable Energy Laboratory (NREL) for their training and support, and also their tireless work on BEopt, without which finishing this thesis would have been far more difficult. I also thank Alex Ferguson and CanmetENERGY for providing access to the Net-Zero Energy Housing Technology and Local Energy Efficiency Partnership (LEEP) cost databases.

I owe a great deal to the help from Burak Gunay, Brent Huchuk, Isis Bennet, and the rest of the growing building energy modelling community at Carleton University. For advice on all things policy related I thank the ever knowledgeable Harris Berton. For the financial support that allowed this project to be possible, I thank the Natural Sciences and Engineering Research Council of Canada (NSERC), and Minto Communities.

Lastly I'd like to thank Mom, Dad, Kristina, Rebecca, Josh, Kelly and the rest of my friends and family for their enduring support and encouragement. 


\section{Table of Contents}

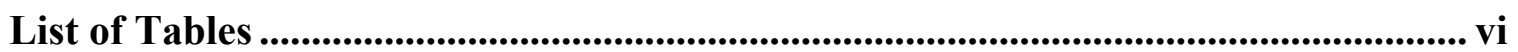

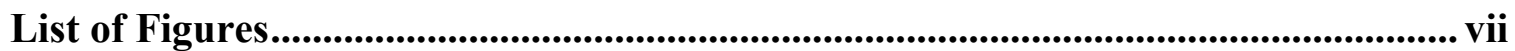

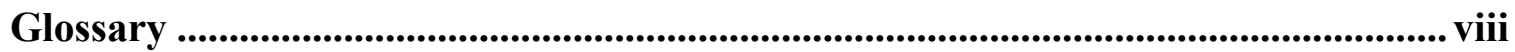

Chapter 1 : Introduction ............................................................................................................. 1

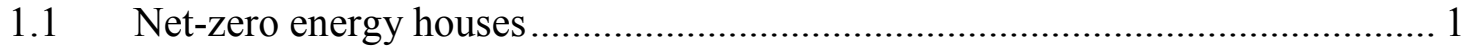

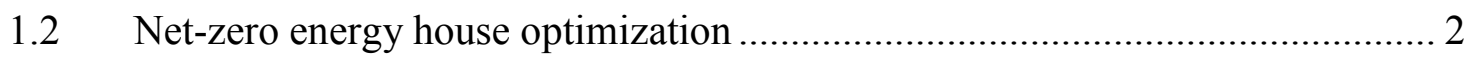

$1.3 \quad$ Cost-effective net-zero energy houses .......................................................... 4

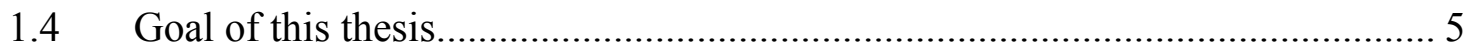

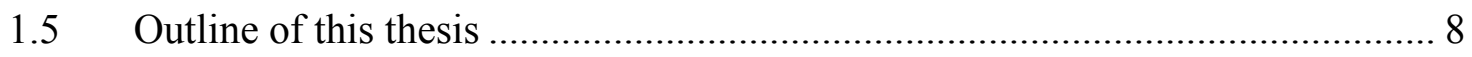

Chapter 2 : Literature Review.............................................................................................. 10

2.1 High-efficiency houses and their systems..................................................... 10

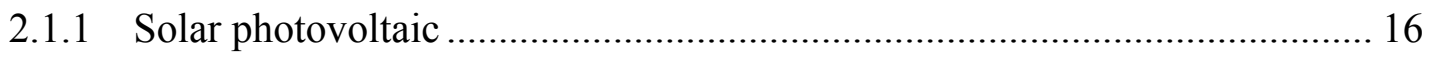

2.1.2 Heating ventilation and air conditioning and domestic hot water ................ 16

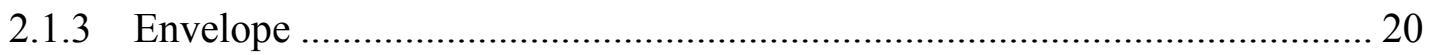

2.1.4 Lighting and appliances ……………………......................................... 22

2.2 Building performance optimization of NZEHs........................................... 25

2.2.1 Manual optimization methods.................................................................... 30

2.2.2 Research oriented automatic optimization methods .................................... 34

2.2.3 Industry oriented automatic optimization methods........................................ 38

Chapter 3 : Methodology ...................................................................................................... 41

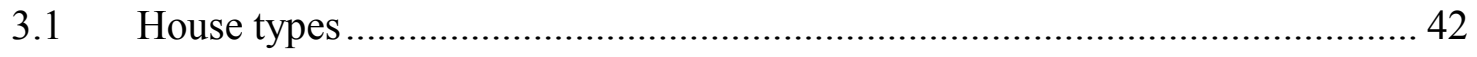




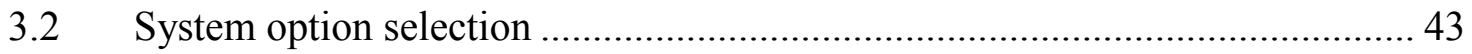

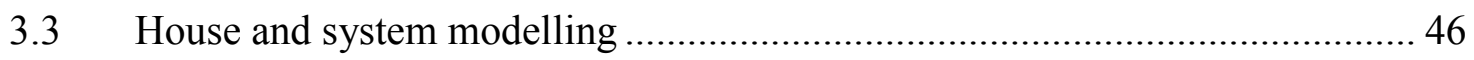

3.3.1 Selection of building performance modelling program ……....................... 47

3.3.2 Building performance modelling template file generation ........................... 49

3.3.3 Building performance modelling assumptions ............................................ 51

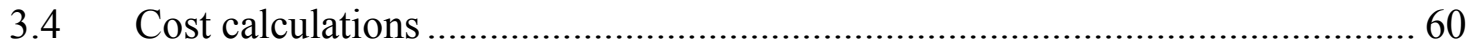

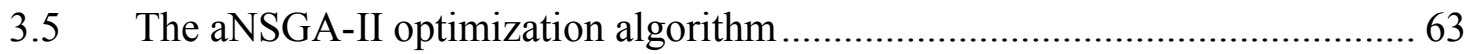

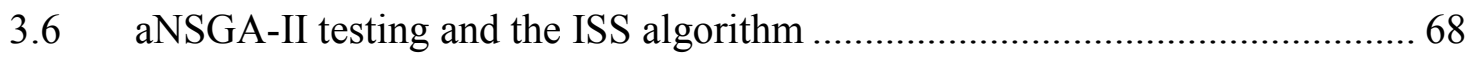

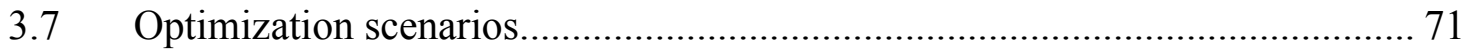

Chapter 4 : Results...................................................................................................................... 77

4.1 aNSGA-II and ISS algorithm performance................................................... 78

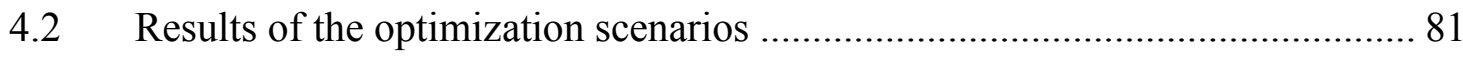

Chapter 5 : Discussion ................................................................................................................ 87

5.1 Comparison of aNSGA-II and ISS algorithms ……...................................... 87

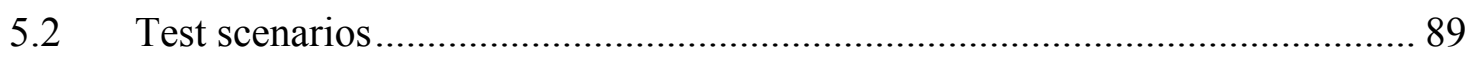

5.3 Combination scenarios and cost-effective NZEHs ......................................... 91

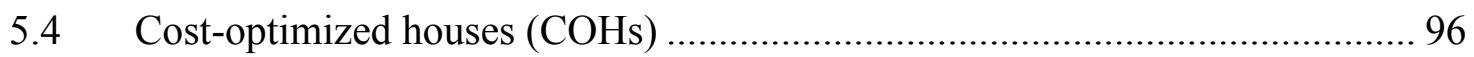

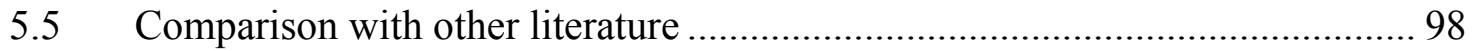

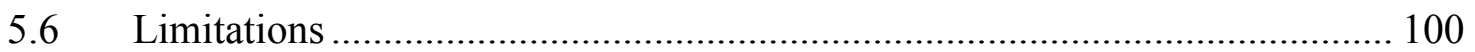

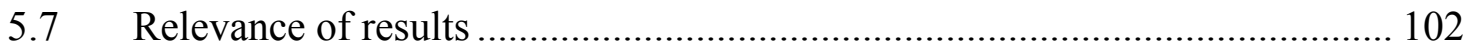

Chapter 6 : Conclusions ........................................................................................................ 104

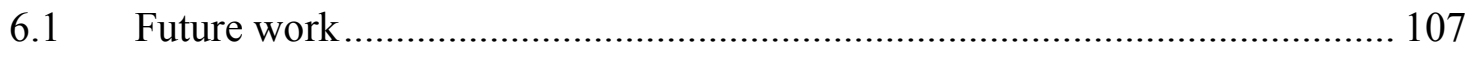

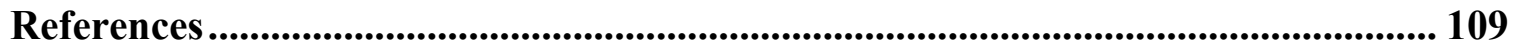


Appendix A House floorplans ............................................................................................. 116

Appendix B Systems not used in optimization ....................................................... 118

Appendix C Parameter sensitivity study ........................................................................... 120

Appendix D EnergyPlus input file generation .................................................................. 122

Appendix E Basement preprocessor settings in EnergyPlus ......................................... 123

Appendix F Costs of technologies........................................................................................ 125

Appendix G Electricity rate increase ................................................................................ 127

Appendix H NZEH and COH results from optimization scenarios............................. 128 


\section{List of Tables}

Table 1.1: Dimensions of house models optimized in this thesis .................................. 7

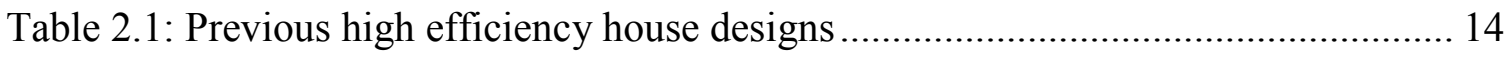

Table 2.2: HVAC and DHW systems used on houses listed in Table 2.1 ..................... 15

Table 2.3: Above ground wall systems used on houses listed in Table 2.1 ................... 15

Table 3.1: Dimensions of houses used in optimization [61], [62] ................................. 43

Table 3.2: Design parameters used in optimization................................................... 46

Table 3.3: Exterior ground temperatures found by basement preprocessor ................... 56

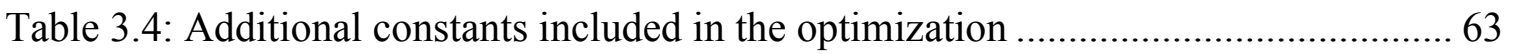

Table 3.5: Optimization scenarios and their descriptions ....................................... 72

Table 4.1: Comparison of performance between aNSGA-II and ISS algorithms............ 80

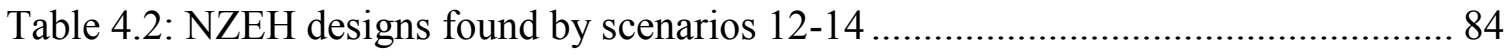

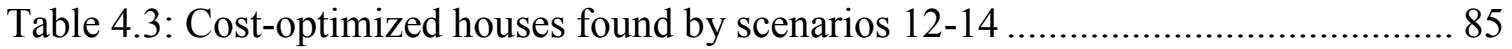

Table 4.4: Most commonly observed systems across optimization scenarios ................. 86

Table 5.1: Conceptual comparison of previously optimized NZEHs or NNZEHs.......... 99

Table B.1: Systems not used in optimization........................................................ 119

Table C.1: Sensitivity study of all system options (from code-built design)................ 121

Table D.1: Placeholders used in EnergyPlus input file templates and their functions ... 122

Table F.1: Costs for technologies used in optimization [44], [71], [73], [31], [33] ...... 125

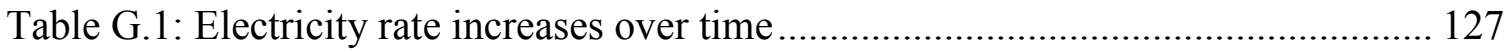

Table H.1: NZEH design and cost results from optimization scenarios...................... 128

Table H.2: $\mathrm{COH}$ design and cost results from optimization scenarios ......................... 129 


\section{List of Figures}

Figure 1.1: Single detached house type rendered in BEopt .......................................... 7

Figure 1.2: Townhouse model for end and middle house types, rendered in BEopt......... 8

Figure 2.1: Daily average electricity use of 345 single detached houses in Ottawa [49]. 24

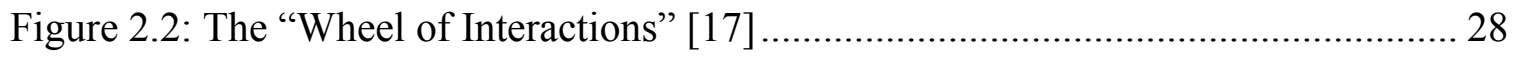

Figure 3.1: ASHP and CCASHP COP versus temperature profiles ............................. 52

Figure 3.2: Average daily profile of miscellaneous appliance load............................... 59

Figure 3.3: Overview of aNSGA-II optimization algorithm used in this thesis .............. 65

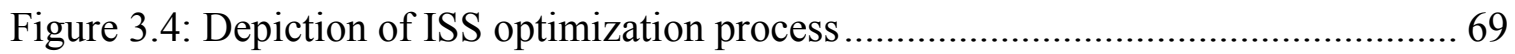

Figure 3.5: NZEH NPV for 10 test runs of the aNSGA-II algorithm........................... 70

Figure 3.6: COH NPV for 10 test runs of the aNSGA-II algorithm ............................ 71

Figure 4.1: Example of an aNSGA-II optimization output (scenario 1)........................ 78

Figure 4.2: Example of ISS optimization output (scenario 1) ...................................... 79

Figure 4.3: Optimization scenario cost results for NZEHs..................................... 81

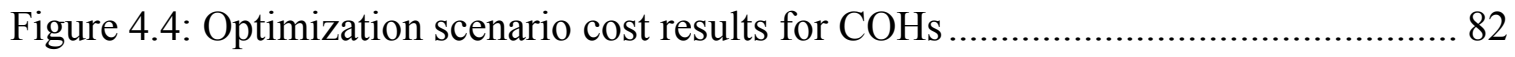

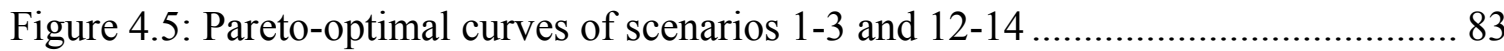

Figure A.1: Townhouse (end and middle unit) floorplans [62] ................................ 116

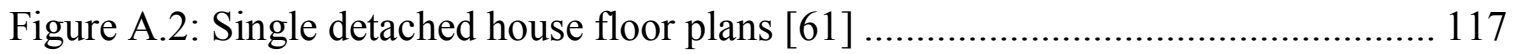




\section{Glossary}

\begin{tabular}{|c|c|}
\hline $\mathrm{AC}$ & Air conditioning \\
\hline $\mathrm{ACH}$ & Air changes per hour \\
\hline $\mathrm{ACH} 50$ & Air changes per hour at 50 Pascals \\
\hline AFUE & Annual fuel utilization efficiency \\
\hline AIA & The American Institute of Architects \\
\hline aNSGA-II & Active Pareto-archive, Non-domination Sorting Genetic Algorithm II \\
\hline ASHP & Air source heat pump \\
\hline ASHRAE & American Society of Heating Refrigerating and Air Conditioning \\
\hline & Engineers \\
\hline BEopt & Building Energy Optimization \\
\hline CCASHP & Cold climate air source heat pump \\
\hline $\mathrm{CHP}$ & Combined heat and power \\
\hline $\mathrm{CMHC}$ & Canadian Mortgage and Housing Corporation \\
\hline $\mathrm{CO}_{2}$ & Carbon dioxide \\
\hline $\mathrm{CO}_{2} \mathrm{e}$ & Carbon dioxide equivalent \\
\hline $\mathrm{COH}$ & Cost-optimized house \\
\hline $\mathrm{COP}$ & Coefficient of performance \\
\hline DG & Double glazed \\
\hline DHW & Domestic hot water \\
\hline $\mathrm{DOE}$ & U.S. Department of Energy \\
\hline DWHR & Drain water heat recovery \\
\hline ECM & Energy conservation measure \\
\hline
\end{tabular}




\begin{tabular}{ll} 
ecoEII & ecoEnergy Innovation Initiative \\
EF & Efficiency factor \\
EPS & Expanded polystyrene \\
ERV & Energy recovery ventilator \\
GenOpt & Generic Optimizer Tool \\
GHG & Greenhouse gasses \\
GSHP & Ground source heat pump \\
HE & High efficiency \\
HPWH & Heat pump water heater \\
HRV & Heat recovery ventilator \\
HSPF & Heating seasonal performance factor \\
HVAC & Heating ventilation and air conditioning \\
IBC & Incremental building costs \\
ICF & Insulated concrete form \\
IDP & Integrated design process \\
IPCC & Intergovernmental Panel on Climate Change \\
IR & Improvement ratio \\
ISS & Iterated Sequential Search \\
LBNL & Lawrence Berkeley National Laboratory \\
LED & Light emitting diode \\
LEEP & Local Energy Efficiency Partnership \\
MATLAB & Matrix Laboratory \\
MicroFIT & Micro Feed-In Tariff \\
\hline
\end{tabular}




\begin{tabular}{|c|c|}
\hline NPV & Net present value \\
\hline NREL & National Renewable Energy Laboratory \\
\hline NSGA-II & Non-domination Sorting Genetic Algorithm II \\
\hline NNZE & Near net-zero energy \\
\hline NNZEH & Near net-zero energy house \\
\hline NZE & Net-zero energy \\
\hline NZEH & Net-zero energy house \\
\hline $\mathrm{PH}$ & Passive House \\
\hline pNSGA-II & Passive Pareto-archive, Non-domination Sorting Genetic Algorithm II \\
\hline PV & Photovoltaic \\
\hline PVT & Photovoltaic thermal \\
\hline $\mathrm{SD}$ & Solar Decathlon \\
\hline SDHW & Solar domestic hot water \\
\hline SEER & Season energy efficiency rating \\
\hline SHGC & Solar Heat Gain Coefficient \\
\hline SIP & Structurally insulated panels \\
\hline TG & Triple glazed \\
\hline ULE & Ultra-low energy \\
\hline VIP & Vacuum insulated panels \\
\hline XPS & Extruded polystyrene \\
\hline
\end{tabular}




\section{Chapter 1: Introduction}

Net-zero energy houses (NZEHs) provide a potential opportunity to cost-effectively reduce greenhouse gas (GHG) emissions. Residential GHG emissions in Canada make up $45 \mathrm{Mt} \mathrm{CO}_{2} \mathrm{e}$ and Canada's goal is to reduce carbon emissions by approximately $122 \mathrm{Mt}$ $\mathrm{CO}_{2} \mathrm{e}$ by 2020 [1]. The construction of NZEHs can assist in meeting these energy targets. While many NZEHs have been built and there have been efforts to minimize the costs of NZEHs through optimization, there have been no viable cost-effective NZEH designs for a Canadian climate. Cost-effective is defined in this thesis as having a net present value (NPV) of $\$ 0$ or better with a discount rate of $4 \%$. The goal of this thesis to find costeffective NZEH designs that could be realistically implemented by builders and used by homeowners.

\subsection{Net-zero energy houses}

There has been a great deal of research on NZEHs to date. NZEHs are most commonly defined as houses that generate as much energy as they consume on an annual basis at the site level [2]. There are other ultra-low energy house definitions. Some examples of these ultra-low energy house definitions are net-zero source energy houses, net-zero emissions houses, and Passive Houses. Net-zero source energy houses are designed so that the energy generated by the house offsets all energy consumed in the process of energy generation and delivery to the house, as well as the energy consumed by the house [2]. Net-zero emission houses are designed so that the carbon emissions generated by the house equal those offset by renewable energy generation [2]. Lastly, Passive Houses are 
designed to meet strict requirements for heating loads $\left(10 \mathrm{~W} / \mathrm{m}^{2}\right.$ maximum heating load, and $15 \mathrm{kWh} / \mathrm{m}^{2}$ year annually) [3]. The Passive House standard does not require renewable energy generation. The net-zero site energy definition was chosen for this research because it is an achievable goal, it is one of the most common ultra-low energy house definitions, and it allows for many different pathways for reducing energy.

There are numerous advantages to NZEHs. The main reason why NZEHs are desirable is because they offset a large amount, if not all, of their greenhouse gas (GHG) emissions, leading to a reduced impact on the environment and climate [4]. NZEHs have some additional benefits [4]. Because NZEHs have more efficient envelopes and ventilation systems, they tend to be more comfortable and have better air quality. NZEHs have low energy bills, so they are insensitive to price fluctuations of utilities and because of NZEH construction, local jobs related to high performance construction are created.

\section{$1.2 \quad$ Net-zero energy house optimization}

Most of the work that has been done on NZEH research in Canada is centered on the EQuilibrium ${ }^{\mathrm{TM}}$ Initiative started in 2006 by the Canadian Mortgage and Housing Corporation (CMHC). This initiative focussed on NZEH design, and fifteen very high efficiency houses were built, with ten being designed as NZEHs [5]. Most of Canada's NZEHs originated from that initiative, or were built afterwards by companies that had

participated in the initiative. For example, Habitat Studio in Edmonton, Alberta has built several NZEHs since their EQuilibrium ${ }^{\mathrm{TM}}$ house, the Riverdale NZE, was built.

Internationally, a competition called the Solar Decathlon promotes NZEHs through a competition involving prototype NZEHs. The Solar Decathlon is now being 
held in the US, Europe and China, at least once per year, and encourages teams of students to design, build and compete NZEHs in ten different challenges.

The research and progress on NZEHs is likely inspired by the fact that energy reductions in buildings (including houses) are one of the most cost-effective ways to reduce carbon emissions [6]. This is also the reason why many areas around the globe are setting targets to significantly improve energy efficiency in buildings and houses [7], [8].

In spite of all the design effort being invested NZEHs, there are large variations in the designs and costs, even when designed for the same climate. It would be expected that NZEHs built for similar climates would have a cost-optimal design, and that designs by different groups would generally be close to optimal and similar to each other, but this is not the case. Industry generally recognizes that designing a NZEH is not difficult, and can be achieved simply by adding more energy saving features, but it is much more difficult to design a cost-optimal NZEH [9]. This difficulty is due to the complexity of the NZEH design problem. The complexity is mainly due to the high number of energy saving approaches and technologies, and the high number of interactions between these energy saving features.

Because of the complexity of the NZEH design problem there has been NZEH optimization research on many levels [10]. Much of the optimization has happened at the academic level, usually with computational optimization. In industry, optimization has typically been limited to iterative heuristics instead of computational optimization, because most computational optimization is too difficult to use [10]. For example, Habitat Studio, which participated in the EQuilibrium ${ }^{\mathrm{TM}}$ Initiative, has refined its design technique for NZEHs. This step by step, iterative design heuristic has allowed them to 
decrease the cost of their NZEHs by several tens of thousands of dollars, while also decreasing complexity. This design technique is essentially a human guided optimization method, which is referred to here as manual optimization [11]. Although manual optimization methods are helpful for reducing costs, Athienitis et al. [12] has shown that computational optimization methods can find more cost-effective designs than can be found with manual optimization. Some NZEH builders use manual optimization, but very few have used computational optimization techniques in designing their NZEHs [13]. Research level optimization of this type has rarely made it into practice [10].

In the U.S., a computer program called BEopt (Building Energy Optimization) may be one of the few tools that can allow industry to perform computational optimization. Developed by the National Renewable Energy Laboratory (NREL), this program was designed to be an accessible house optimization tool. BEopt has a wide array of systems that can be optimized over, with cost information on those systems, an interface for designing house forms and a built in optimization algorithm. Learning BEopt is more straightforward for industry when compared to using other optimization tools that do not have these features.

\subsection{Cost-effective net-zero energy houses}

Numerous studies have performed NZEH optimization in order to try to reduce costs, and, as of 2013, the maximum net present value (NPV) found for a NZEH with a micro feed-in-tariff (MicroFIT) of $\$ 0.546 / \mathrm{kWh}$ designed for Eastman, Quebec was $-\$ 12,600$ (with a discount rate of 4.18\%) [14]. So NZEH research is approaching cost neutrality, where the increased costs are being reduced enough so that energy savings are able to 
offset them. The 2011 Net-Zero Energy Home Coalition survey found that the most significant barrier to the uptake of NZEHs is cost [15]. There are a small number of people who are willing to pay more for NZEHs, but it is likely that if the premium for NZEHs was negligible, then there would be much greater demand. Increased demand for NZEHs means greater energy and carbon emission savings, making it possible for Canada to reach its carbon emissions savings targets.

In this thesis, cost-effectiveness is defined as an NPV of \$0 or more, when compared to and equivalent code-built house, meaning that choosing the NZEH option provides a return of at least the discount rate. However, no studies as of yet have revealed a viable path to cost-effective NZEHs.

\subsection{Goal of this thesis}

This thesis attempts to find the design characteristics of cost-effective NZEHs using formal optimization methods. The houses will be optimized under a number of scenarios that could improve the cost-effectiveness and the most straight-forward path for achieving cost-effectiveness will be chosen.

This method uses building performance modelling in conjunction with multiobjective optimization. The building modelling tool used is EnergyPlus. The optimization algorithm used is called the Non-domination Sorting Genetic Algorithm II with active Pareto- archive (aNSGA-II). This algorithm is a multi-objective genetic algorithm that simultaneously searches for cost-effectiveness and energy efficiency. This property of the optimization allows it find the most cost-effective designs along a Pareto front. An 
Iterated Sequential Search (ISS) algorithm is also run alongside the aNSGA-II algorithm in order to confirm that the algorithm is providing near-optimal results.

The unique contribution of this thesis is that it attempts to find a pathway to a cost-effective NZEH and that it performs this study on a real industry problem, and tests the advantage of large-scale developer costs. Minto Communities, a housing developer, is part of an ecoEnergy Innovation Initiative (ecoEII) funded by NRCan's Office of Energy Research and Development (OERD) and run by Owens Corning. This initiative, referred to as "Integrating renewables and conservation measures in a net-zero energy low-rise residential subdivision", is an initiative to build five net-zero energy (NZE) communities across Canada [16]. Minto is one of five developers that are part of this initiative. Minto is to build one community of five NZEHs in Ottawa, Ontario, and the houses in this community are being optimized in this thesis. Close partnership with Minto ensured the optimization parameters realistically reflected design constraints by providing feedback on cost data, system selection, and possible architectural changes to the houses.

There are three models that are optimized in this thesis: a single detached house, an end unit townhouse and a middle unit townhouse. The simplified house specifications are shown in Table 1.1, the floorplans of the houses are shown in Appendix A and the renderings of the houses are shown in Figure 1.1 and Figure 1.2. It is important to note that although the townhouses are physically modeled as separate houses, the walls are modelled as adjoined where necessary and any windows on adjoined walls are removed. Also, apart from having differences in the number of adjoined walls, the end and middle townhouse units have the same floorplan. 


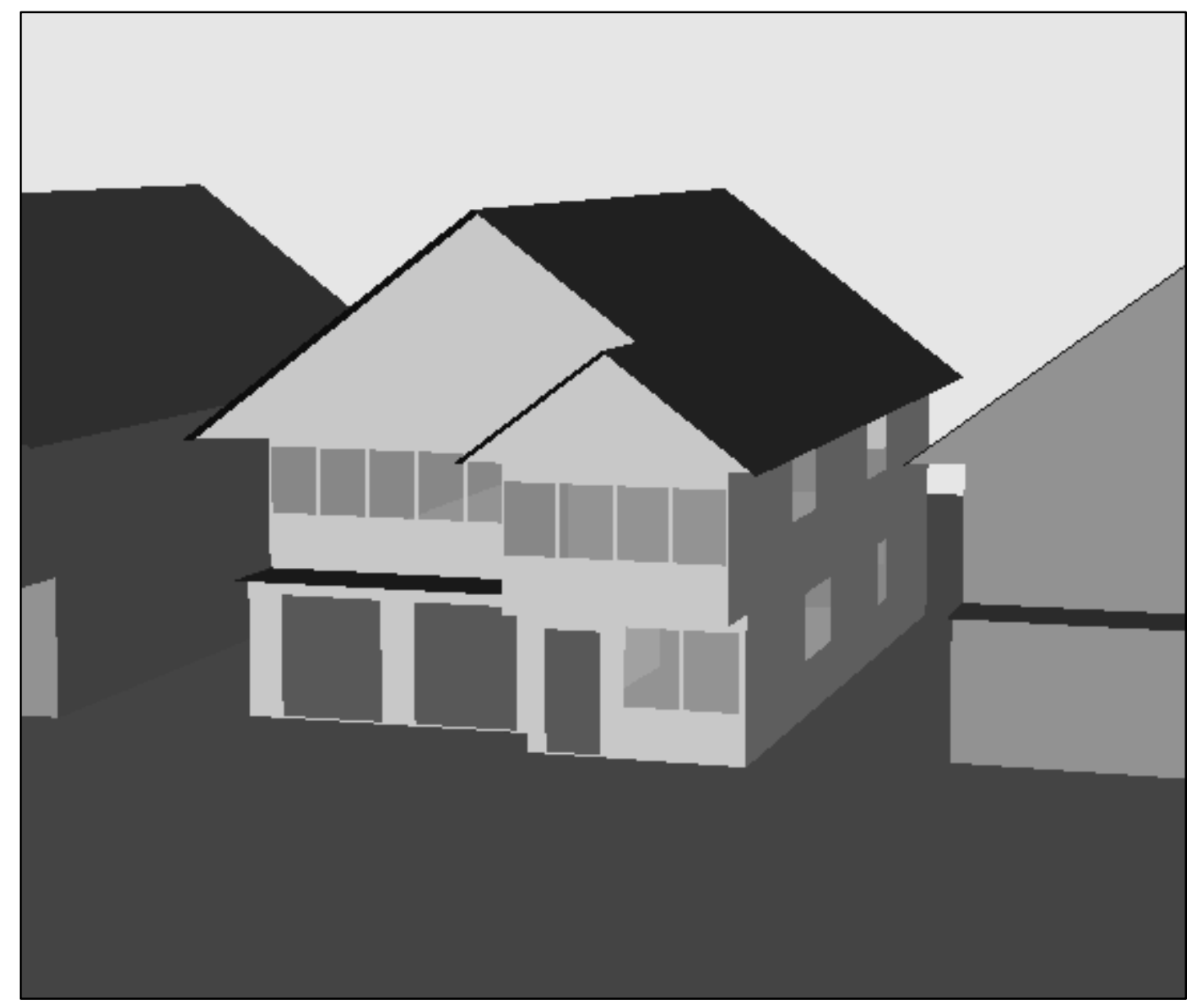

Figure 1.1: Single detached house type rendered in BEopt

Table 1.1: Dimensions of house models optimized in this thesis

\begin{tabular}{lccc}
\hline & Single & End* & Middle* \\
\hline Gross heated floor area $\mathbf{- ~}^{\mathbf{2}}(\mathbf{s q} \mathbf{f t})$ & 318.8 & 195.1 & 195.1 \\
& $(3432)$ & $(2100)$ & $(2100)$ \\
Total exposed wall area $\left.\mathbf{- ~}^{\mathbf{2}} \mathbf{( s q} \mathbf{f t}\right)$ & 240.8 & 115.9 & 74.3 \\
& $(2592)$ & $(1248)$ & $(800)$ \\
Total window area $\mathbf{- ~}^{\mathbf{2}}(\mathbf{s q} \mathbf{f t})$ & 31.8 & 19.6 & 17.3 \\
Orientation of front of house - degrees clockwise from North & 229.8 & 319.8 & 319.8
\end{tabular}

* End and middle units have the same floor plan. The northeast wall of the end unit is modeled as adjoined, and the northeast and southwest walls of the middle unit are modelled as adjoined. 


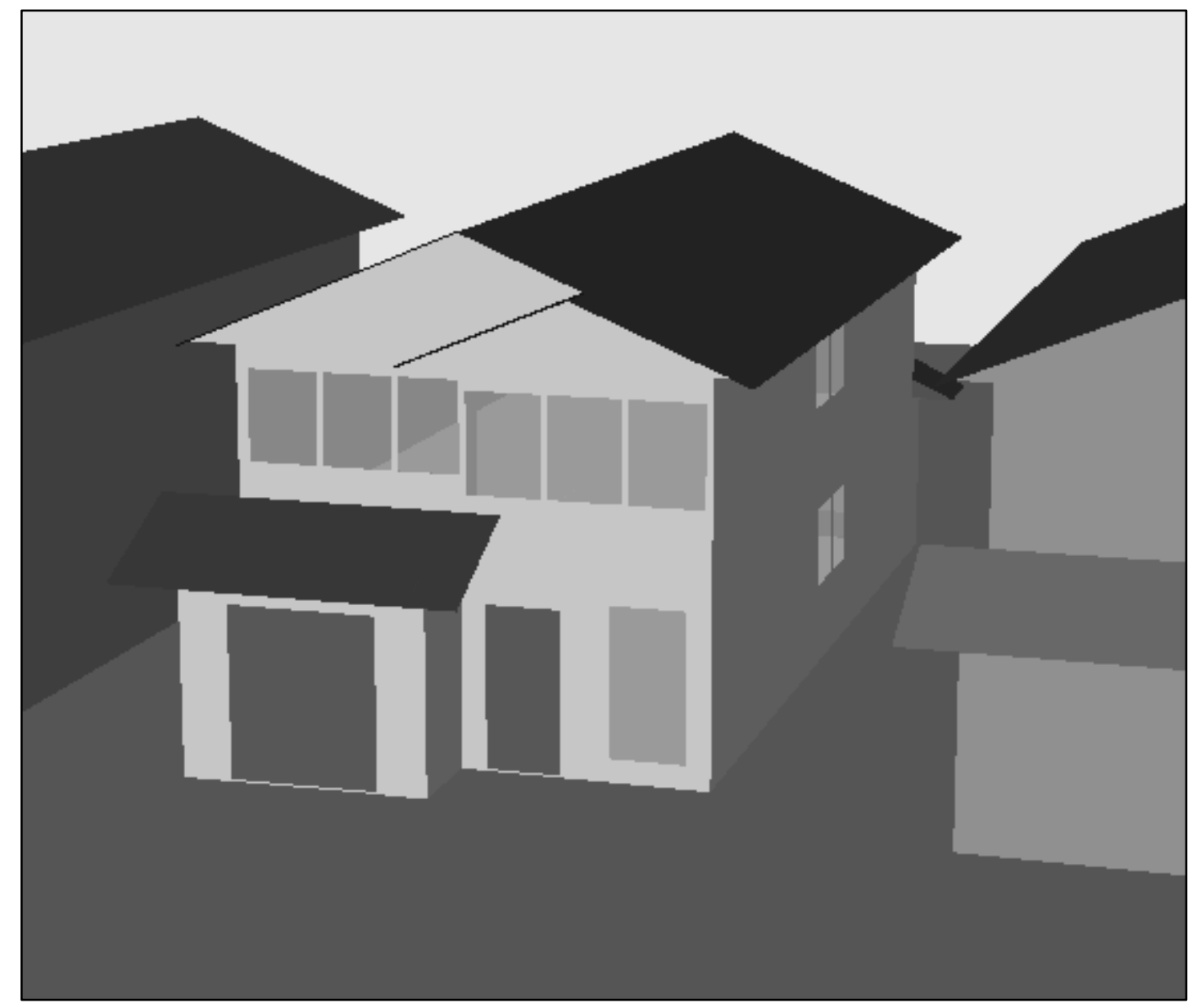

Figure 1.2: Townhouse model for end and middle house types, rendered in BEopt.

\subsection{Outline of this thesis}

Chapter 2 starts by reviewing key cold climate NZEHs, as well as their technologies and design strategies, which sets up a basis for the optimization. An extensive list of upgrade technologies used in NZEHs is presented. The difference between manual and computational optimization is discussed. Chapter 3 discusses the energy modelling assumptions, the programming language and the optimization algorithms. Section 3.7 describes the optimization scenarios that are used in this thesis to determine the impacts of different factors on NZEH cost-effectiveness. Chapter 4 compares the performance of 
the two optimization algorithms and presents the results of the optimization scenarios, which includes the designs and costs for NZEHs and cost-optimized houses (COHs). Chapter 5 discusses the implications of the optimization scenario results, the implications of cost-effective NZEHs, and the limitations of this thesis. Finally the results and conclusions are summarized in Chapter 6 and possible future research areas and improvements on this research are outlined in 6.1. 


\section{Chapter 2: Literature Review}

Net-zero energy houses (NZEHs) or near NZEHs (NNZEHs) are being pursued actively in Europe and the U.S., with both of these entities setting goals to have all of their buildings near net-zero energy (NNZE) or net-zero energy (NZE) in the near future [7], [8]. Unfortunately NZEH design is difficult to optimize for cost. The systems used in NZEHs are significantly different from house to house, demonstrating that NZEH systems design is not yet established. The inherent difficulty is the high level of interaction between different design components [17], which results in unnecessarily complex and expensive NZEHs. Optimization is necessary, and has been used in research to take advantage of these interactions and to design more cost-effective NZEHs [10]. Although establishing these optimizations can require excessive time and expertise in most circumstances, industry oriented tools, such as BEopt, allow NZEH optimization to be more accessible to industry.

\subsection{High-efficiency houses and their systems}

NZEHs currently do not provide an attractive financial return to their owners. The average premium of a NZEH from a code-built houses in Ontario, Canada, in 2012 was around $\$ 120,000$ [15], which is too high to be paid back in energy savings (or revenue generation from micro feed-in-tariffs) over the lifetime of the house. Since 2012, the costs have decreased, but so far no studies have found a path to cost-effective NZEHs. Therefore, NZEHs are not attractive from a cost perspective. Even so, there are many research projects and government initiatives that are promoting the development of 
NZEHs and even the establishment of NZEHs as the building norm. The reason for the high level of activity in this field is likely due to the high level of carbon emissions savings available from building energy reductions. The Intergovernmental Panel on Climate Change (IPCC) has identified building energy reduction as the most costeffective way to reduce carbon emissions worldwide, and much of this can be done at a net-cost benefit, as well as an economic and health benefit to society [6]. As such, many countries are pursuing research on building efficiency, and are making building standards more stringent, with some areas (the U.S. and the European Union) making commitments to have all buildings be NZE or near net-zero energy in the future [7], [8]. Canada is participating as well; there have been several high efficiency house initiatives, especially CMHC's EQuilibrium ${ }^{\mathrm{TM}}$ housing initiative [5]. Because of these initiatives in Canada and abroad, many novel energy saving systems have been developed. In the past, NZEH owners have made substantial reductions in their personal carbon emissions but at a financial net-loss. In the future, however, it is hoped that NZEHs will be much more costeffective and commonly available, and will be a large contribution to carbon emission reductions worldwide. This section details previous NZEHs that have been built for cold climates, and the range of technologies that are used by them.

There are various initiatives worldwide that are promoting and pursuing NZE in buildings and houses. In 2007 the U.S. Congress ratified the Energy Independence and Security Act, which has the goal to make all commercial and residential buildings in the U.S. NZE by 2050. Along with this, the American Society of Heating Refrigerating and Air Conditioning Engineers (ASHRAE) Vision 2020 seeks commercially viable NZE buildings by 2030, and the American Institute of Architects (AIA) seeks carbon neutral 
buildings by 2030. California has more aggressive goals, trying to reach NZE for all their residential buildings by 2020 , and all commercial buildings by 2030 [7]. The U.S. Department of Energy (DOE) also runs an initiative for engaging students on NZEHs, the Solar Decathlon competition, where teams of university students design, build and compete NZEHs [18]. In Europe the goal is to have all new buildings NNZE by 2020 [8], and the Solar Decathlon competition is running in Europe and China as well.

In Canada there have been no specific dates targeted for the implementation of NZE buildings or houses across the board, as is being done in the U.S. and European Union. This type of regulation would be somewhat impractical in Canada as the climates can be so harsh in the northern Canada that NZE buildings (including houses) built there would be expensive and impractical if they would even be possible. Yet there have been many initiatives in Canada to promote NZEHs. The two prominent initiatives are the CMHC's EQuilibrium $^{\mathrm{TM}}$ housing initiative [5], and the ecoEnergy Innovation Initiative (ecoEII) [16]. These initiatives help designers, builders and developers learn effective techniques for designing NZEHs.

As will be shown in more detail in this section, there are many different ways to design a NZEH, as well as many ways to conserve and generate energy, but there has not been a convergence in design strategy in the industry. Some technologies are seen across almost all NZEH designs, but in the categories with the most impact (space heating, domestic hot water and the building envelope) there is very little consensus among designers as to which are the best systems to choose.

As previously mentioned, there are many different technologies available that help designers achieve a NZEH. Twenty-one example NZEHs or high efficiency houses 
are listed in Table 2.1. Most of these houses are EQuilibrium ${ }^{\mathrm{TM}}$ houses, as these houses had complete specification sheets provided by CMHC online [19]. Some other houses from Canada and the U.S. are included, as well as some Solar Decathlon (SD) houses. The Solar Decathlon houses that are included were designed for cold climates, and have a good balance of cost and performance scores as judged by the competition.

ASHRAE uses climate zones in order to indicate the severity of weather in certain locations. Climate zones range from very hot climates (climate zone 1) to subarctic climates (climate zone 8). The letter corresponds to the type of environment: humid (A), dry (B) or marine (C). More details on the definitions of climate zones are listed in “ANSI/ASHRAE/IESNA Standard 90.1 Appendix B" [20]. The climates experienced in Canada range from climate zones 5 to 8 , but the houses in Table 2.1, as well as the majority of Canadian houses, range from climate zones 5 to 7. Outside of the U.S. the letter indicator is not available. Table 2.1 is organized by climate zone in order to discern if there are design strategies corresponding to the climate zone the houses were designed for. In this case it was seen that the houses use many different types of systems and that there is poor consistency among the designs. Part of the variation among the designs may be due to other motivations for system selection, described in detail in [21]. Although cost is the number one factor, other factors such as commercial availability, desire to innovate, home-owner imposed constraints and desire for modular construction are mentioned as motivation for system selection. Additionally, house size, type and climate will all play a role in system selection. Due to this variation in NZEH designs, it is difficult to base a new design on previous work, if the motivation is minimization of cost. 
Table 2.1: Previous high efficiency house designs

\begin{tabular}{|c|c|c|c|c|c|c|c|c|c|c|}
\hline 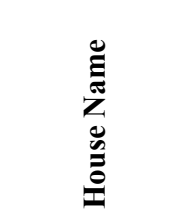 & 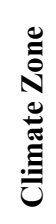 & $\stackrel{\mathscr{L}}{E}$ & 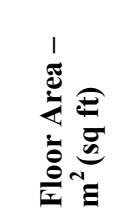 & 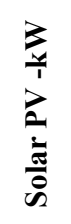 & 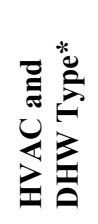 & 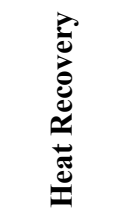 & 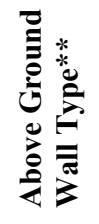 & 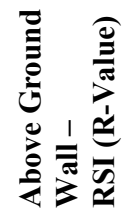 & 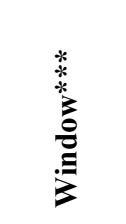 & 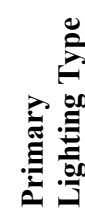 \\
\hline Riverdale [19] & 7 & $\begin{array}{c}\text { NZE } \\
\text { Duplex }\end{array}$ & $\begin{array}{c}234 \\
(2519)\end{array}$ & 5.6 & $\mathrm{H}$ & $\begin{array}{l}\text { HRV, } \\
\text { DWHR }\end{array}$ & B & $\begin{array}{l}9.9 \\
(56)\end{array}$ & 3-L-Ar & $\begin{array}{l}\text { CFL, } \\
\text { LED }\end{array}$ \\
\hline $\begin{array}{c}\text { Mill Creek } \\
\text { [22] }\end{array}$ & 7 & NZE & $\begin{array}{c}278 \\
(2996)\end{array}$ & 6 & A & $\begin{array}{l}\text { HRV, } \\
\text { DWHR }\end{array}$ & B & $\begin{array}{l}9.9 \\
(56)\end{array}$ & $\begin{array}{l}\text { 3-L-Ar- } \\
\text { F }\end{array}$ & LED \\
\hline $\begin{array}{c}\text { Discovery } 3 \\
\text { [19] }\end{array}$ & 7 & NZE & $\begin{array}{c}241 \\
(2592)\end{array}$ & 8.3 & $\mathrm{H}$ & HRV & C & $\begin{array}{l}12.3 \\
(70)\end{array}$ & 3-L-Ar & $\begin{array}{l}\text { CFL, } \\
\text { LED }\end{array}$ \\
\hline $\begin{array}{c}\text { CHESS } \\
{[19]}\end{array}$ & 7 & NZE & $\begin{array}{c}229 \\
(2470)\end{array}$ & 6.7 & K & HRV & $\mathrm{C}, \mathrm{G}$ & $\begin{array}{l}9.2 \\
(52)\end{array}$ & $\begin{array}{c}\text { 4-L-Ar- } \\
\text { F }\end{array}$ & CFL \\
\hline $\begin{array}{c}\text { Echo Haven } \\
{[19]}\end{array}$ & 7 & ULE & $\begin{array}{c}225 \\
(2425)\end{array}$ & 5.5 & A & $\begin{array}{l}\text { HRV, } \\
\text { DWHR }\end{array}$ & $\mathrm{D}, \mathrm{G}$ & $\begin{array}{l}9.5 \\
(54)\end{array}$ & $\begin{array}{c}\text { 3-L-Ar- } \\
\text { F }\end{array}$ & CFL \\
\hline $\begin{array}{c}\text { Urban } \\
\text { Ecology [19] }\end{array}$ & 7 & ULE & $\begin{array}{c}149 \\
(1599)\end{array}$ & 0.5 & $\mathrm{H}$ & $\begin{array}{l}\text { HRV, } \\
\text { DWHR }\end{array}$ & B & $\begin{array}{l}11.4 \\
(65)\end{array}$ & $\begin{array}{c}\text { 3-L-Ar- } \\
\text { F }\end{array}$ & CFL \\
\hline $\begin{array}{c}\text { Factor } 9 \text { home } \\
{[23]}\end{array}$ & 7 & ULE & $\begin{array}{c}301 \\
(3239)\end{array}$ & - & $\mathrm{H}$ & $\begin{array}{l}\text { ERV, } \\
\text { DWHR }\end{array}$ & C & $\begin{array}{l}7.2 \\
(41)\end{array}$ & $\begin{array}{c}\text { 3-L-Ar- } \\
\text { F }\end{array}$ & CFL \\
\hline $\begin{array}{c}\text { Abondance } \\
\text { [19] }\end{array}$ & 6 & $\begin{array}{l}\text { NZE } \\
\text { Triplex }\end{array}$ & $79(854)$ & 4.6 & $\mathrm{~F}$ & $\begin{array}{l}\text { HRV, } \\
\text { DWHR }\end{array}$ & D & $\begin{array}{l}7.9 \\
(45)\end{array}$ & $\begin{array}{l}\text { 3-L-Ar- } \\
\text { Al }\end{array}$ & CFL \\
\hline $\begin{array}{c}\text { Inspiration } \\
{[19]}\end{array}$ & 6 & NZE & $\begin{array}{c}310 \\
(3332)\end{array}$ & 6.2 & $\mathrm{H}$ & $\begin{array}{l}\text { HRV, } \\
\text { DWHR }\end{array}$ & B & $\begin{array}{l}7.7 \\
(44)\end{array}$ & 3-L-Ar & CFL \\
\hline EcoTerra [19] & 6 & NNZE & $\begin{array}{c}234 \\
(2519)\end{array}$ & 3 & G & $\begin{array}{l}\text { HRV, } \\
\text { DWHR }\end{array}$ & $\mathrm{D}, \mathrm{G}$ & $\begin{array}{l}6.7 \\
(38)\end{array}$ & 3-L-Ar & CFL \\
\hline $\begin{array}{c}\text { Now House } \\
{[19]}\end{array}$ & 6 & $\begin{array}{c}\text { ULE } \\
\text { Retrofit }\end{array}$ & $\begin{array}{c}139 \\
(1496)\end{array}$ & 2.7 & $\mathrm{H}$ & $\begin{array}{l}\text { HRV, } \\
\text { DWHR }\end{array}$ & A, D & $\begin{array}{l}7.2 \\
(41)\end{array}$ & 2-L-Ar & $\begin{array}{l}\text { CFL, } \\
\text { LED }\end{array}$ \\
\hline $\begin{array}{l}\text { Rainbow } \\
\text { complex [24] }\end{array}$ & 6 & $\mathrm{PH}$ & $\begin{array}{c}110 \\
(1184)\end{array}$ & - & E & $\begin{array}{l}\text { HRV, } \\
\text { DWHR }\end{array}$ & B & $\begin{array}{l}8.3 \\
(47)\end{array}$ & $3-\mathrm{L}-\mathrm{Ar}$ & HAL \\
\hline $\begin{array}{c}\text { Ontario } 2013 \\
{[25]}\end{array}$ & 6 & $\begin{array}{l}\text { NZE } \\
\text { (SD) }\end{array}$ & $87(940)$ & 7.8 & $\mathrm{~J}$ & $\mathrm{E} / \mathrm{HRV}$ & $\begin{array}{l}\mathrm{D}, \mathrm{E} \\
\mathrm{G}\end{array}$ & $\begin{array}{c}9.3 \\
(53)\end{array}$ & $\begin{array}{l}\text { 3-L-Ar- } \\
\text { Al }\end{array}$ & LED \\
\hline $\begin{array}{l}\text { Norwich } \\
2013[26]\end{array}$ & $6 a$ & $\begin{array}{l}\text { NZE } \\
\text { (SD) }\end{array}$ & $72(780)$ & 5.8 & B & HRV & $\mathrm{B}, \mathrm{G}$ & $\begin{array}{c}9.0 \\
(51)\end{array}$ & 3-L-Ar & LED \\
\hline $\begin{array}{l}\text { Harmony } \\
\text { House [19] }\end{array}$ & 5 & NZE & $\begin{array}{c}438 \\
(4714)\end{array}$ & 14.9 & $\mathrm{D}$ & HRV & $\mathrm{E}, \mathrm{F}$ & $\begin{array}{l}6.9 \\
(39)\end{array}$ & $\begin{array}{c}\text { 3-L-Ar- } \\
\text { F }\end{array}$ & $\begin{array}{l}\text { CFL, } \\
\text { LED }\end{array}$ \\
\hline $\begin{array}{c}\text { Green Dream } \\
{[19]}\end{array}$ & 5 & NZE & $\begin{array}{c}284 \\
(3057)\end{array}$ & 8.3 & E & $\begin{array}{l}\text { HRV, } \\
\text { DWHR }\end{array}$ & $\mathrm{F}$ & $\begin{array}{l}7.7 \\
(44)\end{array}$ & $\begin{array}{c}\text { 3-L-Ar- } \\
\mathrm{V}\end{array}$ & $\begin{array}{l}\text { CFL, } \\
\text { LED }\end{array}$ \\
\hline $\begin{array}{c}\text { NREL / } \\
\text { Habitat [27] }\end{array}$ & $5 b$ & NZE & $\begin{array}{c}119 \\
(1280)\end{array}$ & 4 & A & ERV & B & $\begin{array}{l}7.0 \\
(40)\end{array}$ & $\begin{array}{c}\text { 2-L-Ar- } \\
\text { W }\end{array}$ & $\mathrm{CFL}$ \\
\hline $\begin{array}{c}\text { Illinois } \\
2011[28]\end{array}$ & $5 \mathrm{a}$ & $\begin{array}{l}\text { NZE } \\
\text { (SD) }\end{array}$ & $90(965)$ & 6.7 & $\mathrm{C}$ & ERV & $\mathrm{D}, \mathrm{G}$ & $\begin{array}{l}7.9 \\
(45)\end{array}$ & 3-L-Ar & LED \\
\hline $\begin{array}{c}\text { Purdue } 2011 \\
\text { [29] }\end{array}$ & $5 \mathrm{a}$ & $\begin{array}{l}\text { NZE } \\
\text { (SD) }\end{array}$ & $91(984)$ & 9 & $\mathrm{C}$ & ERV & $\mathrm{C}$ & $\begin{array}{l}4.2 \\
(24)\end{array}$ & 3-L-Ar & $\begin{array}{l}\text { CFL, } \\
\text { LED }\end{array}$ \\
\hline $\begin{array}{c}\text { Illinois } 2009 \\
{[30]}\end{array}$ & $5 a$ & $\begin{array}{l}\mathrm{NZE} \\
(\mathrm{SD})\end{array}$ & $48(517)$ & 9.1 & $\mathrm{C}$ & ERV & $\mathrm{D}, \mathrm{G}$ & $\begin{array}{l}8.8 \\
(50) \\
\end{array}$ & 3-L-Ar & LED \\
\hline
\end{tabular}

* Mechanical system identifiers A-K are listed in Table 3. ${ }^{* *}$ Insulation type identifiers A-G are listed in Table 4. *** The window codes correspond to number of panes of glass ( 2 or 3 ), if the glass is low-e or uncoated (L or U), if the gas fill is argon or air ( $\mathrm{Ar}$ or Ai), and the window frame type: aluminum, vinyl, fibreglass or wood (Al, V, F or W).4

The columns in Table 2.1 give a sample of the major systems for NZE and other types of high-efficiency houses, and there are still many other design parameters involved in the design of a NZEH. Sections 2.1.1 to 2.1.4 describe common systems used on NZEHs, not 
limited to those listed in Table 2.1. These systems include solar photovoltaic (PV) systems, heating ventilation and air conditioning (HVAC) systems, domestic hot water (DHW) systems, building envelope systems, lights and appliances. Note that the house types: net-zero energy (NZE), near net-zero energy (NNZE), ultra-low energy (ULE), Passive House (PH) and Solar Decathlon (SD), are abbreviated in order to save space. The ULE houses are houses that use less than half of the energy of a typical house of similar size. The NNZE houses are houses that approach the NZE target but do not meet it when modelled. Passive houses have specific heating energy requirements (see Section 1.1 above). Lastly, SD house are prototype NZE houses for the purpose of competition. Table 2.2 and Table 2.3 provide legends and supplementary data for Table 2.1.

Table 2.2: HVAC and DHW systems used on houses listed in Table 2.1

\begin{tabular}{l|r|l|l}
\hline Type & Occurrences & Primary heating and cooling & Primary DHW \\
\hline A & 3 & Conventional & SDHW \\
B & 1 & ASHP & Conventional \\
C & 3 & ASHP & HPWH \\
D & 1 & ASHP & SDHW \\
E & 2 & GSHP & SDHW \\
F & 1 & GSHP combi-system with SDHW \\
G & 1 & GSHP combi-system with PVT \\
H & 6 & Solar thermal combi-system \\
I & 1 & Solar thermal combi-system with backup ASHP \\
J & 1 & Solar thermal assisted heat pump combi-system \\
K & 2 & Solar thermal combi-system with backup GSHP \\
\hline
\end{tabular}

Table 2.3: Above ground wall systems used on houses listed in Table 2.1

\begin{tabular}{l|r|l}
\hline Type & Occurrences & Description \\
\hline A & 1 & Conventional stud and batt \\
B & 7 & Double stud \\
C & 4 & SIPs \\
D & 7 & Spray foam \\
E & 2 & VIP \\
F & 2 & ICF \\
G & 7 & Rigid board insulation \\
\hline
\end{tabular}




\subsubsection{Solar photovoltaic}

In Table 2.1 the solar PV size varied on the houses largely because of their type, for instance an ultra-low energy house could be designed so that it does not offset any energy with solar PV. For NZEHs, the size of the PV array is dependent on the systems used in the house, and the size of the house.

There are several different types of solar PV panels: amorphous, poly-crystalline and mono-crystalline. There are also different applications of solar PV for houses: rack mounted, building integrated and solar PV thermal systems. These systems have varying levels of efficiency and cost.

The current prices for roof installed rack mounted PV are mostly made up of installation costs and other overhead costs [31], which means that it is more cost-effective to install very high efficiency (mono-crystalline) panels. High efficiency panels are smaller for the same power output, and therefore require less labour. Building integrated solar has an aesthetic advantage over regular solar panels, and can sometimes save costs on roofing, as it replaces regular roofing systems, instead of being installed on top of the existing roofing like typical solar panels [32]. Photovoltaic thermal (PV/T) systems are a combination of solar PV and solar thermal systems. PV/T systems collect low grade heat from the solar panels, which adds additional space or DHW heating and cools down the solar panels, making them more efficient [32].

\subsubsection{Heating ventilation and air conditioning and domestic hot water}

In this subsection, as in Table 2.1, the heating ventilation and air conditioning (HVAC) systems and domestic hot water (DHW) systems had to be placed together. This is 
because HVAC and DHW systems are sometimes combined into what are called combisystems. As can be seen in Table 2.2, system types from A-E have separate HVAC and DHW systems, whereas F-K are combi-systems. Combi-systems provide both space heating and hot water from a shared heat source. Many combi-systems are one-off units, designed specifically for the house that it is designed to heat such as the system used on the Riverdale house in Edmonton, Alberta [19]. Combi-systems can incorporate a number of strategies for heating or cooling. For instance, HVAC/DHW combi-system type F is a GSHP combi-system, meaning the GSHP does both space heating and DHW, but this DHW is also augmented with additional heat from solar thermal collectors. Any of these additional systems are also listed in Table 2.2. One interesting type of combi-system is the solar thermal assisted heat pump. This system uses solar collectors as its heat source, similar to a solar thermal combi-system, but uses a heat pump to improve the grade of the heat and help the solar thermal panels run more efficiently [25].

There are three general types of heating systems that are not combi-systems. These are conventional systems, air source heat pumps (ASHPs) and ground source heat pumps (GSHPs). Conventional systems (defined here) are any systems with efficiencies up to $100 \%$. They include gas and electric furnaces and boilers, as well as electric baseboard heating. Gas systems usually come in two types, condensing and noncondensing. The condensing gas systems can extract the latent heat from the phase change of water vapour in exhaust gasses, making these systems much more efficient, whereas the non-condensing furnaces do not have this ability and have much lower efficiencies [33]. 
Air source heat pumps (ASHPs) and ground source heat pumps (GSHPs) have higher thermal efficiency than conventional systems. Instead of generating heat these systems pump heat from one area to another. They can pump more heat than can be generated by the power to run them. A ground source heat pump in an ASHRAE climate zone 6 has a coefficient of performance (COP) of 3.0, meaning it can pump 3.0 units of heat into a house for 1.0 unit of electricity. Air source heat pumps pump heat from outdoor air into the house, whereas ground source heat pumps pump heat from the ground. ASHPs are usually less efficient than GSHPs, but GSHPs tend to be more expensive than ASHPs. There has also been work on cold climate ASHPs (CCASHPs). CCASHPs have multiple refrigerant stages to improve efficiency at low temperatures [34]. Counter-intuitively, heating seasonal performance factor (HSPF) ratings for CCASHPs do not reflect their added efficiency, because ASHPs are rated at moderate temperatures (ASHRAE climate zone 5). For instance, an ASHP with a rated 9.4 HSPF can have an equivalent HSPF as low as 5.7 in a climate zone 6 [35] whereas a CCASHP with a 9.4 HSPF has an equivalent HSPF of 8.2 in a climate zone 6 [34]. CCASHPs now occupy a space between regular ASHPs and GSHPs in terms of both cost and efficiency. It should be noted that solar thermal space heating systems do exist but are rarely used independent of a combi-system.

There are three main types of independent DHW systems: conventional systems, heat pump water heaters (HPWHs) and solar domestic hot water (SDHW). Again the conventional systems are any systems with efficiencies up to $100 \%$, which includes gas and electric systems. These systems can be tanked or instantaneous. Gas DHW systems can also be condensing or non-condensing. Instantaneous systems are more efficient than 
tanked. As with gas space heating systems, condensing gas water heaters are substantially more efficient than non-condensing systems [33].

HPWHs work in a similar fashion to ASHPs, except that HPWHs pump heat from the air inside the house into a hot water tank. Because HPWHs take heat from inside, they are inextricably linked to the space heating system. For instance, a HPWH with a COP of 2.3 transfers 1.3 units of heat into the tank, with 1 unit coming from the electricity used by the heat pump. These 1.3 units of heat come from the interior air and represent an additional heating load on the HVAC system in the heating season [36]. So the heating system must be taken into account when calculating the impact of a HPWH. Conversely, in the cooling season, HPWHs provide free cooling. So in cooling dominated climates, HPWH interaction with the heating system is of less importance.

SDHW systems use solar thermal energy to heat water. In cold climates these systems have been found to have annual solar fractions in excess of $60 \%$ [37]. For independent DHW systems, SDHW systems are the most efficient; they are also the most expensive because they are the most complex to install.

There are heat recovery devices used on NZEHs as well. These systems capture heat that would otherwise leave the house in a fluid stream. The air heat recovery devices are called heat recovery ventilators (HRVs) or energy recovery ventilators (ERVs). Both of these devices replace the exhaust fan in typical houses and transfer heat from the exhausting air to the incoming air (and vice versa in the cooling season). ERVs are similar to HRVs except that they have the capacity to transfer moisture as well, which can be beneficial in certain climates [38]. 
The second type of heat recovery device is the drain water heat recovery (DWHR) device. The DWHR device works by transferring heat from warm waste water to the cold water going to the hot water heater or to the shower. The DWHR device can recover heat when hot water is draining at the same time hot water is being consumed, but it is not effective when the draining of hot water is delayed. Hence DWHR devices work with showers but not with baths [19].

\subsubsection{Envelope}

As can be seen in the example houses, there are many of different wall systems with combinations of these types in certain cases, which can be seen in Table 2.1 and Table 2.3. These wall systems have to balance a number of different factors to be effective. For a wall section it is desirable to improve thermal resistance, reduce air leakage, minimize moisture accumulation, reduce costs and reduce wall thickness [39], [40].

Wall insulation levels tend to be higher in colder climates, although even some houses designed for ASHRAE climate zone 5 (listed in Table 2.1) have very high thermal resistances. The highest thermal resistance for climate zone 5 out of the example houses was 8.8 RSI (R50), whereas code wall insulation in Ontario is 3.87 RSI (R22) [41].

Air leakage can be as significant as conduction in terms of heat loss and can also introduce moisture, so it is important to minimize air leakage as much as possible [40]. This can be done through various sealing techniques such as using tapes, foam sealing strips, expanding foam and minimizing penetrations through the envelope. Air leakage is typically measured in terms of air change rate; specifically this is performed using a blower door test, which pressurizes the house to $50 \mathrm{~Pa}$ of pressure. The air change rate is 
measured in ACH50 (air changes per hour at $50 \mathrm{~Pa}$ ). Most of the EQuilibrium ${ }^{\mathrm{TM}}$ homes had an average ACH50 of less than 1.5 [42], whereas the ACH50 of a typical residential house in Ontario in 2009 was 3.14 [43]. Air leakage is one of the main ways that moisture accumulation can occur but moisture accumulation is more likely to become an issue with thicker wall sections [40].

Cost is a factor in high performance envelopes, which can sometimes make certain designs prohibitively expensive. Vacuum insulation panels and spray foam are typically expensive upgrades, while typical stud and batt walls are less expensive [44].

However, when considering the costs of the envelope, the thickness of the exterior walls can become a factor. Walls can become so thick that it forces developers to change their lot spacing. Changing lot spacing decreases the number of houses in a development and reduces revenue, but this is not a factor for houses on larger lots, such as in rural areas. In developments, there typically is some buffer in wall thickness to allow for thicker types of cladding, so only after a certain thickness would lot spacing have to change.

Basement wall and basement slab insulation are primarily underground, and thus have a lower temperature difference to insulate over than above ground walls, so they tend to be less insulated [45]. Roof insulation is not as constrained as other surfaces and tends to be substantially thicker and more highly insulated than exterior walls [45].

In circumstances where the house is adjoined (duplex, triplex, townhouse, etc.) one or more of the walls will be a party wall, adjoined to another unit. These walls have a minimal amount of insulation, mainly to reduce sound transfer. Having adjoined units 
reduces heating demand and cost, since it reduces the exposed wall area for each unit [46].

Windows also have a large impact on heating and cooling energy. Because of the difficulty insulating windows, they tend to be one of the greatest heat loss areas on a building envelope. On the other hand, their solar transmission characteristics can be managed in order to maximize heat gain in the winter, as well as minimize heat gain in the summer [46]. The measurement of heat gain performance is called the solar heat gain coefficient (SHGC). A typical design of high performance windows are high gain, triple pane, low-e, and argon filled windows. These types of windows were seen frequently in the sample houses of Table 2.1. Solar gains can also be managed by window shading devices like external shades, internal shades, and overhangs [46].

With large windows with high SHGCs, it can become useful to include increased thermal mass to store solar gains to minimize heating loads and avoid overheating. Typically this has been done with flooring materials. Tile flooring or patterned concrete floors with high solar absorptivity are two main ways this has been achieved [21].

The solar absorptivity of other materials also makes a difference in heating and cooling energy; in the heating season it is desirable that the envelope and blinds have a dark colour to absorb as much solar radiation as possible, whereas in the cooling season lighter colours are more desirable [46].

\subsubsection{Lighting and appliances}

There are many different systems that are operated by or interact with the occupants of a house. Because of this, some of the systems tend to have a high variability in terms of 
their predicted energy usage. These are lighting devices, water fixtures, and large and miscellaneous appliances. Although there are higher and lower efficiency versions of these devices, there is high variability in terms of how these will be used by the occupants. In many of the sample houses CFL and/or LED lights were used, and likely many had high efficiency appliances. NRCan has found that the Canada-wide baseline for occupant electricity usage (excludes building mechanical systems) is $19.5 \mathrm{kWh} /$ day. Energy savings of the following amounts can be applied to this baseline: $1.5 \mathrm{kWh} /$ day for Energy Star appliances, $2.7 \mathrm{kWh} /$ day for best in class appliances and $2.0 \mathrm{kWh} /$ day for CFL or LED lightbulbs [47].

In spite of this, studies have shown that occupants have a wide range of daily energy use. Total electricity use from Hydro Ottawa on 513 townhouses and 345 single detached houses shows how much variation there is in occupant energy use. The data was primarily occupant energy use with some ventilation and cooling electricity use, and was collected over several years. Only houses with at least a year of data, and without any lapses in occupancy were used. The townhouses had an average electricity usage of 15.3 $\mathrm{kWh} / \mathrm{day}$, with a standard deviation of $5.6 \mathrm{kWh} /$ day [48]. The single detached houses had an average electricity usage of $19.5 \mathrm{kWh} /$ day, and a standard deviation of $6.3 \mathrm{kWh} /$ day [49]. Figure 2.1 shows the distribution of average daily energy usage for the single detached houses, where the range goes from around 10 to $30 \mathrm{kWh} /$ day, meaning that some houses used about $50 \%$ of the average, where some used about $150 \%$ of the average. This high variability in occupant energy usage is one of the major obstacles to the accurate prediction of energy usage in houses. 


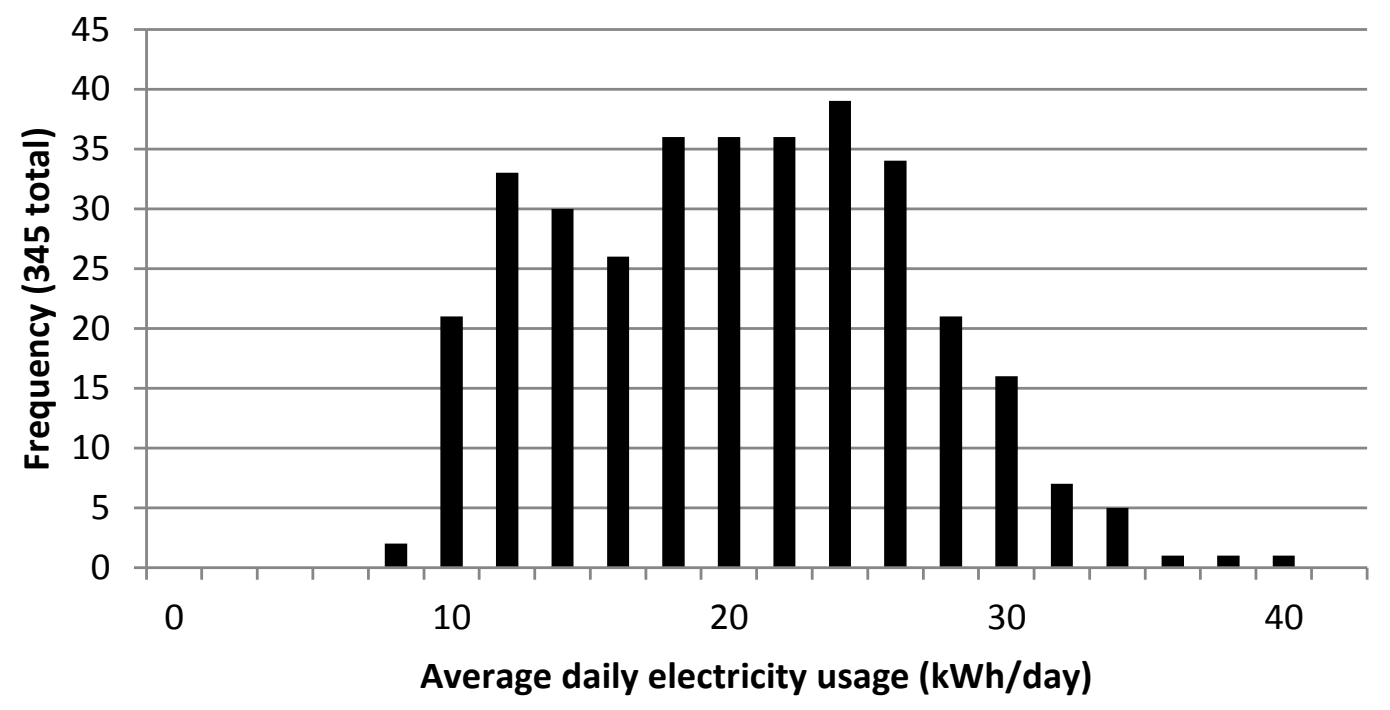

Figure 2.1: Daily average electricity use of 345 single detached houses in Ottawa [49]

Real-time energy monitors try to influence the occupants by making them more aware of their energy usage. It has been found that real-time energy monitors that give a breakdown of energy use by appliance can reduce energy usage by about $12 \%$ [50]. Programmable and smart thermostats also try to minimize energy usage by giving occupants finer control over their temperature setpoints throughout the day and week, without needing constant attention. However, programmable thermostats are not recommended since it has been found that they usually programmed incorrectly [51]. Smart thermostats have the potential to be more effective because they are selfprogramming. Some high efficiency houses have integrated user interfaces, which are usually web or tablet based applications called a smart house applications. Smart house applications can give occupants control of lights, appliances, temperature setpoints, and can provide the occupant with energy monitor readings [52]. 


\subsection{Building performance optimization of NZEHs}

There are many types of advanced HVAC and DHW systems, envelope systems, and lighting and appliances that go into NZE and high efficiency houses. These systems have been used in NZE and high efficiency houses in the past and have significant energy and cost impacts that must be balanced in order to achieve a cost-effective NZEH. As was shown in Table 2.1 there is a high variability in the design strategies for NZE and high efficiency houses, especially the HVAC systems and envelope, two of the most important categories. It is the goal of this thesis to use energy and cost optimization to find a costeffective NZEH design.

Habitat Studio, a custom home builder in Edmonton that was part of the EQuilibrium $^{\mathrm{TM}}$ initiative has built several NZEHs. These NZEHs provide an example of the different design strategies used by home builders. Habitat Studio has developed their own optimization methodology (see section 2.2.1) and has found ways to reduce the prices of their NZEHs over the years. Their first three houses show the most changes. Their first NZEH, the Riverdale house, was built in 2006, their second, Mill Creek, was built in 2010 and their third, the Belgravia, was built in 2011[5]. The incremental cost for these houses has decreased from $\$ 110,000$ to $\$ 67,000$ to $\$ 58,000$ [53] from a code-built house of equivalent size. Part of this decrease is due to the decreasing price of solar photovoltaics (PV), but the main part of this savings is due to using more simple systems on their houses. While all three houses use a 16" thick double stud wall, they differ in the type of heating system they use. The Riverdale house uses an elaborate seasonal storage combined space heating and DHW system. Mill Creek and Belgravia both have electric baseboard heating and have separate DHW systems. Mill Creek has simple solar DHW 
system and Belgravia has a highly insulated hot water tank. So the Mill Creek house has simpler systems than the Riverdale house, and the Belgravia has even simpler systems. The Belgravia house was not included in Table 2.1 because there was incomplete data on it, but a few conclusions can be gained from this example. This sequence of houses shows that optimization can help significantly reduce costs and that simpler designs likely lead to more cost-effective NZEHs. Another advantage of simpler systems is that they are simpler to install and maintain, which reduces unforeseen problems and costs.

Different optimization schemes have been used for finding more cost-effective NZEH designs; however, optimization requires substantial time and expertise. The goal is to make NZEHs more cost-effective so that they will be more attractive to build and a greater GHG reduction can be achieved. This section describes NZEH design and optimization methods that have been used by researchers and industry. The difficulty in NZEH design arises primarily from choosing the right combination of energy saving systems. The systems interact with each other, and this complicates system selection. For instance, optimal south facing window size is impacted by glazing type, wall insulation level, thermal mass, orientation, and overhangs. In work done by O'Brien et al. [17], the interactions between different components were determined, and are displayed in Figure 2.2. The existence of interactions means that the systems cannot be selected on an individual basis, but taking into account all possible interactions makes the problem computationally impossible. The case described by O'Brien et al. [17] had 26 factors. If each factor had two options (some had more than that) there would be $2^{26}=$ 67.1 million different house designs, which would take several years to simulate. There are also large uncertainties in the costs of systems that add further difficulty. The high 
number of interactions also makes the problem unintuitive, making it difficult to pick systems based on the designer's experience. Although trial and error is commonly used in NZEH design, it does not result in near-optimal designs [13]. Because of these reasons it is clear that some type of optimization technique is necessary to find cost-effective NZEH designs.

Nevertheless only $59 \%$ of designers use building modelling tools at the early design stages of NZEHs [12], while many others use published design guidelines. Published design guidelines (such as [46]) are quick and inexpensive to use. Published designs are useful for finding systems and techniques that make up NZEHs, but they are specific to the place they were designed for and are not widely applicable. Climates vary significantly from location to location. One of the most substantial effects of building location is the orientation (also called azimuth angle). Most published designs are made for ideal conditions of an unshaded site, with a house that is oriented on the north-south axis [13]. A house that is off-axis or heavily shaded by nearby objects will perform poorly if it is designed to capture large solar gains. The optimal design for those types of sites will be much different than published designs. 


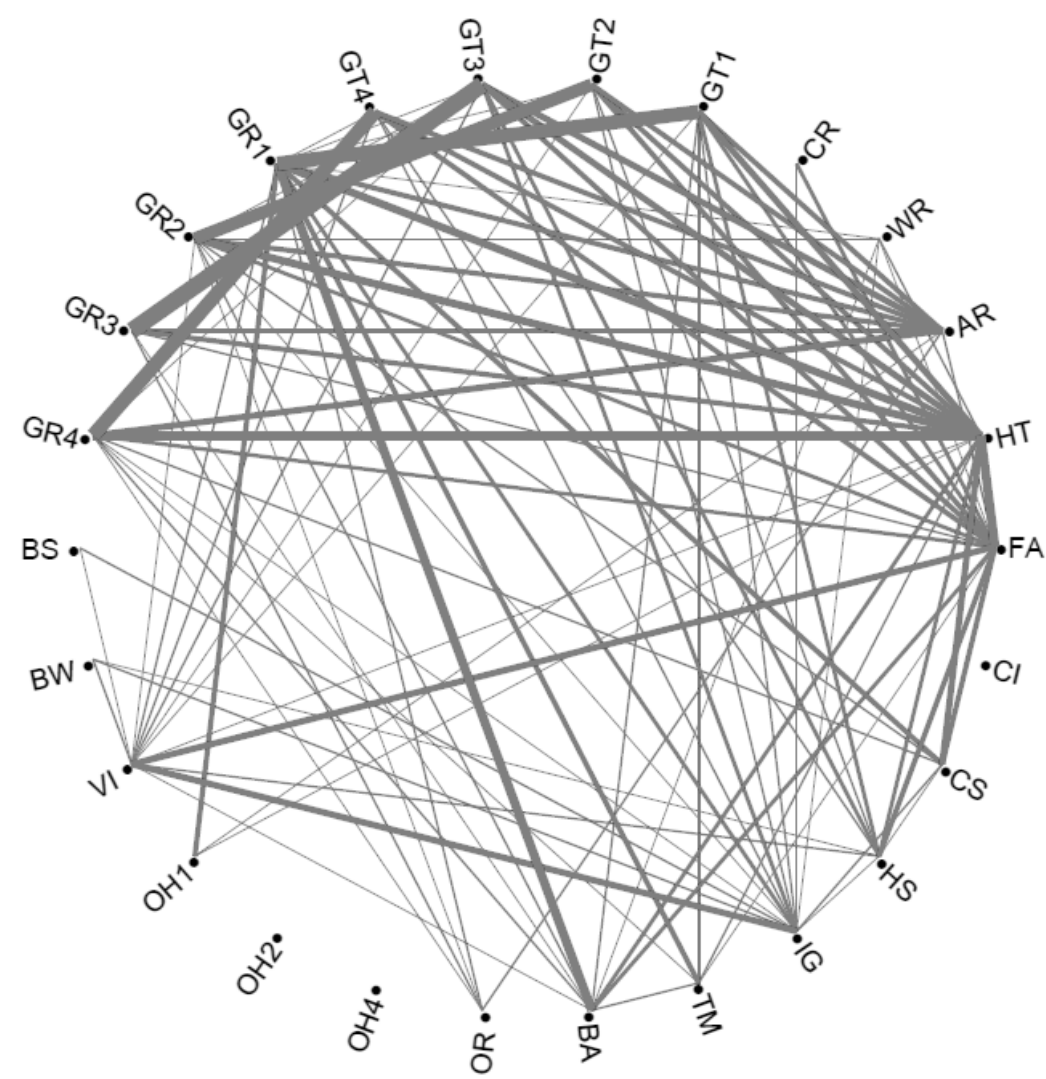

\begin{tabular}{|l|l|}
\hline Abr. & Name \\
\hline FA & Footprint Area \\
\hline HT & Height \\
\hline AR & Aspect Ratio \\
\hline WR & Wall Resistance \\
\hline CR & Ceiling Resistance \\
\hline GT1 & Glazing Type 1 \\
\hline GT2 & Glazing Type 2 \\
\hline GT3 & Glazing Type 3 \\
\hline GT4 & Glazing Type 4 \\
\hline GR1 & Glazing Ratio 1 \\
\hline GR2 & Glazing Ratio 2 \\
\hline GR3 & Glazing Ratio 3 \\
\hline GR4 & Glazing Ratio 4 \\
\hline BS & Basement Slab \\
\hline BW & Basement Wall \\
\hline VI & Ventilation \\
\hline OH1 & Overhang 1 \\
\hline OH2 & Overhang 2 \\
\hline OH4 & Overhang 3 \\
\hline OR & Orientation \\
\hline BA & Basement Present \\
\hline TM & Thermal Mass \\
\hline IG & Internal Gains \\
\hline HS & Heating Setpoint \\
\hline CS & Cooling Setpoint \\
\hline Cl & Air circulation Rate \\
\hline & \\
\hline
\end{tabular}

Figure 2.2: The "Wheel of Interactions" [17]

Costs also vary with location, availability of systems and with time. As certain novel technologies become more established in the market, their price subsequently decreases, making it more attractive for use within NZEHs. For instance, the price of solar PV has dropped by about $15 \%$ per year since 2009 [31]. This is making solar PV more attractive for reducing net-energy use, than using more expensive and complex energy conservation measures. Cost changes like these also impact the optimality of designs. Therefore, more advanced design techniques are needed that can optimize NZEHs for specific projects.

Integrated design processes (IDPs) are also sometimes used in NZEH design [13]. An IDP usually takes the form of a design charrette where many design experts meet for the purposes of rapid design. The goal is to have as many different building disciplines 
and stakeholders as possible, so that a wide range of factors will be considered and their interactions will be taken into account. A particularly important part of the design process is having engineers and architects work together from the initiation of the project, so that designs reflects both aesthetics, constructability and energy efficiency. IDPs go above and beyond this requirement, taking into account many major factors and can result in the output of creative designs. Nevertheless, IDPs are not used often because they are expensive, and it is difficult to coordinate many different experts at one time and location $[12]$.

Building modelling techniques are valuable when used in conjunction with IDP, as different design options can be modelled for comparison. However, building modelling is usually performed in a trial and error fashion with or without an IDP [13]. There are simple and complex modelling tools. The simple tools can be used quickly, but they have low model resolution and they lack the ability to model complex or novel systems, which means they can only inform design changes to a certain extent. Also, many of the simple tools have specific modelling areas, so they are not able to model all building systems simultaneously and characterize their interactions. For that reason usually around three to eight building modelling tools are used in the design of a NZE building or house [12]. Building modelling tools with high model resolution are more difficult and time consuming to use, so they are used less often by industry. Yet almost all modelling tools lack optimization capabilities, parametric analysis, financial analysis and design support [12].

House designers would like the ability to optimize for minimum cost to make high efficiency buildings and houses more financially attractive. The Building America 
program found through optimization techniques that energy use of houses can be reduced by $50 \%$ with negligible impact on cost [13]. In one Canadian study, optimization was able to find ways to reduce the incremental cost of a typical NZEH by $30 \%$ [15]. Optimization can find optimal designs for specific sites and costs, and can find designs that are outside the range of experience of the designer. Optimization methods can simultaneously take into account energy use, costs, and thermal comfort [12]. However, while optimization makes up for the deficiencies with typical design techniques, integrating all of the necessary components for an optimization can be very difficult and time consuming, and it must be well configured so that it can find "near-optimal" designs. The following sections will describe different types of optimization methods. Some optimization methods are manual methods that guide the building designer, while others are automatic methods that use a computer to automate the modelling and optimization process.

\subsubsection{Manual optimization methods}

The EQuilibrium ${ }^{\mathrm{TM}}$ Initiative prescribed methods to the design teams. As some of these built subsequent NZEHs, the methods evolved. The following section describes an example of the initial design method, and the current method used by Habitat Studio, who built the Riverdale EQuilibrium ${ }^{\mathrm{TM}}$ home. The current method used by Habitat Studio requires determining the effectiveness of upgrades based on their price per $\mathrm{kWh}$ saved. This method is iterative and completed in steps. The benefit of manual optimization is that it requires no additional set-up; the building modeller can simply incorporate iteration into the design process. There are three difficulties with manual optimization 
techniques: they do not explore the search space widely, they require good knowledge of a wide range of NZE conservation measures and they are time consuming to implement. As part of the EQuilibrium ${ }^{\mathrm{TM}}$ Initiative it was mandatory that the teams use certain design methods. The teams were required to use IDP, as well as the HOT2000 energy modelling program [13]. The design process of one the EQuilibrium ${ }^{\mathrm{TM}}$ houses, the EcoTerra $^{\mathrm{TM}}$ house is described below, as an initial design methodology.

Steps used in the design of the EcoTerra ${ }^{\mathrm{TM}}$ NZEH [54]:

1. Collect rules of thumb for passive design, form and material

2. Rules of thumb given to architect to determine general form of house

3. Two day design charrette for design of mechanical systems, which included building modelling with HOT2000

4. One day follow up meeting

5. Detailed design

6. Alouette Homes (builder) in-house design of lighting, forced air and electrical

7. Control system designed by Regulvar Canada Inc. and Concordia University

The major design methods used in the conceptual design in this case are rules of thumb, and IDP. These methods, as was mentioned above, have some drawbacks that prevent optimal designs from being found. Rules of thumb assume ideal conditions, which usually leads to a sub-optimal optimal design, and design charrettes for IDP are difficult to organize and can be expensive, especially if it requires bringing in many experts. 
Another team in the EQuilibrium ${ }^{\mathrm{TM}}$ initiative, custom home builder Habitat Studio, would have used a similar method on the first NZEH they built. Since then they have built several more NZEHs. During the design and construction of the first three houses they developed a design strategy that they have used on all subsequent NZEHs. It builds upon the previous method with a more systematic process.

The evolved method is based on work by Gary Proskiw, who proposes comparing design upgrades based on their energy savings potential [11]. The proposed solution recommends determining the price per annual $\mathrm{kWh}$ saved by each energy conservation measure (ECM). This is called the ECM Value Index (see Equation 1). Each measure is then compared to the PV Value Index. The PV Value Index is the price per annual $\mathrm{kWh}$ offset by solar PV (see Equation 2). If the ECM Value Index is below the PV Value Index, then it is a valuable investment, and should be chosen over adding more solar PV. Alternatively, if it is above the PV Value Index, then it is more cost-effective to add more solar PV, and the measure should not be used [9].

$$
\begin{array}{cc}
\text { ECM Value Index }=\frac{\text { Incremental cost of measure }}{\text { Energy savings }} & \text { Equation 1 } \\
\text { PV Value Index }=\frac{\text { Solar PV system cost }}{\text { Energy savings }} & \text { Equation 2 }
\end{array}
$$

The ECM and PV Value Indices are not the only guides; the manual optimization process also divides the house into system types and involves iterative modelling. 
Steps used in Habitat Studio's design method [11]:

1. Site assessment, taking into account NZE related factors such as shading

2. Preliminary design: architectural design mixed with NZE experience

3. Initial modelling and costing of design before anything is finalized

- Architects work closely with building modellers

- Use value index method to determine suitability of various options

- Iterate design and modelling

4. Use the value index method and iteration, while keeping in mind the quality of life of the occupant for the following four steps:

5. Optimize envelope

6. Optimize solar thermal space and/or DHW

7. Reduce DHW loads

8. Reduce lighting and appliance loads

9. Size solar PV to meet remaining load

10. Detailed design

This method has two main advantages over the initial EQuilibrium ${ }^{\mathrm{TM}}$ method. First, iteration of the design is encouraged significantly more throughout the method. Second, systematic quantifications of the cost impacts, while trying many different design options at each stage of design, likely results in more cost-effective designs than a typical IDP. It also holds onto some elements of IDP as architects, building modellers and buyers are encouraged to work together during the design process. Seeing the direct cost and energy impacts will inform and encourage more cost-effective decisions. 
Yet, this process is more time consuming than an automated optimization process. Secondly, the process does not take into account interactions between different groups of systems. Finally, the quality of the design iteration process depends on the creativity and experience of the modeller. Without automated building modelling, there are only so many models that the designer can simulate. Therefore, it is likely that portions of the design space will be missed. The main advantage of automated optimization methods is the ability to explore the design space more thoroughly.

\subsubsection{Research oriented automatic optimization methods}

The typically applied scheme for automated building optimization is the genetic algorithm [10], which is well suited for design problems such as these. Genetic algorithms generally search out more favourable areas of the design space, but search in a random manner so they are unlikely to become trapped in local optima [10]. It is hoped that by trying multiple options, eventually near-optimal designs will be found. The issues with genetic algorithms are that it is difficult to know how long to run an optimization, and there are many different types of genetic algorithms and different optimization parameters that can to be chosen [55].

Most research oriented optimization is established by the user. The user chooses a building modelling software and an optimization tool. The most common optimization tools used for buildings are Matrix Laboratory (MATLAB) and Generic Optimizer Tool (GenOpt) [10]. These two programs have many built in optimization tools that can be chosen and linked to the designer's building simulation software of choice. After the user chooses the optimization type and the optimization parameters, the user must write an 
objective function. The objective function in most cases calculates the energy usage and costs of a design. To do this the objective function relies on writing input files for the building modelling program, calling the modelling program, and interpreting the modelling program results. The objective function then uses the modelling results to calculate costs. After the programs have been integrated and the objective function has been written, the designer simply runs the optimization and analyses the results.

Although these optimization methods are likely to achieve better results than manual optimization methods due to their ability to widely search the design space, it still requires a significant amount of expertise of the individual, and configuring the optimization is time intensive. These types of methods are usually not suitable for industry because of the time and expertise required to perform such optimizations.

Some difficulties that designers have experienced with optimization [10]:

1. High amount of invested time may not be worth return

2. Lack of systematic approach

3. Requirement of high expertise

4. Uncertainty with model input (design, cost)

5. Difficulty linking simulation and optimization

Some notable examples of NZEH optimization that fall under this category have been performed by Charron [56], Verbeeck and Hens [57], CanmetENERGY [15], Hamdy, Palonen and Hasan [58] and Bucking [14]. 
Research by Charron [56] was on the development of an optimization tool for houses. There were 40 cases in this study, but the default house was a $150 \mathrm{~m}^{2}(1610 \mathrm{sq} \mathrm{ft})$ house in Montreal, Quebec. The study used genetic algorithm optimization, and the objective function was discounted life-cycle cost converted to monthly values. The cost function also included penalties for not meeting thermal comfort, visual comfort, and roof size requirements. TRNSYS was used for building modelling. The optimization of the default case yielded and incremental cost of $\$ 415.91 /$ month for a NZEH compared to code-built, and no cases had a negative monthly cost, meaning that none were costeffective.

Research by Verbeeck and Hens [57] attempted to find cost-effective houses that had extremely low life-cycle energy usage, i.e. the embodied energy and disposal energy of the houses was taken into account as well as the ongoing energy usage. The research optimized five house types located in Brussels, Belgium, using a multi-objective genetic algorithm. The objective functions were life-cycle energy usage, and discounted total present value. TRNSYS was used for the building modelling. This study found that while extremely low life-cycle energy houses were viable, they were not cost-effective.

Research done by CanmetENERGY [15] involved using a particle swarm optimization to reduce the cost of NZEHs in Toronto, Ontario. The objective function of the optimization was to minimize the upgrade cost of the house. The house design was chosen as the average house type that is built in the Greater Toronto Area, at $225 \mathrm{~m}^{2}$ (2420 sq ft). ESP-r was used for the building modelling. This study found that the minimum upgrade cost to achieve NZE for this house was $\$ 78,846$. 
Hamdy, Palonen and Hasan [58] modified the Non-domination Sorting Genetic Algorithm II (NSGA-II) multi-objective genetic algorithm, with two variations, an active Pareto-archive, and a passive Pareto-archive, denoted as aNSGA-II and pNSGA-II, respectively. The test case was a $156 \mathrm{~m}^{2}(1680 \mathrm{sq} \mathrm{ft})$ house in Finland. The objective functions were the discounted 30 year life-cycle cost and the primary energy consumption. The result of the study was that the aNSGA-II had higher repeatability and improved convergence to the global optimal than the pNSGA-II and the original NSGAII algorithms. The study also found near net-zero energy houses that were more costeffective than Finnish building code.

The goal of the research by Bucking [14] was to develop a hybrid optimization algorithm that includes both random and deterministic processes. The optimization algorithm was tested on a conceptual NZEH redesign of the EcoTerra ${ }^{\mathrm{TM}}$ EQuilibrium ${ }^{\mathrm{TM}}$ house. The EcoTerra ${ }^{\mathrm{TM}}$ house is $234 \mathrm{~m}^{2}(2520 \mathrm{sq} \mathrm{ft})$ and is located in Eastman, Quebec. The objective functions of the optimization were discounted life-cycle cost, and netenergy consumption. The modelling software that was used was EnergyPlus. This study found that the hybrid optimization algorithm improves convergence speed and solution quality. The best NZEH redesign of the EcoTerra ${ }^{\mathrm{TM}}$ found by the optimization had a net present value (NPV) of $-\$ 32,000$ but this cost performance could be improved substantially through the use of feed-in-tariffs (FITs) or reductions in solar PV price.

In all these cases the optimization and modelling was configured by the researcher. In all these studies the researchers were minimizing the cost impacts of a NZEH, by reducing its initial cost, annualized costs, or its life-cycle cost. The optimizations were performed either to help with designing a house, or to help with 
designing a better optimization algorithm. All of these projects were complex and would be outside the reach of most industry projects.

\subsubsection{Industry oriented automatic optimization methods}

The final type of modelling tool is industry oriented automatic optimization. The most well developed example of this is BEopt (Building Energy Optimization), which is used to optimize NZEHs or high efficiency houses. These types of tools are integrated modelling and optimization tools. They include standard design options and their associated cost information, which facilitates rapid design and optimization. The default costs and systems can be used for basic optimization situations, although in more advanced problems the cost data can be replaced and the building systems can be modified.

BEopt, as it stands, has two slight drawbacks. One, the optimization methodology is an advanced type of sequential search. There have been many improvements made to improve the speed and accuracy of the sequential search algorithm used by BEopt [59]. In spite of this, the inherent problem with sequential search is that it only changes one system at a time so it cannot take into account the interactions between the systems [60]. To illustrate this deficiency, consider two systems that interact in a complementary way but do not perform well individually. For example, ASHPs and HPWHs could be given costs within certain ranges where the addition of either an ASHP or a HPWH on their own would not be cost-effective, but since they have a positive interaction, they may be cost-effective when used together. Sequential search cannot modify the design so that both of these systems are selected simultaneously. Sequential search will select each of 
the systems individually, possibly many times, but will reject them. Because it lacks the ability to take advantage of these interactions, sequential search can become trapped in local optima. While it is also possible for evolutionary algorithms to become trapped in local optima, the probability is lower because evolutionary algorithms can change multiple systems in a single innovation. To fix this problem, BEopt has a function that can optimize a group of parameters if it is known that there are interactions between these parameters [59]. However, this relies upon the experience of the designer; plus, as can be seen in Figure 2.2, almost all systems interact with other systems. The second drawback is that it does not have all the possible options that an individual might want to model. For instance BEopt was missing cold climate air source heat pumps and solar thermal combi-systems when this study was being performed. However, more features are being added to BEopt with each updated version so systems such as these will most likely be added eventually.

Industry would also benefit from a large-scale building version of BEopt. In the future Opt-E-Plus, an in-house optimization tool within NREL, might be added to OpenStudio, a user interface for EnergyPlus [10]. If Opt-E-Plus is added to OpenStudio it would likely have the same features that BEopt has in order to be helpful for industry: built in design options with associated cost data, and a built in optimization algorithm.

Although there are many different system options, and many ways of designing a $\mathrm{NZEH}$, it is difficult to design one that maximizes cost-effectiveness. There are no dominant designs or design methods so NZEHs tend to be quite different from each other. The most common method is a trial and error method involving building performance simulation. There are also more systematic methods like the one used by 
Habitat Studio, which attaches cost indices to all upgrades, and encourages continuous iteration of the design, yet automatic optimization yields the best results.

Research level tools for optimizing NZEHs automate the iteration process by using evolutionary search algorithms connected with building performance simulation. These have an advantage over manual iterative methods because, once automated, the designer does not have to monitor the optimization process, and the design space is searched more thoroughly. On the other hand, these optimizations are very time consuming and difficult to configure. One tool, BEopt, fixes these problems by having a prepackaged optimization tool with built in options and cost data, which allows industry to run optimizations much faster. In this thesis, because more time was available, a custom optimization method was established in order to help find cost-effective NZEH designs more effectively. 


\section{Chapter 3: Methodology}

The goal of this thesis is to determine if cost-effective NZEHs are possible. To do this, optimization is performed on both the annual energy usage and net present value (NPV) of the Minto ecoEIl house designs. The optimization algorithm used is the multiobjective Non-domination Sorting Genetic Algorithm II with active Pareto-archive (aNSGA-II), which is compared to the Iterated Sequential Search (ISS) algorithm. The designs are modelled in EnergyPlus and are based on template files that are generated with the help of BEopt. System options that the optimization chooses can be encoded into template files to make EnergyPlus input files. The optimization algorithms are programmed in Octave, which is an open source programming language similar to MATLAB. Unlike MATLAB, Octave does not require licencing, so it was chosen because of this added flexibility.

The Octave optimization programs that were written have three main functions:

1. Running the aNSGA-II optimization algorithm (described in detail in Section 3.5)

2. Running the ISS optimization algorithm (described in Section 3.6)

3. Calculating the objective function, which involves: converting template files (modified BEopt EnergyPlus input files) into design input files, calling EnergyPlus to run design input files (in parallel), reading EnergyPlus output files, and calculating annual energy usage and net present value based on the EnergyPlus outputs. 
The aNSGA-II optimization algorithm is tested initially to confirm that it provides repeatable results. After the optimization algorithm is tested, different optimization scenarios are run to see what conditions would be necessary for a cost-effective NZEH to be found.

\subsection{House types}

Three house types are to be optimized: a single detached house, and two types of townhouses, an end and a middle unit. The end unit of a town house could also be seen as half of a duplex. These house types will be referred to as single, end and middle and they represent the house types that Minto intends to build for the ecoEII project. The floorplans of the house types are shown in Appendix A. Note that the end unit's northeast wall is adjoined, whereas for the mid unit, both the northeast and southwest walls are adjoined. The BEopt renderings of the house models are shown in Figure 1.1 and Figure 1.2. Table 3.1 describes the house dimensions in more detail. These dimensions are slightly different than the floorplans since the designs have been simplified for modelling. Also, it should be emphasized that the houses are not at an ideal site orientation. A more ideal NZEH orientation is where the side of the house with the most amount of window area is facing south [46], in order to make the best use of solar gains. Yet the backs of the townhouses face 40.2 degrees away from south, and the back of the single detached house faces 130.2 degrees away from south. Therefore these houses will not be able to rely on solar gains as much as houses with more ideal orientations. The 
reason the house types have different orientations from each other is that the townhouses will be built in a different part of the development than the single detached house.

Table 3.1: Dimensions of houses used in optimization [61], [62]

\begin{tabular}{|c|c|c|c|c|}
\hline & & $\begin{array}{l}\text { Single } \\
\text { Detached }\end{array}$ & $\begin{array}{l}\text { Townhouse } \\
\text { End }\end{array}$ & $\begin{array}{l}\text { Townhouse } \\
\text { Middle } \\
\end{array}$ \\
\hline & & \multicolumn{3}{|c|}{ Area $-\mathrm{m}^{2}(\mathrm{sq} \mathrm{ft})$} \\
\hline \multirow[t]{7}{*}{ Floor } & Basement & $94.8(1020)$ & $61.3(660)$ & $61.3(660)$ \\
\hline & Main floor & $94.8(1020)$ & $61.3(660)$ & $61.3(660)$ \\
\hline & Top floor & $129.3(1392)$ & $72.5(780)$ & $72.5(780)$ \\
\hline & Garage & $35.1(378)$ & $18.6(200)$ & $18.6(200)$ \\
\hline & Attic & $129.3(1392)$ & $72.5(780)$ & $72.5(780)$ \\
\hline & Gross heated & $318.8(3432)$ & $195.1(2100)$ & $195.1(2100)$ \\
\hline & Gross total & $354.0(3810)$ & $213.7(2300)$ & $213.7(2300)$ \\
\hline \multirow[t]{2}{*}{ Wall } & Total insulated exposed & $240.8(2592)$ & $115.9(1248)$ & $74.3(800)$ \\
\hline & Total insulated submerged & $117.4(1264)$ & $74.3(800)$ & $43.1(464)$ \\
\hline \multirow[t]{7}{*}{ Windows } & Northwest & $0.0(0)$ & $5.6(60)$ & $5.6(60)$ \\
\hline & Southeast & $6.6(71)$ & $11.7(126)$ & $11.7(126)$ \\
\hline & Northeast & $12.6(136)$ & $0.0(0)$ & $0.0(0)$ \\
\hline & Southwest & $12.5(135)$ & $2.3(25)$ & $0.0(0)$ \\
\hline & Total & $31.8(342)$ & $19.6(211)$ & $17.3(186)$ \\
\hline & & \multicolumn{3}{|c|}{ Degrees clockwise from North } \\
\hline & Orientation (front of house) & 229.8 & 319.8 & 319.8 \\
\hline
\end{tabular}

\subsection{System option selection}

In Chapter 2 it was mentioned that there are wide variety of upgrades that could be used to help make a NZEH. In light of the scope of this research, there are a few key reasons why certain technologies were included in this optimization and why some were not:

1. Preliminary analysis of systems showed unfavourable costs relative to efficiency gains

2. A system or combination of systems with similar cost and efficiency performance were already selected

3. The system was not in the BEopt database and could not be easily adapted 
The first reason why certain systems were not included in the optimization is because after running preliminary house models and cost estimation, it was found that the systems did not provide efficiency gains proportional to their costs. For example, the orientation of the houses in this study and architectural constraints reduced the ability of thermal mass to affect the heating load in a substantial way. Because the addition of thermal mass is an expensive upgrade, in this case a $25.4 \mathrm{~mm}$ ( 1 inch) thick concrete layer, it was likely that this upgrade would not be selected by the optimization and thus it was not included.

Removing these extraneous options saves computational time. If there are systems that are more cost-effective and more efficient than other options in the optimization, the less cost-effective, less efficient options are not likely to be selected [63]. For instance a lower heating setpoint would always be selected by the optimization if there were no cost implications, so having higher setpoint options are unnecessary and would slow the optimization down. Similarly, if there are two systems with similar costs and efficiencies, then either may be selected, but having both does not add any additional value to the optimization, and would slow it down as well. So if there are two similar options only one option should be included in the optimization. This is the second reason why some systems were not included in the optimization.

The final reason why certain technologies were not selected was the result of using BEopt to create the templates for the optimization. Section 3.3 explains the process and reasoning for using BEopt in more detail. While BEopt has many of the technologies that can be used to make NZEHs and many models that can be adapted to model other options, there are some options that are not in BEopt's database and cannot be adapted or 
modeled easily. For instance, it would be outside of the scope of this work to create a model of solar thermal combi-system to add to the optimization.

Using the above filtering techniques led to the selection of the options shown in Table 3.2. Appendix B shows the list of systems that were considered but were not used in the optimization scenarios. A similar "coarse optimization" procedure for screening out systems was performed in work by CanmetENERGY [15].

It was also necessary to define a code-built house design option and its respective systems. For the code-built design, compliance package J from Table 2.1.1.2.A within the SB-12 supplementary standard of the Ontario Building Code was selected since it is a commonly chosen design option within industry [41]. Because the code-built design is selected, all of the system options that make up this design are included as system options. The code-built house system options are marked in Table 3.2 with an asterisk. The cost and energy impact on the code-built single detached house from each upgrade option is shown in Appendix C. 
Table 3.2: Design parameters used in optimization

\begin{tabular}{|c|c|c|c|c|c|c|}
\hline \multirow{2}{*}{ Parameter } & \multirow{2}{*}{ Category } & \multicolumn{5}{|c|}{ Option number for each parameter } \\
\hline & & 1 & 2 & 3 & 4 & 5 \\
\hline 1 & $\begin{array}{l}\text { Heating and } \\
\text { Cooling }\end{array}$ & $\begin{array}{l}95 \mathrm{AFUE} \mathrm{Gas} \\
\text { furnace + SEER } \\
15 \mathrm{AC}^{*}\end{array}$ & $\begin{array}{l}\text { Electric furnace } \\
\text { (100\% efficient) } \\
+ \text { SEER } 15 \mathrm{AC}\end{array}$ & $\begin{array}{l}\text { ASHP (HSPF } \\
\text { 9.3 SEER 18) }\end{array}$ & $\begin{array}{l}\text { CCASHP } \\
\text { (HSPF 9.3 } \\
\text { SEER 15) }\end{array}$ & $\begin{array}{l}\text { GSHP } \\
\text { (COP 3.7) }\end{array}$ \\
\hline 2 & Hot Water & $\begin{array}{l}\text { Gas hot water } \\
\operatorname{tank}(0.67 \mathrm{EF})^{*}\end{array}$ & $\begin{array}{l}\text { Instantaneous } \\
\text { gas hot water } \\
(0.96 \mathrm{EF})\end{array}$ & $\begin{array}{l}\text { Electric hot } \\
\text { water tank } \\
(0.95 \mathrm{EF})\end{array}$ & $\begin{array}{l}\text { HPWH (COP } \\
2.3)\end{array}$ & $\begin{array}{l}\text { SDHW } \\
\left(5.95 \mathrm{~m}^{2}\right)\end{array}$ \\
\hline 3 & Ventilation & Exhaust fan & $60 \% \mathrm{HRV}^{*}$ & $75 \% \mathrm{HRV}$ & & \\
\hline 4 & $\begin{array}{l}\text { Exterior wall } \\
\text { type }\end{array}$ & $\begin{array}{l}3.87 \text { RSI (R22) } \\
\text { batt* }\end{array}$ & $\begin{array}{l}\text { 4.76 RSI (R27) } \\
\text { batt + XPS }\end{array}$ & $\begin{array}{l}5.64 \text { RSI } \\
\text { (R32) batt }+ \\
\text { XPS }\end{array}$ & $\begin{array}{l}6.52 \text { RSI } \\
\text { (R37) batt }+ \\
\text { XPS }\end{array}$ & $\begin{array}{l}7.40 \text { RSI } \\
\text { (R42) batt } \\
+ \text { XPS }\end{array}$ \\
\hline 5 & Air tightness & $2.3 \mathrm{ACH} 50^{*}$ & $1.9 \mathrm{ACH} 50$ & $1.5 \mathrm{ACH} 50$ & $1.0 \mathrm{ACH} 50$ & $0.6 \mathrm{ACH} 50$ \\
\hline 6 & $\begin{array}{l}\text { Ceiling } \\
\text { insulation }\end{array}$ & $\begin{array}{l}\text { 8.81 RSI (R50) } \\
\text { blown-in } \\
\text { fibreglass* }\end{array}$ & $\begin{array}{l}10.57 \text { RSI (R60) } \\
\text { blown-in } \\
\text { fibreglass }\end{array}$ & $\begin{array}{l}12.33 \text { RSI } \\
\text { (R70) blown- } \\
\text { in fibreglass }\end{array}$ & $\begin{array}{l}14.09 \text { RSI } \\
\text { (R80) blown- } \\
\text { in fibreglass }\end{array}$ & \\
\hline 7 & $\begin{array}{l}\text { Basement } \\
\text { wall } \\
\text { insulation }\end{array}$ & $\begin{array}{l}2.11 \text { RSI (R12) } \\
\text { batt* }\end{array}$ & $\begin{array}{l}3.52 \text { RSI (R20) } \\
\text { batt }\end{array}$ & $\begin{array}{l}4.40 \text { RSI } \\
(\text { R25) batt }+ \\
\text { XPS }\end{array}$ & $\begin{array}{l}5.28 \text { RSI } \\
(\text { R30) batt }+ \\
\text { XPS }\end{array}$ & $\begin{array}{l}6.16 \text { RSI } \\
\text { (R35) batt } \\
+ \text { XPS }\end{array}$ \\
\hline 8 & Under-slab & $\begin{array}{l}\text { No under-slab } \\
\text { insulation* }\end{array}$ & $\begin{array}{l}0.88 \text { RSI (R5) } \\
\text { XPS }\end{array}$ & $\begin{array}{l}1.76 \text { RSI } \\
\text { (R10) XPS }\end{array}$ & & \\
\hline 9 & Window type & $\begin{array}{l}\text { Double glazed } \\
\text { (USI } 1.65 \\
\text { SHGC } 0.51)^{*}\end{array}$ & $\begin{array}{l}\text { Double glazed } \\
\text { (USI 1.65 } \\
\text { SHGC 0.19) }\end{array}$ & $\begin{array}{l}\text { Triple glazed } \\
\text { (USI } 1.08 \\
\text { SHGC } 0.44 \text { ) }\end{array}$ & $\begin{array}{l}\text { Triple glazed } \\
\text { (USI } 1.14 \\
\text { SHGC } 0.17 \text { ) }\end{array}$ & \\
\hline 10 & DWHR & No DWHR* & $\begin{array}{l}37 \% \text { DWHR on } \\
\text { one shower }\end{array}$ & $\begin{array}{l}54 \% \text { DWHR } \\
\text { on both } \\
\text { showers }\end{array}$ & & \\
\hline 11 & Lighting & $\begin{array}{l}\text { All halogen } \\
\text { lighting* }\end{array}$ & $\begin{array}{l}\text { All fluorescent } \\
\text { lighting }\end{array}$ & $\begin{array}{l}\text { All LED } \\
\text { lighting }\end{array}$ & & \\
\hline 12 & Blinds & Light blinds* & Dark blinds** & & & \\
\hline 13 & Siding & $\begin{array}{l}\text { Light vinyl } \\
\text { exterior* }\end{array}$ & $\begin{array}{l}\text { Dark vinyl } \\
\text { exterior** }\end{array}$ & & & \\
\hline 14 & $\begin{array}{l}\text { Water } \\
\text { fixtures }\end{array}$ & $\begin{array}{l}\text { Code water } \\
\text { fixtures* }\end{array}$ & $\begin{array}{l}\text { High efficiency } \\
\text { water fixtures }\end{array}$ & $\begin{array}{l}\text { HE water } \\
\text { fixtures }+\mathrm{HE} \\
\text { toilet }\end{array}$ & & \\
\hline 15 & Thermostat & $\begin{array}{l}\text { Regular } \\
\text { thermostat* }\end{array}$ & $\begin{array}{l}\text { Smart } \\
\text { thermostat }\end{array}$ & & & \\
\hline 16 & $\begin{array}{l}\text { Real-time } \\
\text { energy } \\
\text { monitoring }\end{array}$ & $\begin{array}{l}\text { No energy } \\
\text { monitoring* }\end{array}$ & $\begin{array}{l}\text { Energy monitor } \\
\text { with breakdown } \\
\text { by appliance** }\end{array}$ & & & \\
\hline 17 & Appliances & $\begin{array}{l}\text { Typical } \\
\text { appliances* }\end{array}$ & $\begin{array}{l}\text { High efficiency } \\
\text { appliances }\end{array}$ & $\begin{array}{l}\text { Best in class } \\
\text { appliances** }\end{array}$ & & \\
\hline 18 & Solar PV & No solar PV* & $\begin{array}{l}\text { Full or required } \\
\text { solar PV }\end{array}$ & & & \\
\hline
\end{tabular}

\subsection{House and system modelling}

This section describes how the building energy modelling was carried out. In this thesis

BEopt was used to generate EnergyPlus input files. These input files retained most of the 
original BEopt assumptions, but some modifications were made in order to improve accuracy. The input files were converted into templates files that the optimization algorithm uses to create the EnergyPlus input files for specific house designs.

\subsubsection{Selection of building performance modelling program}

For this thesis BEopt was used to generate energy model input files that would be used to make templates files for the optimization. BEopt is a U.S. funded, home energy modelling tool that uses either DOE-2 or EnergyPlus and can be used to rapidly generate energy modelling input files. Using BEopt to generate templates limited the energy modelling software choices to DOE-2 or EnergyPlus, as these are the energy modelling engine choices available in BEopt.

It was decided that EnergyPlus would be used, because EnergyPlus is more accurate and is able to model more systems than DOE-2, although it is slower [64]. While EnergyPlus and DOE-2 both use conduction transfer functions to calculate conduction through their envelopes, EnergyPlus and DOE-2 differ in calculations of air and surface temperature [64]. EnergyPlus uses the heat balance method on interior and exterior surfaces and on zone air nodes, instead of the response function method used by DOE- 2 . As an example of the heat balance method, Equation 4 shows how the air temperature of a zone is calculated by EnergyPlus [65]. This equation reflects the physics of the problem more accurately than the response function method, and is therefore more widely applicable to different problems. Another accuracy advantage EnergyPlus has over DOE2 is that it simultaneously calculates solutions for the zones, systems, and plant, rather than sequentially. This iterative method allows for more accurate predictions of space 
temperatures and building loads [64]. The use of the heat balance method and simultaneous solving improves the accuracy of EnergyPlus, although these accuracy improvements result in longer simulation times.

EnergyPlus is also more versatile than DOE-2 because it does not have fixed HVAC templates like DOE-2. Unique HVAC systems can be built from sub-components, allowing EnergyPlus to model system that cannot be modelled on DOE-2. For example, EnergyPlus has four more modelling options in BEopt than DOE-2: heat pump water heaters (HPWHs), heat recovery ventilators (HRVs), dehumidifiers, and solar domestic hot water (SDHW).

$$
C_{z} \frac{d T_{z}}{d t}=\sum_{i=1}^{N_{s l}} \dot{Q}_{i}+\sum_{i=1}^{N_{\text {suffaces }}} h_{i} A_{i}\left(T_{s i}-T_{z}\right)+\sum_{i=1}^{N_{\text {zones }}} \dot{m}_{i} C_{p}\left(T_{z i}-T_{z}\right)+\dot{m}_{\text {inf }} C_{p}\left(T_{\infty}-T_{z}\right)+\dot{Q}_{s y s}
$$

Equation 3 [65]

where:

$\sum_{i=1}^{N_{s l}} \dot{Q}_{i}=$ sum of the convective internal loads

$\sum_{i=1}^{N_{\text {sufaces }}} h_{i} A_{i}\left(T_{s i}-T_{z}\right)=$ convective heat transfer from the zone surfaces

$\dot{m}_{\text {inf }} C_{p}\left(T_{\infty}-T_{z}\right)=$ heat transfer due to infiltration of outside air

$\sum_{i=1}^{N_{\text {zones }}} \dot{m}_{i} C_{p}\left(T_{z i}-T_{z}\right)=$ heat transfer due to interzone air mixing

$\dot{Q}_{s y s}=$ air systems output

$C_{z} \frac{d T_{z}}{d t}=$ energy stored in zone air

$\mathrm{C}_{\mathrm{z}}=\rho_{\text {air }} \mathrm{C}_{\mathrm{p}} \mathrm{C}_{\mathrm{T}}$

$\rho_{\text {air }}=$ zone air density

$\mathrm{C}_{\mathrm{p}}=$ zone air specific heat

$\mathrm{C}_{\mathrm{T}}=$ sensible heat capacity multiplier 
One weakness of EnergyPlus is that the conduction transfer function assumes one dimensional conduction heat transfer, and constant thermophysical properties, i.e. the wall properties cannot change with time or with temperature. The thermal resistivity of many materials changes with temperature and this is not taken into account. In response to this deficiency a conduction finite difference algorithm has been added to EnergyPlus, which can take into account these changes in thermophysical properties, but this feature increases simulation time substantially [65] and was not used for this thesis. For more information on the differences between DOE-2 and EnergyPlus see [64], and for detailed information on the modelling calculations used by EnergyPlus see [65].

\subsubsection{Building performance modelling template file generation}

In order to allow for efficient conversion from the coded representation of designs (chromosomes) to EnergyPlus input files, templates were used. Template files in this case are EnergyPlus input files that have placeholders within them. The placeholders are codes that can be replaced with variables. When generating the EnergyPlus input files the optimization algorithm takes a template file and searches for and replaces the placeholders with numerical values according to the specific design. The template files were generated by taking a BEopt-generated EnergyPlus input files and adding these placeholders. Appendix D has a list of all of the placeholders used in the template files and describes each of their functions. There are two types of placeholder variables, ones that scale the BEopt defaults and others that represent physical variables, such as thermal resistance. It should be noted that the placeholders were not sufficient to change the HVAC, DHW, and ventilation systems within a template as this required replacing large 
blocks of text. Therefore, templates for all HVAC, DHW, and ventilation options were created.

Other than some modifications, the model follows the building and systems models used by BEopt, and the Building America House Simulation Protocols BEopt uses for schedules and default values [45]. For instance, BEopt creates different zones based on space type. In this case there are three different zones in each house model: a living space zone, a basement zone and a garage zone. The lighting and appliance usage profiles from Building America House Simulation Protocols provide, for example, can be scaled by the optimization depending on what options are chosen.

Modifications were made to the BEopt-created EnergyPlus template files mainly to increase the accuracy of the model. For instance the basement floor and wall were modeled differently than the default procedure because by default BEopt assumes that the basement floor loses no heat to the ground, whereas heat loss from the basement to the ground is non-negligible in a Canadian climate [66]. Many of these modifications are similar, either adapting the model to be more accurate in a cold climate, or changing the model so that it meets the code minimum for Ontario. Some additional changes as well as other modelling assumptions are described in more detail in Section 3.3.3.

Miscellaneous changes made to the BEopt-created EnergyPlus input files included:

- Changed location type from urban to suburban

- Added ground reflectance and snow modifier

- Changed exposed floor insulation to 5.46 RSI (R31) as specified in Ontario Building Code [41] 
- Garage walls and ceiling constructions changed to the same as exterior wall except without cladding

- Made sure correct walls were adiabatic for adjoining units

- Added time-of-use calculations to electrical usage

\subsubsection{Building performance modelling assumptions}

The modelling assumptions for the building performance models in this thesis are based on the assumptions used by BEopt, although there have been many alterations. This section describes the modelling assumptions for the key houses systems and describes any changes that have been made.

\section{Heating and cooling systems:}

Heating and cooling systems were modelled based on BEopt options, and in some cases slight modifications were made. Out of the five different options chosen for the heating and cooling systems the only one that was modified was the cold climate air source heat pump (CCASHP). All the other systems are based off of built in options in BEopt. The gas furnace system was chosen as the built in BEopt option: "Furnace: Gas, 92.5\% AFUE" (was adjusted to 95\%); "Central air conditioner: SEER 15". The electric furnace system was chosen as the built in BEopt option: "Furnace: Electric, 100\% AFUE";

"Central air conditioner: SEER 15". The air source heat pump (ASHP) system was chosen as the built in BEopt option: "Air Source Heat Pump: SEER 16, 8.6 HSPF". This was chosen since it is close to the average rating of Energy Star ASHPs. The GSHP 
system was chosen as the built in BEopt option:" Ground Source Heat Pump: EER 18.2, COP 3.7, Low-k soil, Enh grout", since this option represents a middle efficiency GSHP.

A CCASHP option was desired, and the Mitsubishi Zuba type CCASHP was chosen since it has the best cold climate performance from a recognized brand. The regular ASHP has a HSPF of 8.6 which equates to an equivalent heating seasonal COP of 2.0 for an ASHRAE climate zone 6, where Ottawa is located. The Zuba however has an advertised equivalent COP of 2.4 for the same climate zone [34]. Unfortunately heatpump performance curves for the Zuba could not be obtained. In order to replicate the advertised annual performance of the Zuba, the COP factors of the original ASHP were increased. Figure 3.1 shows the modifications made to the COP so that the CCASHP model would provide similar performance to that advertised by Mitsubishi.

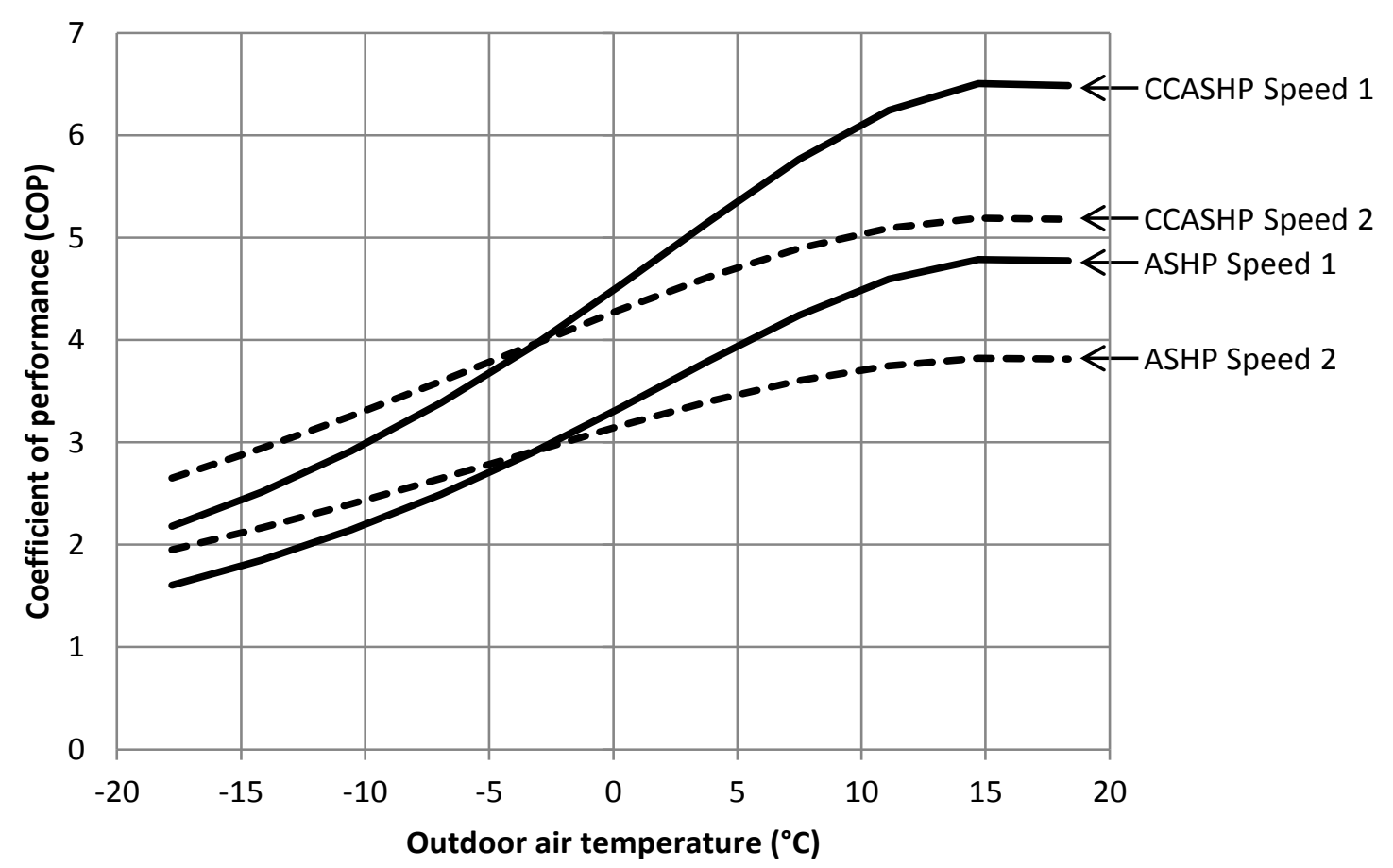

Figure 3.1: ASHP and CCASHP COP versus temperature profiles 
The sizing for the systems is $10.3 \mathrm{~kW}$ for conventional systems and $12.3 \mathrm{~kW}$ for air conditioning and heat-pump systems. The electric back-up systems for the ASHP and the CCASHP are $10.3 \mathrm{~kW}$ electric coils. This sizing was chosen because it met the heating requirements of the code-built single detached house design.

\section{Domestic hot water:}

Hot water systems were also chosen based on options in BEopt. The system options: Water Heater: "Gas Premium" (0.67 EF); "Gas Tankless, Condensing” (0.96 EF); and "Electric Premium" (0.95 EF) were used for the conventional systems.

The system option "HPWH, 50 gal" (COP 2.8) was used for the HPWH option in this thesis. It may be interesting to note that the HPWH model uses constant COP versus temperature. However, since the indoor air temperature is not changing substantially, this assumption is likely reasonable.

A SDHW system option was added, the system was chosen as two panel and flat plate. Two panels were chosen over one, since the incremental cost of a second panel is lower. Flat plate collectors were chosen because they have lower costs than evacuated tube collectors. This BEopt system option is labeled as "64 sqft, Closed Loop". The azimuth and tilt angles for the panels are $139.8^{\circ}$ and $26.6^{\circ}$, respectively, for the single detached house, and $139.8^{\circ}$ and $22.6^{\circ}$ for the townhouses. These angles are the same as for the solar PV panels. The backup system for the SDHW is the "Electric Premium" system option. 


\section{Air infiltration:}

The air leakage options used by this thesis $(2.3,1.9,1.5,1.0$ and $0.6 \mathrm{ACH} 50)$ were created by modifying the $1.0 \mathrm{ACH} 50$ system option in BEopt. The infiltration model used by BEopt is the AIM-2 model, which takes into account wind and stack effects and is described in more detail here [67]. Although BEopt would typically modify garage leakage based on the rated ACH50, effective leakage area in garage was fixed, since it is likely that garage air leakage would not be modified since it is an unheated zone.

\section{Basement wall and basement slab heat transfer:}

BEopt assumes that there is no heat transfer with the ground through the basement floor, which is not a realistic assumption in Canadian climates [66]. Therefore the EnergyPlus ground heat transfer preprocessor was used instead. The monthly average exterior ground temperatures for the basement wall and basement floor were generated by the preprocessor for both the single detached house type and the townhouse types. The townhouses were modelled as a block of five units.

Typically, the preprocessor would be run for each basement insulation configuration. However, in this case it was decided to use the median value of basement wall and basement floor insulation from the options in Table 3.2. This was done to more accurately quantify the energy savings of additional basement insulation. The problem with using steady state values of exterior ground temperature for cases with low insulation is that the transient period is very long, on the order of decades [68]. With a basement air temperature of $18^{\circ} \mathrm{C}$ the under-slab ground temperature was modelled to be about $17.5^{\circ} \mathrm{C}$ when no under-slab insulation is used, even though the undisturbed ground 
temperature in Ottawa is $5.7^{\circ} \mathrm{C}$. Due to the lengthy time to heat up the ground thermal mass, the house will lose a lot of energy through the basement slab, and will not perform as modelled for decades, until the ground temperature reaches steady state.

A more accurate way to simulate the basement temperature would be to average the ground temperatures over the project lifespan and use the averages as the boundary conditions, however this is beyond the scope of this thesis. In this thesis, the ground temperatures for the median basement insulation case were used for all cases since it prevents the unrealistic ground temperatures that are generated when surfaces are uninsulated, and allows a more accurate comparison between the insulation levels. The exterior ground temperature profiles shown in Table 3.3 were generated with the basement wall insulated to 4.4 RSI and the basement floor insulated to $0.88 \mathrm{RSI}$.

Since the exterior soil temperature was sought after, it was easier to change the concrete wall and slab properties in the preprocessor so that they would provide the necessary thermal resistance. The interior basement temperature was a constant $18^{\circ} \mathrm{C}$, so the thermal mass properties of the concrete would not have a significant impact even if they were retained. Appendix E shows the EnergyPlus input for the basement preprocessor.

The basement interacts with the living zone (the ground and second floor) through the ventilation system which directs $12.5 \%$ of the airflow to the basement. Heat transfer also occurs through an uninsulated interzonal floor separating the zones, which has a nominal thermal resistance of $0.89 \mathrm{RSI}$ (R5.1). A carpet layer was also added to basement floor as this is a likely scenario for finished basements. 
Table 3.3: Exterior ground temperatures found by basement preprocessor

\begin{tabular}{|c|c|c|c|c|}
\hline \multirow{2}{*}{ Month } & \multicolumn{4}{|c|}{ Exterior Ground Temperature ( $\left.{ }^{\circ} \mathbf{C}\right)$} \\
\cline { 2 - 5 } & \multicolumn{2}{|c|}{ Single Detached } & \multicolumn{2}{c|}{ Townhouse } \\
\cline { 2 - 5 } & Basement Wall & Basement Floor & Basement Wall & Basement Floor \\
\hline $\mathbf{1}$ & -3.55 & 15.18 & -3.29 & 15.68 \\
\hline $\mathbf{2}$ & -4.43 & 14.93 & -4.14 & 15.49 \\
\hline $\mathbf{3}$ & -0.79 & 14.88 & -0.52 & 15.46 \\
\hline $\mathbf{4}$ & 2.85 & 14.96 & 3.09 & 15.51 \\
\hline $\mathbf{5}$ & 8.68 & 15.21 & 8.87 & 15.7 \\
\hline $\mathbf{6}$ & 12.98 & 15.51 & 13.12 & 15.92 \\
\hline $\mathbf{7}$ & 15.16 & 15.77 & 15.27 & 16.11 \\
\hline $\mathbf{8}$ & 16.01 & 15.98 & 16.11 & 16.27 \\
\hline $\mathbf{9}$ & 13.93 & 16.06 & 14.03 & 16.33 \\
\hline $\mathbf{1 0}$ & 10.39 & 16 & 10.52 & 16.29 \\
\hline $\mathbf{1 1}$ & 5.43 & 15.8 & 5.6 & 16.14 \\
\hline $\mathbf{1 2}$ & -0.19 & 15.52 & 0.04 & 15.93 \\
\hline
\end{tabular}

\section{Windows properties:}

The simulation used the simple window model in EnergyPlus, i.e. specific window properties were not specified other than the U-value and SHGC. Window sizes could not be changed due to architectural constraints. Additionally, the ability to change window type based on orientation was not included. Allowing only one window type was done in order to prevent the improper placement of different window types. The thermal resistance of the front exterior door does not change based on changes to the window type and was modelled to have a constant thermal resistance of 1.23 RSI (R7).

\section{Blinds and siding properties:}

The blind and siding solar absorptivity is modified as one of the occupant engagement options. The default is light coloured blinds and light coloured siding with a solar absorptivity of 0.3 , but if the occupant engagement options are available the absorptivity can be set to 0.75 . These absorptivities were chosen because they approximate the 
absorptivities of lighter and darker surfaces that are not fully white or fully black, meaning there is some flexibility in the colours that can be chosen. It is shown that people do not use their blinds consistently, so the blind occlusion was set to $50 \%$ at all times [69].

\section{Occupant energy usage model:}

The NRCan NZEH energy calculation tool was used to calibrate the occupant energy usage schedules used by BEopt [47]. The NRCan model defines the base case electricity usage to be $19.5 \mathrm{kWh} /$ day and hot water usage to be 186 1/day. Given the breakdown of the hot water usage, the cold water usage can be estimated at $147 \mathrm{l} /$ day by using the information in the NZEH energy calculation tool [47], and a statistical report on Canadian household energy use [70]. The cold water usage was calculated separately from the EnergyPlus energy models.

The occupant energy usage profiles were calibrated so that the total occupant electricity usage is $19.5 \mathrm{kWh} /$ day for the base case, with a breakdown of $3.5 \mathrm{kWh} /$ day for lighting, $6.3 \mathrm{kWh} /$ day for large appliance loads, and $9.7 \mathrm{kWh} /$ day for miscellaneous appliance loads. There are three things that can change the occupant electricity usage: upgrading the lighting, upgrading the large appliances, and adding an energy monitor. NRCan estimates energy savings due to putting in energy star appliances reduces the large appliance loads by $1.5 \mathrm{kWh} /$ day, and putting in best-in-class energy efficient appliances reduces loads by $2.7 \mathrm{kWh} /$ day. NRCan estimates that the savings from fluorescent and LED bulbs is the same, at $2 \mathrm{kWh} /$ day. 
Energy monitors are not supported energy reduction mechanisms under the current NZEH certification program. Even so, they are included here because of their potential to reduce energy usage for low cost. It has been found that energy monitors that provide an energy usage breakdown by appliance, reduce energy usage by $12 \%$ [50]. This $12 \%$ reduction is subtracted from the large appliances, miscellaneous appliances, lighting, and hot water loads (when the hot water system is electric).

The hot water usage profiles were calibrated so that the total hot water usage changed to $1861 /$ day for the base case, with a breakdown of $1361 /$ day for showers and sink faucets, and $50 \mathrm{l} /$ day for clothes washing and dishwashing. The cold water usage was changed to $147 \mathrm{l} /$ day for the base case, with a breakdown of $59 \mathrm{l} /$ day for showers and sinks, 41 1/day for clothes washing and dishwashing, and 47 1/day for toilets. The water reduction due to high efficiency showers $(<7.6 \mathrm{l} / \mathrm{min})$ and sink faucets $(<5.7 \mathrm{l} / \mathrm{min})$ results a water reduction of $27 \mathrm{l} /$ day of hot water, and $12 \mathrm{l} /$ day of cold water. The water reduction due to high efficiency dishwashers and clothes washers is $21 \mathrm{l}$ /day hot water, and 19 1/day cold water. Improving the efficiency of the toilet to $31 /$ flush reduces cold water usage by 18 1/day. Drain water heat recovery (DWHR) devices do not save water but save on hot water load. One 37\% efficient DWHR device on one shower saves about $20 \%$ of the total shower hot water load. Two $54 \%$ efficient DWHR devices on both showers save about $44 \%$ of the total shower hot water load.

The load profiles from BEopt are retained, but are scaled to match the desired load. An example of one of these load profiles is the average hourly load profile of miscellaneous electric energy generated by BEopt. This profile has been scaled in order 
to meet the NRCan specified $9.7 \mathrm{kWh} /$ day (see Figure 3.2). The occupant energy usage and savings described above are applied to all three house types.

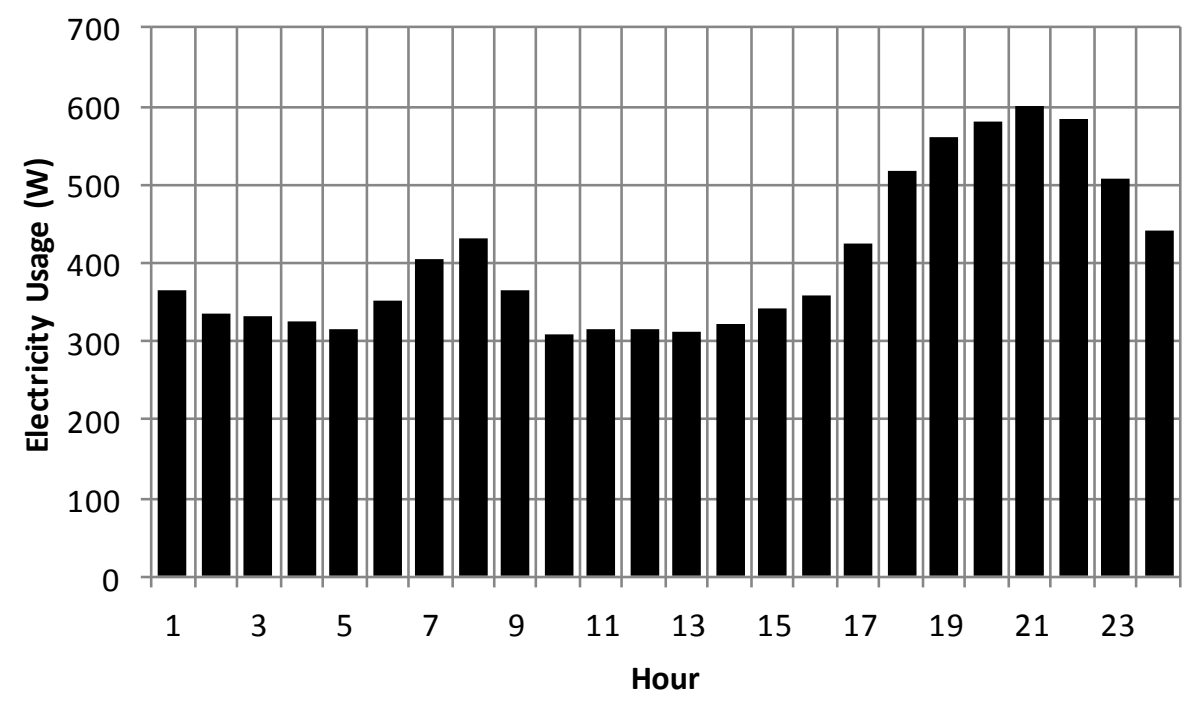

Figure 3.2: Average daily profile of miscellaneous appliance load

\section{Smart thermostat:}

It has been found that programmable thermostats are typically not programmed correctly and do not provide their anticipated savings [51]. Smart thermostats are selfprogramming thermostats so they do not rely on occupant input in order to save energy. The temperature assumptions for the smart thermostat are based on the night-time setbacks in winter and the daytime setups in summer that BEopt uses as defaults.

The default heating setpoint temperature is $21.7^{\circ} \mathrm{C}\left(71^{\circ} \mathrm{F}\right)$ and this is decreased to $18.3^{\circ} \mathrm{C}\left(65^{\circ} \mathrm{F}\right)$ at night if nighttime setback is enabled. Because smart thermostats can also maximize the efficiency of heat pumps, a method was sought to eliminate efficiency losses caused by the use of back up heating when there are rapid changes in the temperature setpoint. Thus, the temperature setpoint was set to $20.0^{\circ} \mathrm{C}\left(68^{\circ} \mathrm{F}\right)$ for all 
hours of the day for the smart thermostat case. This allows the impact of the smart thermostat to be quantified more accurately when heat pumps are used.

The default cooling setpoint from BEopt is $24.4^{\circ} \mathrm{C}\left(76^{\circ} \mathrm{F}\right)$ and this is increased to $29.4^{\circ} \mathrm{C}\left(85^{\circ} \mathrm{F}\right)$ during the day on weekdays when daytime setup is enabled. Since cooling can only be achieved through an air conditioning or heat pump system, rapid changes in the heating setpoints do not affect the efficiency of cooling significantly. Therefore the original BEopt cooling setpoint temperatures were retained for the smart thermostat case.

Although the actual setpoint temperature of the smart thermostat is dependent on the occupancy schedule and the temperature preferences of the occupant, these temperature setpoints allow for a rough quantification of the energy savings of the smart thermostat.

\subsection{Cost calculations}

There was one main cost database used to determine the costs of the design options. CanmetENERGY provided a database of cost information from their Affordable NetZero Energy Housing project [44]. The Affordable Net-Zero Energy Housing cost database was used for the bulk of the costs. There were other sources used to find data not found in this database, or to replace outdated cost information. The CanmetENERGY Local Energy Efficiency Partnership (LEEP) program also has a cost database [71] which was used only for updated window cost information, as high efficiency window costs had decreased rapidly during the course of this research [72].

The costs for water fixtures, thermostats and real time energy monitors were taken from Amazon.ca since they were not available in either cost database [73]. Additionally, the cost of solar PV had dropped substantially and the NRCan databases had out of date 
solar PV costs, so the cost of installed solar PV was taken from predictions from the U.S. DOE SunShot Initiative [31].

Comparing the CanmetENERGY costs to proprietary cost information from Minto, it was found that on average the Minto costs are approximately $15 \%$ lower than those provided by CanmetENERGY. Therefore this $15 \%$ factor is used as a representation of the savings in building costs that a large-scale developer would experience, compared to the costs for small scale construction. This factor is added to some of the optimization scenarios in Section 3.7. The non-discounted costs for the systems listed in Table 3.2 can be found in Appendix F.

The lifespans of the systems can be found in Appendix F as well. These lifespans come from the NREL Measures Database version 3.0.0 [33] and indicate the replacement period for the systems. For any system missing from the database, the lifespan of the most similar system was used, or the lifespan was estimated. Please note that any system that has a replacement period over 30 years is represented by a dash.

This optimization has two objectives: energy and cost. It tries to minimize the annual net-energy usage (site energy usage minus site energy generation) and maximize net present value (NPV). The NPV is the total value that an owner would gain between the proposed house and a code-built house, in discounted dollars. If the NPV is positive for a NZEH, then purchasing the NZEH is a worthwhile investment, and the NZEH is considered cost-effective. This metric incorporates the following costs: energy costs, mortgage payments, taxes, down-payment costs, system replacement costs, and revenue generation from solar PV if applicable. Equation 4 shows how the NPV is calculated. In 
Equation $4 r$ is the discount rate, which in this case is set to the mortgage rate (4\%), $k$ is the current year, and $n$ is the project length ( 25 years).

$$
\mathrm{NPV}=\sum_{k=0}^{k=n} \Delta(\text { Total Costs })_{\text {year }=k}(1+r)^{-k}
$$

Other constants that influence the cost, based on circa 2014 prices and trends, are shown below in Table 3.4. Time-of-use pricing was used for electricity but average natural gas price was used instead of tiered pricing, since it was found that the electricity price is much more significant for NZEHs. The electricity rate increase comes from the rate increases in the OPA Long Term Energy Plan [74] and the gas rate increase comes from predictions from the U.S. Energy Information Administration [75]. For the purposes of this thesis the mortgage length and down payment was set to the minimum down payment that would avoid additional CMHC insurance costs [76]. The mortgage rate and inflation rate was taken from the Bank of Canada [77]. Although the buyer may choose a different type of mortgage, the rest of the constants in Table 3.4 do not rely on the choice of the buyer. These constants are used in the optimization and most are used across all optimization scenarios (see Section 3.7). However, electricity rate increase, natural gas rate increase, interest rate and down payment percentage are changed in a few optimization scenarios (see Table 3.5). 
Table 3.4: Additional constants included in the optimization

\begin{tabular}{|c|c|c|}
\hline Constant & Value & Unit \\
\hline Electricity monthly fee [78] & 9.55 & \$/month \\
\hline Electricity off-peak cost [78] & 0.072 & $\$ / \mathrm{kWh}$ \\
\hline Electricity mid-peak cost [78] & 0.109 & $\$ / \mathrm{kWh}$ \\
\hline Electricity on-peak cost [78] & 0.129 & $\$ / \mathrm{kWh}$ \\
\hline Electricity delivery cost [78] & 0.04774 & $\$ / \mathrm{kWh}$ \\
\hline Electricity rate increase [74] & Varies* & $\%$ \\
\hline Natural gas monthly fee [79] & 20 & \$/month \\
\hline Natural gas average cost [79] & 0.2992 & $\$ / \mathrm{m}^{3}$ \\
\hline Natural gas rate increase [75] & 3.5 & $\%$ \\
\hline Water monthly fee [80] & 2.94 & \$/month \\
\hline Water average cost [80] & 3.25 & $\$ / \mathrm{m}^{3}$ \\
\hline Water rate increase [81] & 2.6 & $\%$ \\
\hline Inflation rate [77] & 2 & $\%$ \\
\hline Mortgage interest rate [77] & 4 & $\%$ \\
\hline Mortgage down payment [76] & 20 & $\%$ \\
\hline Mortgage term length [76] & 25 & years \\
\hline Markup on incremental building cost [82] & 20 & $\%$ \\
\hline Single detached cost (w tax) [61] & 444,900 & $\$$ \\
\hline End unit cost (w tax) [62] & 298,900 & $\$$ \\
\hline Middle unit cost (w tax) [83] & 294,900 & $\$$ \\
\hline
\end{tabular}

* See Appendix $\mathrm{G}$ for the detailed electricity rate increase over time

\subsection{The aNSGA-II optimization algorithm}

The goal of the optimization is to find the lowest incremental costs and maximum energy savings simultaneously, so a multi-objective optimization algorithm was necessary. The optimization algorithm that is used in this thesis is a modified version of the Nondomination Sorting Genetic Algorithm II, with active Pareto-archiving (aNSGA-II) as described by Hamdy et al. [58]. The aNSGA-II was shown to have good performance when used on near net-zero energy house (NNZEH) optimization. The original version, the NSGA-II algorithm, is commonly used for multi-objective optimization, and has been used for building performance optimization [10]. Because of its popularity, there are NSGA-II script codes available online. The example NSGA-II code written by Aravind 
Seshadri [84] was adapted into an aNSGA-II by adding the active Pareto-archive function, and was used for this thesis. It is possible that BEopt might have been used to perform the optimizations without modification, saving the time needed to establish a purpose built optimization script, yet it was decided to use a purpose built optimization script. Using this script, advantageous system options that are not in BEopt could be added to the optimization and an evolutionary algorithm could be used instead of sequential search. As described in Section 2.2.3, evolutionary algorithms can take advantage of interactions that a sequential search algorithm (used in BEopt) may miss.

Therefore the aNSGA-II was selected for three reasons:

1. The aNSGA-II has been shown to be a reliable multi-objective optimization algorithm for the optimization of NNZEHs [58]

2. The NSGA-II is commonly used, so example code was available online, and it is straightforward to convert the code into an aNSGA-II [84]

3. The aNSGA-II is a genetic algorithm, so it can take advantage of interactions between systems [59]

An overview of the optimization algorithm function is shown in in Figure 3.3. The aNSGA-II works by sorting chromosomes based on where they are in relation to the Pareto front, and how close they are to other chromosomes in the objective space. The highest scoring designs are those that are nearest to the Pareto front and farthest from other designs. For the original NSGA-II, after each generation the child population is combined with the previous generation population and the best fifty percent are retained. 
However, with the addition of the active Pareto-archive, the Pareto-optimal designs are retained in an archive after each generation, and they participate in creating the next generation of chromosomes. The objective functions for these chromosomes are evaluated, then are sorted and the process repeats itself until a stopping criteria is met.

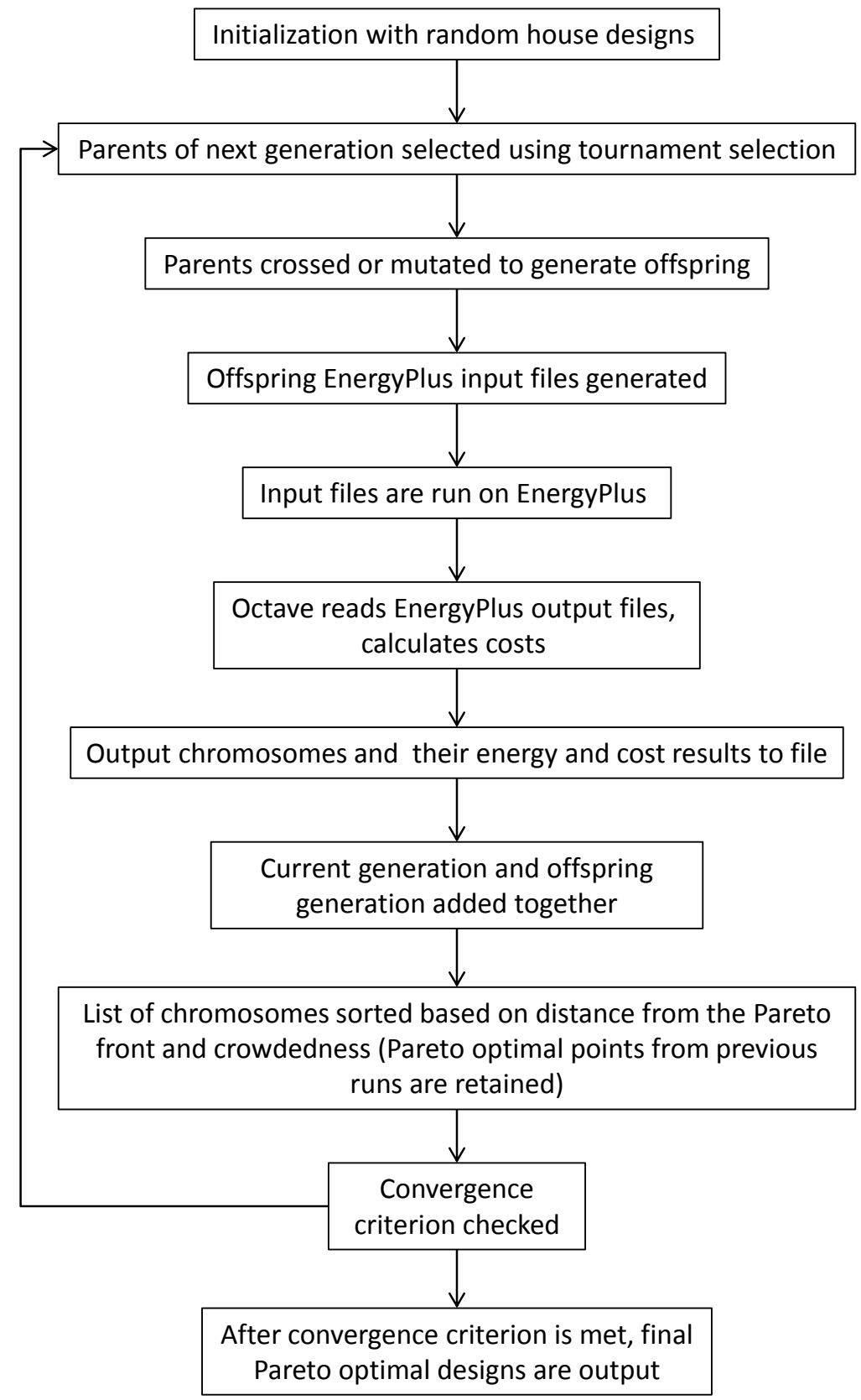

Figure 3.3: Overview of aNSGA-II optimization algorithm used in this thesis 
The aNSGA-II definition is somewhat misleading because it refers to the selection of designs through non-domination sorting, and the active Pareto-archive only. However there are many more optimization functions that are not specific to the aNSGAII and can be interchanged. These functions were chosen based on previous optimization work, as well as by trial and error in order to improve the performance of the optimization. The algorithm here uses tournament selection, discrete representation, uniform mutation, uniform crossover, a uniqueness function, a convergence criterion, and a shrink function.

Tournament selection repeatedly selects two designs from the current population randomly, and then chooses the more fit designs to become part of the mating pool. In this way the mating pool is populated with generally more fit designs.

Discrete representation expresses chromosomes as discrete codes for each design parameter (non-binary), in order to reduce genetic errors that can arise from crossing over designs in binary.

The uniform mutation function and uniform crossover functions were chosen because these work well with discrete design parameters. Uniform mutation applies a constant probability of mutation to each parameter; if a parameter is chosen for mutation, it replaces the current option for that parameter with another randomly selected option. Uniform crossover applies a 50\% crossover probability to each parameter, so that the offspring designs have a random combination of options from each parent.

The uniqueness function rejects any offspring chromosome that has been modelled before, so the optimization is more efficient and does not have to re-simulate past designs. 
A convergence criterion was added to the optimization in order to know when to stop the optimization. Choosing a fixed number of generations is problematic because optimizations with different constraints will have different convergence rates. A convergence criterion from Goel \& Stander [85] was chosen since it had been applied to the NSGA-II. This criterion is the number of Pareto-optimal points that are overtaken by new Pareto-optimal points divided by the total number of Pareto-optimal points, which is called the improvement ratio (IR) (see Equation 5). As the Pareto front advances towards the objectives, the points that were previously on the Pareto front are left behind and are removed from the Pareto-archive. The number of "passed" Pareto-optimal points decreases as the optimization moves closer to the true Pareto curve. In this case it was taken that when the weighted average of the improvement ratio $(\overline{\mathrm{IR}})$ goes below 0.01 , the optimization will quit. A weighting constant $(\alpha)$ of 1/6 was used in order to make sure that the optimization would not quit if any significant improvements had been made in the last several generations. See Equation 6 for exponential weighting equation.

Based on the idea that optimization algorithms are more effective if they have an exploratory phase at the beginning of the optimization, a shrink function that increases randomization at the beginning of the optimization was added [86]. This shrink function is tied to the convergence criteria, which allows it to adapt to different levels of problem complexity, i.e. it will have a longer randomized period for longer optimization problems. The shrink function changes the mutation fraction from $50 \%$ to $10 \%$, while also varying the mutation probability from $25 \%$ to $5 \%$, and since the convergence criteria decreases exponentially, these factors also decrease exponentially. 


$$
\begin{array}{cc}
I R_{i}=\frac{\text { Number of "passed" Pareto-optimal points }}{\text { Total number of Pareto-optimal points }} & \text { Equation } 5 \\
\overline{I R}_{i}=I R_{i} \cdot \alpha+(1-\alpha) \cdot \overline{I R}_{i-1} & \text { Equation } 6
\end{array}
$$

\section{6 aNSGA-II testing and the ISS algorithm}

It is difficult to know if an optimization algorithm is running successfully without running an exhaustive search to find the global optima and comparing the optimization results to these points. As with most building optimization problems, an exhaustive search in this case was not possible. Nevertheless, convergence to the optimal can be verified in some way, since if many optimizations are run, and they converge to the same point multiple times, the point found repeatedly is likely a local optimal point. Also, while it cannot be said for sure that the particular local optimal is the global optimal, it is likely that many different peaks (or design strategies) have been tried, due to the random nature of genetic algorithms, so it is possible that an optimal point found consistently by a genetic algorithm is the global optimal. Additionally this optimization is more exploratory than a typical genetic algorithm, due to the added shrink and uniqueness functions. So, there is a possibility that repeated results found by this optimization could be the global optimal, because of its exploratory nature and the strict convergence criteria. Ten test runs were performed on the optimization algorithm, to confirm that the optimization was achieving consistent results. It is important to achieve consistent optimal designs since that allows for comparisons between the different test scenarios, to see how the scenarios impact the costs and designs of the houses. These ten test runs were performed on a prototype optimization of the base case single detached house. 
These ten test runs were also compared to a simple iterated sequential search (ISS) algorithm. The ISS is a rule based algorithm that geometrically searches for the Pareto-optimal points. Since it is rule based and not randomized like a genetic algorithm, it achieves the same results for every run. The ISS algorithm used by BEopt is more sophisticated than the one used in this thesis, having additional functions to improve speed and accuracy [59]. However, the ISS in this case is only used for comparison purposes and to ensure that the aNSGA-II algorithm is performing effectively, so these additional functions were not used.

The ISS in this thesis starts from the code-built house design and models each variation in house design, changing only one variable at a time. Once it simulates all the variations, it selects the one with the most vertical forward angle, i.e. it selects the smallest angle from $0^{\circ} \leq$ Angle $<180^{\circ}$ (clockwise from vertical). A graphical representation of this selection mechanism is shown in Figure 3.4.

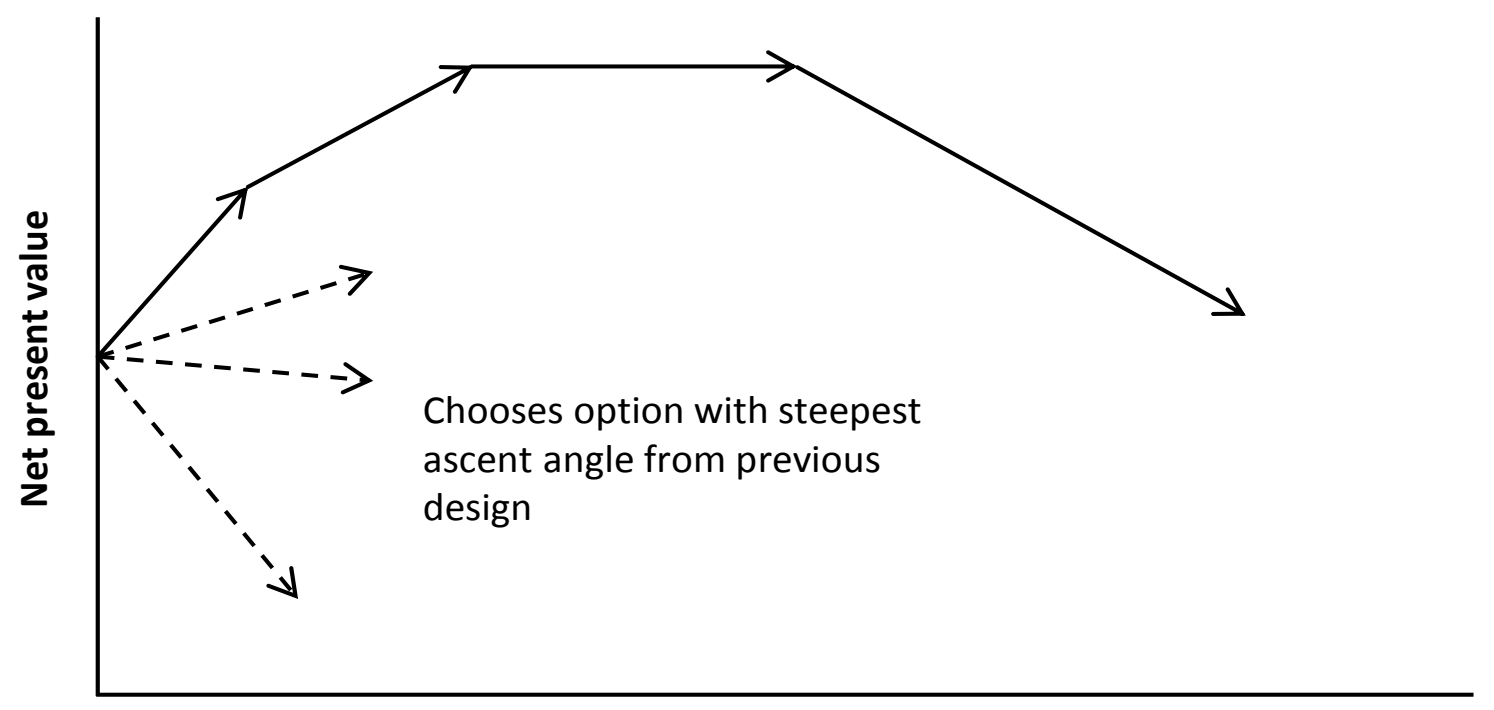

Energy savings

Figure 3.4: Depiction of ISS optimization process 
While high repeatability was observed for the aNSGA-II algorithm, good performance was also observed from the ISS algorithm. Figure 3.5 and Figure 3.6 show the NZEH and $\mathrm{COH}$ performance for the aNSGA-II test runs and the performance of the ISS. The aNSGA-II algorithm was very consistent in finding the same well performing NZEH, and only in one case significantly diverged. However for the COHs, the aNSGA-II was not consistent, with almost each optimization run finding a different design.

The performance of the ISS was unexpectedly good, achieving approximately equal performance to the aNSGA-II. Due to approximately equivalent performance of the ISS, it was decided to run both the aNSGA-II and the ISS for each of the optimization runs (described in Section 3.7) in order to verify and compare with the results from the aNSGA-II.

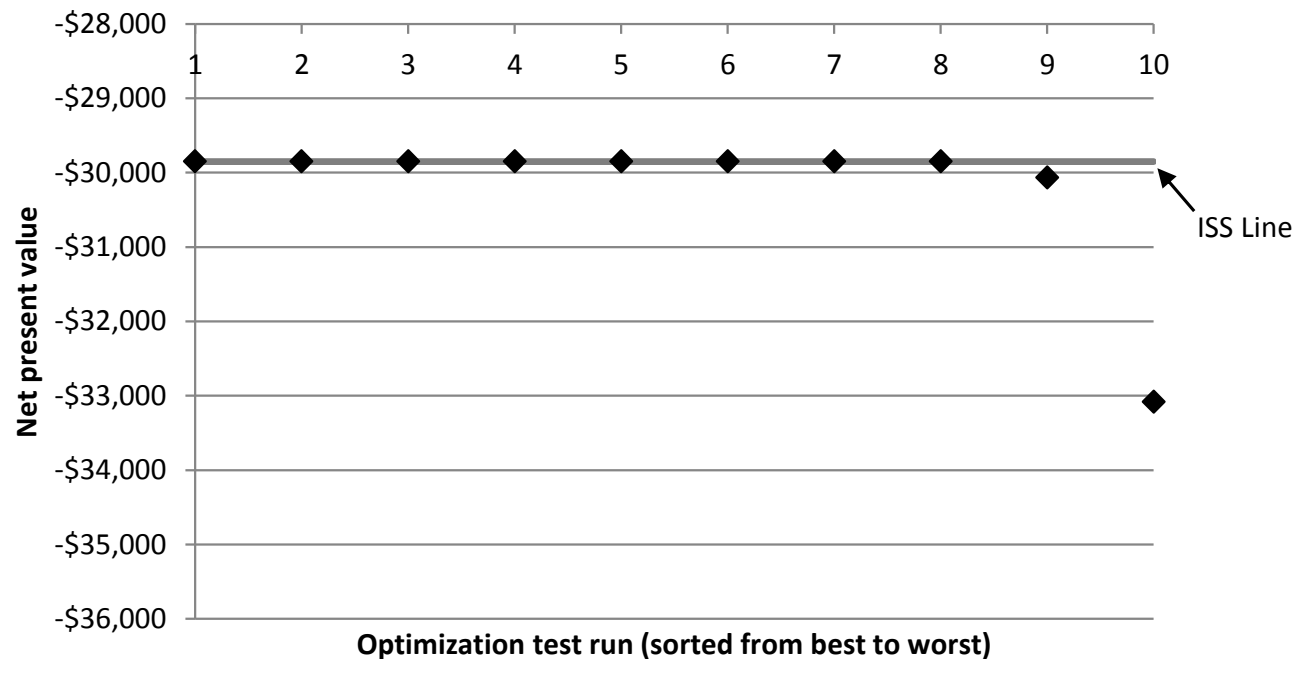

Figure 3.5: NZEH NPV for 10 test runs of the aNSGA-II algorithm 


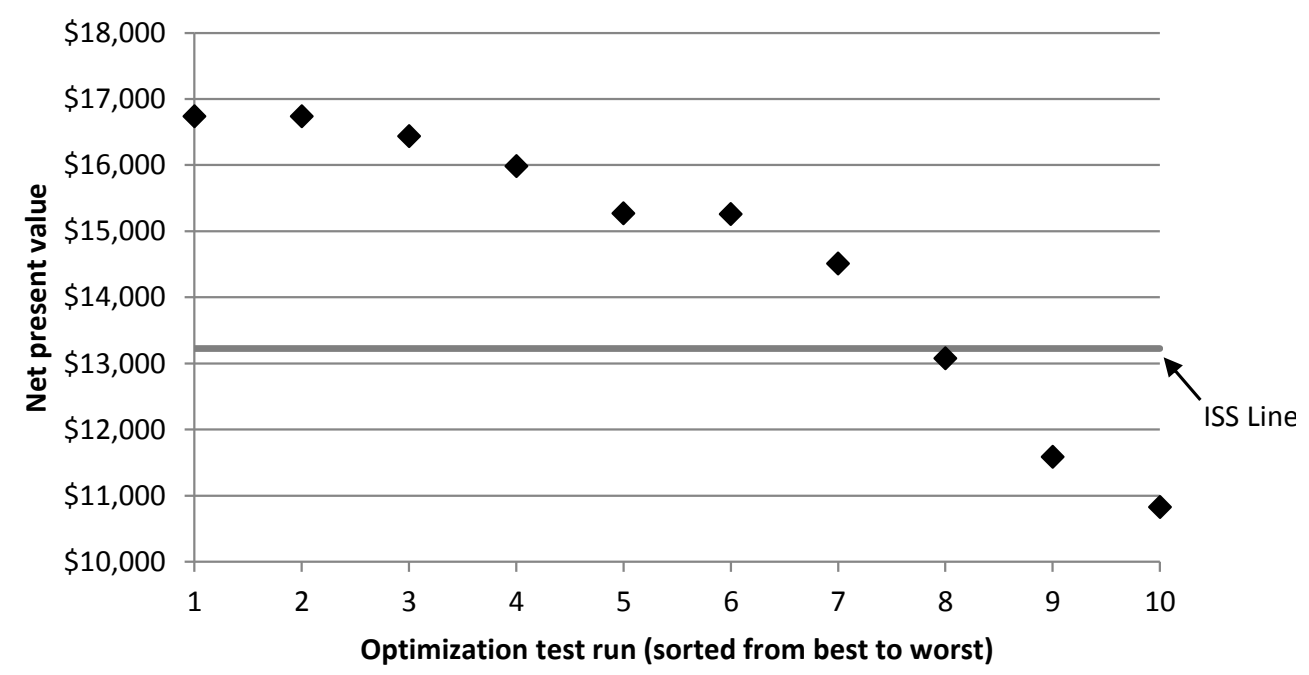

Figure 3.6: COH NPV for 10 test runs of the aNSGA-II algorithm

\subsection{Optimization scenarios}

For this thesis many different optimization scenarios were run with different inputs. The goal of the scenarios was to show what can be done to help make NZEHs more costeffective, and to show how the design and costs change as different factors change. Table 3.5 shows a list of all the scenarios.

\section{Base case runs (scenarios 1-3):}

The base case scenarios use current prices and policies; they assume NRCan building costs, they do not assume occupant engagement options and they do not assume a MicroFIT. The base case scenarios are run on all three house types; however, the test scenarios (scenarios 4-11) are based only on changes to the single detached base case scenario (scenario 1). 
Table 3.5: Optimization scenarios and their descriptions

\begin{tabular}{|c|c|c|}
\hline \# & Unit & Optimization Scenario \\
\hline \multicolumn{3}{|c|}{ Base case scenarios: } \\
\hline 1 & Single & Standard \\
\hline 2 & End & Standard \\
\hline 3 & Middle & Standard \\
\hline \multicolumn{3}{|c|}{ Test scenarios: } \\
\hline 4 & Single & $\begin{array}{l}\text { Adds possibility for options that put constraints on owner choices (dark exterior, dark } \\
\text { blinds, energy monitor, best in class appliances) }\end{array}$ \\
\hline 5 & Single & Uses potential future solar PV installed price (half of 2014 price) \\
\hline 6 & Single & Adds 2014 MicroFIT price for solar energy sold back to the grid \\
\hline 7 & Single & Assumes electricity price will increase at $1 \%$ higher rate than predicted (see Appendix $G$ ) \\
\hline 8 & Single & Assumes natural gas price will increase at $1 \%$ higher rate than predicted $(4.5 \%)$ \\
\hline 9 & Single & Assumes large-scale production costs ( $15 \%$ lower than NRCan costs) \\
\hline 10 & Single & Adds carbon tax of $\$ 30 /$ tonne \\
\hline 11 & Single & $\begin{array}{l}\text { Assumes government loan of } 100 \% \text { of the upgrade costs at } 1 \% \text { lower interest rate than } \\
\text { the mortgage costs }(3 \%)\end{array}$ \\
\hline \multicolumn{3}{|c|}{ Combination scenarios: } \\
\hline 12 & Single & Combination of scenarios 4,5 and 9 \\
\hline 13 & End & Combination of scenarios 4,5 and 9 \\
\hline 14 & Middle & Combination of scenarios 4,5 and 9 \\
\hline 15 & Single & Combination of scenarios $4,5,9,10$ and 11 \\
\hline 16 & End & Combination of scenarios $4,5,9,10$ and 11 \\
\hline 17 & Middle & Combination of scenarios $4,5,9,10$ and 11 \\
\hline
\end{tabular}

\section{Adding occupant engagement options (scenario 4):}

Adding the options that impact occupant behaviour or choices shows the effect of occupant engagement assumptions on energy. Typically, buyers of a house would not have any type of restriction on appliances, the colour of the siding and the blinds, and whether they have and use an energy monitor. Alternatively, the occupant engagement assumption is that the owners of the house are engaged in trying to reduce their energy usage and will select the optimal appliances and colours, and will use an energy monitor. The higher efficiency options in these categories (design parameters 12, 13, 16 and 17 from Table 3.2) are considered the "occupant engagement package". This test scenario permits the optimization to select the occupant engagement options, which allows the impact of the occupant engagement package to be quantified. 


\section{Half-price solar PV, and MicroFIT (scenarios 5, 6):}

These two optimization runs show what happens when the price of solar PV is less prohibitive. For scenario 5 the estimated price for installed solar PV was dropped from $\$ 3.375 / \mathrm{W}$ to $\$ 1.688 / \mathrm{W}$. Since the price of installed solar PV has dropped by about $15 \%$ per year since 2009 [31], and it is predicted to continue to decrease, this is not an unrealistic possibility. The cost of rooftop installed solar PV in Germany is already half of what it is in North America [31], and the LBNL SunShot target is a reduction in installed solar PV prices to $\$ 1.75 / \mathrm{W}$ by 2020 . At that rate the price of solar PV would be nearly half within the next five years. However, currently there is still the possibility that homebuyers can obtain the MicroFIT in Ontario, so this scenario is also run. The MicroFIT pays $\$ 0.396 / \mathrm{kWh}$ on electricity generated, which replaces the net-metering price structure in the base case [87].

\section{Price of energy increasing more rapidly (scenarios 7-8):}

The price increase of electricity and natural gas in most of the scenarios is what was determined to be the most likely rise in price. The increase in electricity cost was determined from the Ontario Power Authority (OPA) Long Term Energy Plan, and is shown in Appendix G [74]. The price increase in natural gas cost is determined from the U.S. Energy Information Administration at 3.5\% per year [75]. These optimization runs show what would happen if the prices were to increase slightly faster. Scenario 7 increases the electricity price by an additional $1 \%$ per year. Similarly, scenario 8 has an increase in natural gas price of $4.5 \%$ per year. 


\section{Large-scale developer costs (scenario 9):}

Minto Communities is a large-scale developer based in Canada. Through partnership with Minto and comparison of their costs with costs provided by CanmetENERGY, a reduction in cost due to large-scale development, compared to smaller scale development can be quantified. It was found that there is approximately a $15 \%$ difference in cost between the Affordable Net-Zero Energy Housing [44] cost database provided by NRCan and Minto costs. Therefore, this scenario provides a $15 \%$ reduction on all house system costs.

\section{Addition of a \$30/tonne carbon tax (scenario 10):}

Although Canada does not have a nationwide carbon tax, the provinces of Quebec, British Columbia, and Alberta all have provincially run carbon taxes. British Columbia has the most effective carbon tax, in terms of encouraging the reduction of fossil fuel usage. The carbon tax is $30 \$ /$ tonne $\mathrm{CO}_{2}$ equivalent, and applies to all sources of carbon emissions [88]. It is possible that this type of carbon tax could be applied to Ontario in the future, either through provincial or national measures. This scenario assumes a carbon tax of $30 \$ /$ tonne $\mathrm{CO}_{2}$ equivalent, in order to determine the effectiveness of this policy measure on NZEH cost-effectiveness. Note that the carbon intensity in Ontario is approximately $31 \mathrm{~kg} \mathrm{CO}_{2} \mathrm{e} / \mathrm{GJ}$ for electricity consumption and $69 \mathrm{~kg} \mathrm{CO}_{2} \mathrm{e} / \mathrm{GJ}$ for natural gas consumption [89]. 


\section{Government green loan (scenario 11):}

The last test scenario assumes a potential green loan for NZEHs upgrades. This loan would be provided by a government body, either at the municipal, provincial or federal level, and would cover $100 \%$ of the upgrade price, with an interest rate $1 \%$ less than that of the mortgage loan rate (from $4 \%$ to $3 \%$ ). For a cost-effective NZEH with a typical mortgage, the buyer has to pay an increased down payment on the house, and would recoup this cost over the length of the mortgage. This green loan, on the other hand, would be more accessible, since if the house is cost neutral, the buyers would not have to pay an increased down payment. Also, if the house is cost-effective, the utility cost savings would balance out the increased loan, making the house cost-effective from day one. This test scenario shows how a green loan of this type would impact costs. A more detailed description of this loan type can be found here [90].

\section{Combination scenarios (scenarios 12-17):}

These scenarios are combinations of different scenarios, chosen in attempt to find what would be necessary for the house designs to achieve cost-effectiveness. These combination scenarios are run on all three house types.

The first level combination scenarios (scenarios 12-14) combine occupant engagement options, half-price solar PV, and large-scale development costs (scenarios 4, 5 and 9). Occupant engagement can likely be achieved in a low cost manner, so this scenario can be completed by large-scale developers in the near future when the price of solar decreases. These scenarios do not require any additional policy measures, and do not rely on the MicroFIT, which developers cannot implement on behalf of buyers. Note 
that the combination of reduced solar PV price and large-scale developer costs reduces the price of solar PV to $\$ 1.434 / \mathrm{W}$.

The second level of combination scenarios (scenarios 15-17) adds to this the policy options of the green loan and the carbon tax. So in total these scenarios combine scenarios 4, 5, 9, 10 and 11. These policies do not yet exist in Ontario, however both policies incentivize green technology in a way that is cost neutral for the government, so it is possible that they may be implemented in the future [88], [90]. The results of testing the optimization algorithm, and the results of these scenarios are described in Chapter 4 . 


\section{Chapter 4: Results}

Chapter 3 described the optimization methodology; this chapter shows the results of seventeen optimization scenarios used to find cost-effective NZEH designs. The procedure for finding cost-effective NZEH designs included running optimizations with both the Non-domination Sorting Genetic Algorithm II with active Pareto-archiving (aNSGA-II) and Iterated Sequential Search (ISS) algorithms:

1. The optimizations were run for the base case scenario for all three unit types

2. The optimizations were run for a number of different test scenarios, with different constants that affect the affordability of NZEHs

3. Based on the test scenarios, combination scenarios were chosen to help find costeffective NZEHs, and these optimizations were run on all three unit types

The first level combination scenario for the single detached house achieved costeffectiveness for the NZEH with a combination of occupant engagement strategies, solar PV price that is half of the current price, and large-scale developer costs. This scenario attained cost-effective NZEHs for the single detached house type only.

While the goal of the project was to find cost-effective NZEHs, cost-optimized houses $(\mathrm{COHs})$ are also found by the optimization. $\mathrm{COHs}$ are houses that have the highest net present value (NPV), and represent the most financially favourable options, but they do not conserve as much energy as NZEHs. In certain cases NZEHs were not 
found by the optimizations, in those cases, the closest near net-zero energy house (NNZEH) was chosen.

\section{1 aNSGA-II and ISS algorithm performance}

There are discontinuities observed on the Pareto-optimal curves for the aNSGA-II optimization. The discontinuities are due to the different primary and renewable energy systems in the house that shift the points. Figure 4.1 is an example of one of the aNSGAII optimizations, which shows where every simulated point is and where the Paretooptimal points are. Each of the simulations is marked with a grey dot, and the Paretooptimal points are marked with solid black dots. Figure 4.1 shows what systems are in each cluster of house designs and also marks the points of interest, showing where the code-built house, the $\mathrm{COH}$, and the NZEH are found for this run.

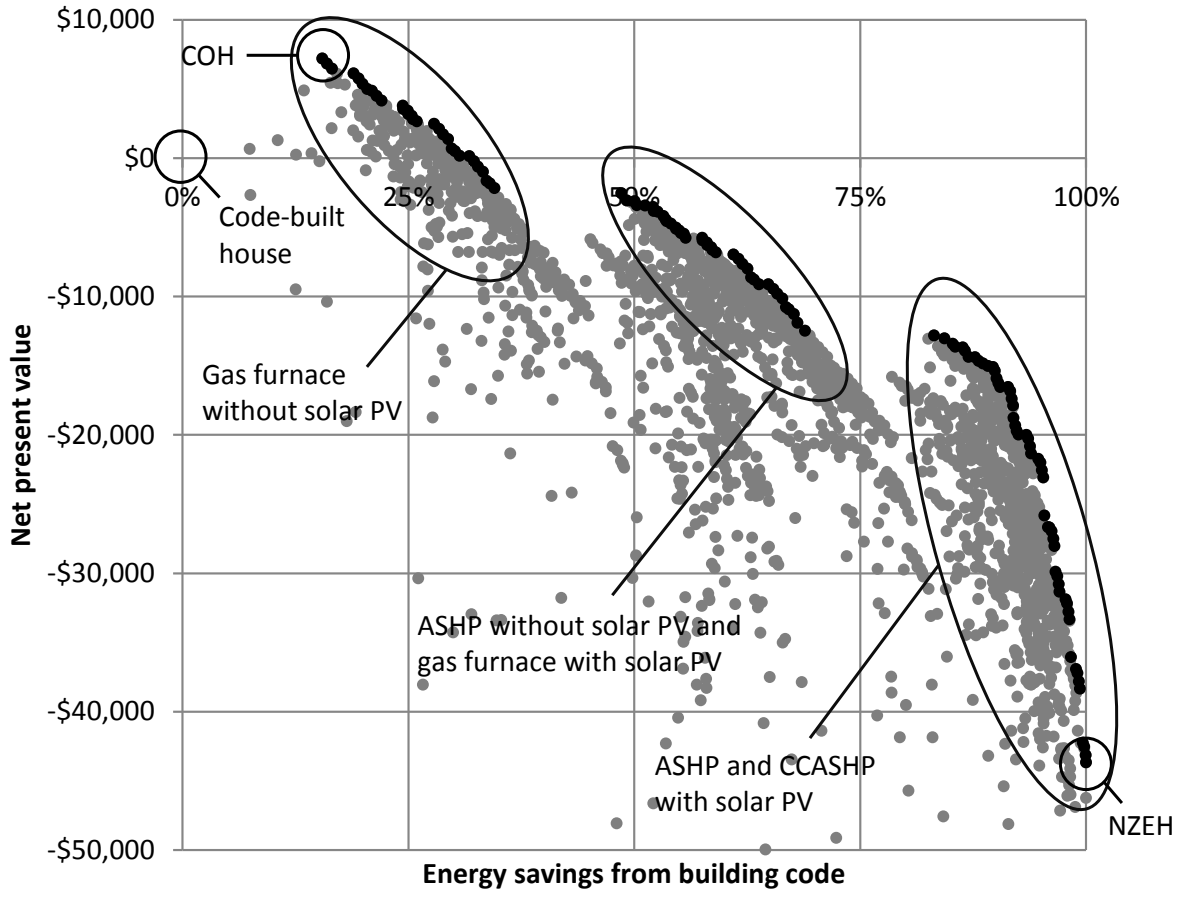

Figure 4.1: Example of an aNSGA-II optimization output (scenario 1) 
Figure 4.2 shows that the ISS algorithm follows a different pathway than the aNSGA-II. The black dots in this case are not Pareto-optimal points but the points selected in each incremental step by the optimization. See Section 3.5 for a more detailed description of the optimization algorithms. The ISS algorithm does not have as detailed a Pareto-archive as the aNSGA-II but as will be shown below, the ISS algorithm does have generally better performance.

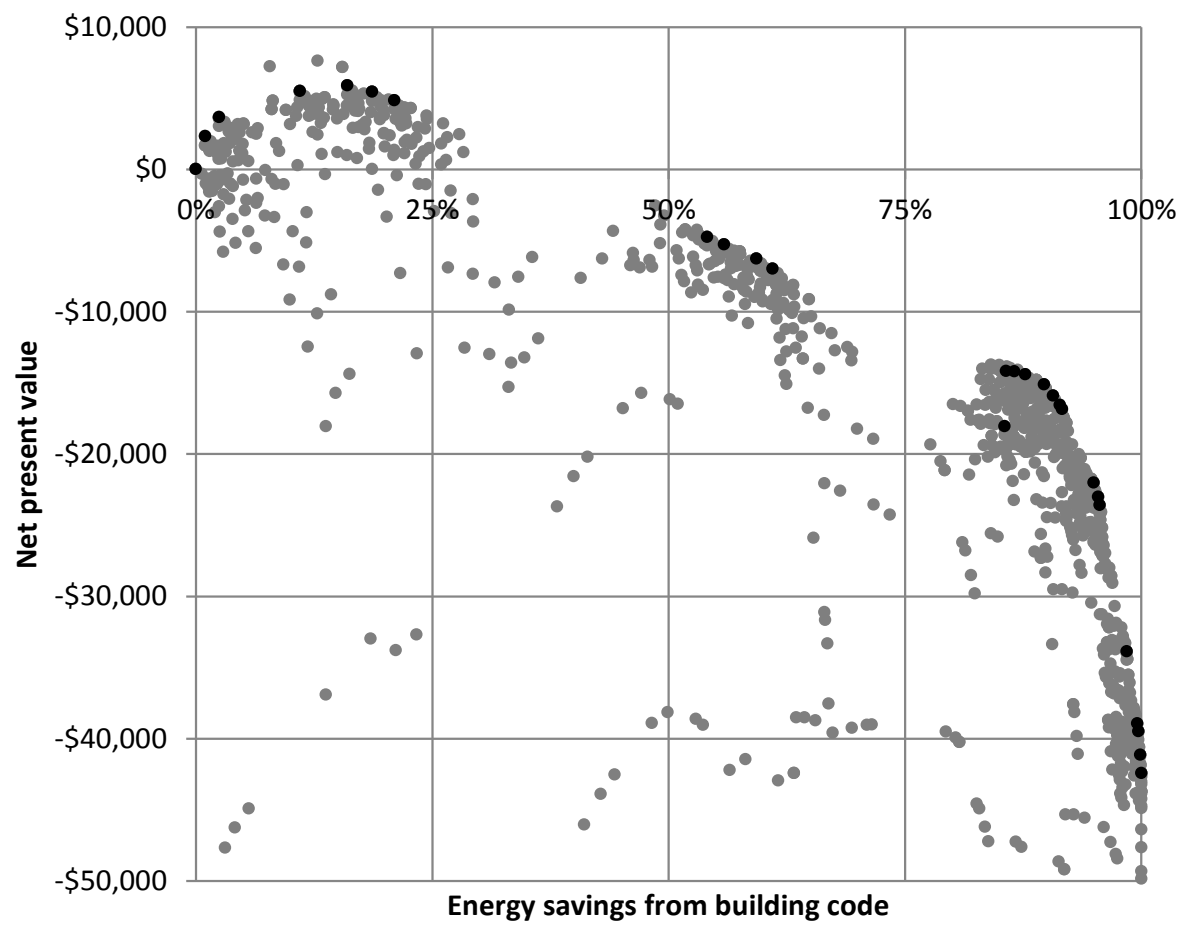

Figure 4.2: Example of ISS optimization output (scenario 1)

The ISS algorithm has better performance than the aNSGA-II in terms of finding more cost-effective NZEHs, and doing it with fewer simulations per optimization. Table 4.1 compares the performance between the two algorithm types. The aNSGA-II does have 
one advantage in that it is slightly better at finding COHs than the ISS algorithm. Because certain algorithms were better in some circumstances than others, the results from both algorithms is combined to provide the resulting designs and Pareto-optimal curves for the rest of this thesis. Table 4.1 also shows that for certain scenarios, NZEHs were not possible. NZEHs were not possible in those scenarios because of the assumptions and limitations of the house types, mostly due to the lack of available roof space for solar PV. These conditions meant that the maximum amount of energy saving systems did not result in a NZEH, which proves that the failure to find NZE was not a limitation of the optimization algorithms.

Table 4.1: Comparison of performance between aNSGA-II and ISS algorithms

\begin{tabular}{|c|c|c|c|c|c|c|}
\hline \multirow{2}{*}{ Scenario } & \multicolumn{2}{|c|}{ NZEH - NPV } & \multicolumn{2}{|c|}{$\mathrm{COH}$ - NPV } & \multicolumn{2}{|c|}{ Number of Simulations } \\
\hline & aNSGA-II & Simple ISS & aNSGA-II & Simple ISS & aNSGA-II & Simple ISS \\
\hline 1 & $-\$ 43,700$ & $-\$ 42,400$ & $\$ 7,200$ & $\$ 5,900$ & 2121 & 1054 \\
\hline 2 & N/A & N/A & $\$ 6,600$ & $\$ 4,900$ & 2625 & 1289 \\
\hline 3 & N/A & N/A & $\$ 1,600$ & $\$ 4,600$ & 2919 & 1210 \\
\hline 4 & $-\$ 29,800$ & $-\$ 27,700$ & $\$ 9,900$ & $\$ 8,100$ & 2226 & 1162 \\
\hline 5 & $-\$ 32,800$ & $-\$ 20,900$ & $\$ 17,800$ & $\$ 18,300$ & 3045 & 1015 \\
\hline 6 & $-\$ 10,800$ & $-\$ 11,100$ & $\$ 28,800$ & $\$ 27,500$ & 3759 & 1054 \\
\hline 7 & $-\$ 43,900$ & $-\$ 38,800$ & $\$ 7,000$ & $\$ 6,200$ & 3150 & 1054 \\
\hline 8 & $-\$ 38,800$ & $-\$ 39,000$ & $\$ 6,600$ & $\$ 6,300$ & 3066 & 1054 \\
\hline 9 & $-\$ 29,100$ & $-\$ 27,800$ & $\$ 7,700$ & $\$ 6,200$ & 3255 & 1054 \\
\hline 10 & $-\$ 50,000$ & $-\$ 38,100$ & $\$ 6,900$ & $\$ 6,600$ & 4137 & 1054 \\
\hline 11 & $-\$ 34,400$ & $-\$ 32,700$ & $\$ 5,800$ & $\$ 6,100$ & 4305 & 1054 \\
\hline 12 & $\$ 3,100$ & $\$ 3,100$ & $\$ 25,200$ & $\$ 24,700$ & 1995 & 1162 \\
\hline 13 & N/A & N/A & $\$ 19,700$ & $\$ 18,600$ & 4158 & 1549 \\
\hline 14 & $-\$ 24,700$ & $-\$ 24,800$ & $\$ 17,500$ & $\$ 18,200$ & 4998 & 1721 \\
\hline 15 & $\$ 12,000$ & $\$ 12,900$ & $\$ 28,100$ & $\$ 29,000$ & 2478 & 1162 \\
\hline 16 & N/A & N/A & $\$ 20,900$ & $\$ 21,600$ & 2646 & 1549 \\
\hline 17 & $-\$ 17,200$ & $-\$ 16,700$ & $\$ 20,900$ & $\$ 21,000$ & 2352 & 1721 \\
\hline
\end{tabular}




\subsection{Results of the optimization scenarios}

Different optimization scenarios were run on the house types to try to find cost-effective NZEH designs. The seventeen test scenarios are summarized in Table 3.5. The results of these test scenarios is seventeen optimized NZEHs (or NNZEHs) and seventeen

optimized COHs. Figure 4.3 and Figure 4.4 both show the incremental building cost

(IBC) and net present value (NPV) of these designs compared to the code-built house.

For the cases where NZEHs were not possible, the scenarios have been noted and the IBC and NPV of the closest NNZEH design is used.

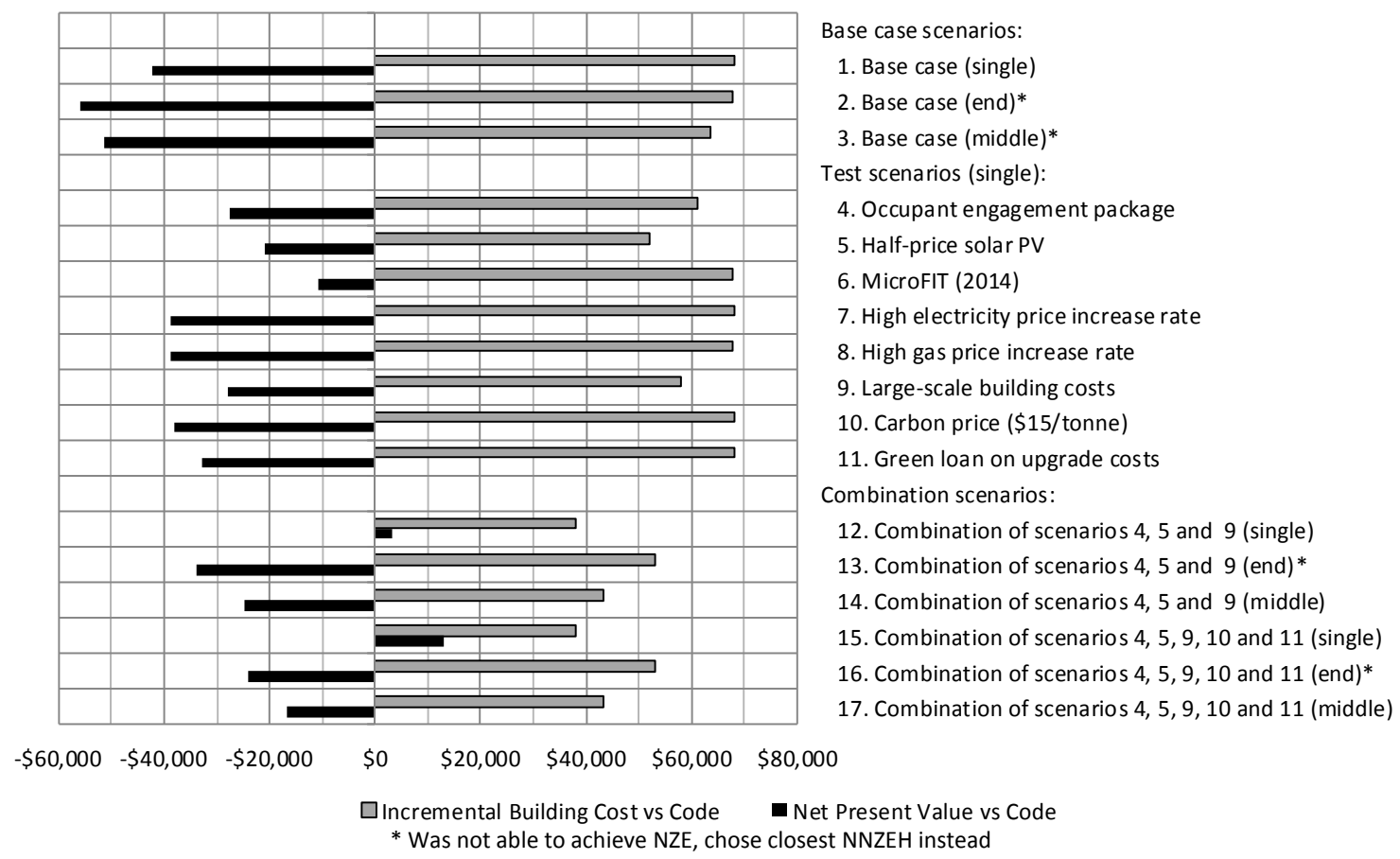

Figure 4.3: Optimization scenario cost results for NZEHs 
The IBC is the additional cost the developer would have to pay to construct the house,

and the NPV is the discounted sum of the incremental savings and costs over 25 years, including changes to upfront costs, mortgage costs, maintenance costs and utility costs.

For all cases the IBC is higher than for the code-built house, meaning the houses are

more expensive to build. As well, because the NPV is being optimized, in all COH cases and in certain NZEH cases the NPV is positive. A positive NPV means that the house is cost-effective compared to a similar code-built house.

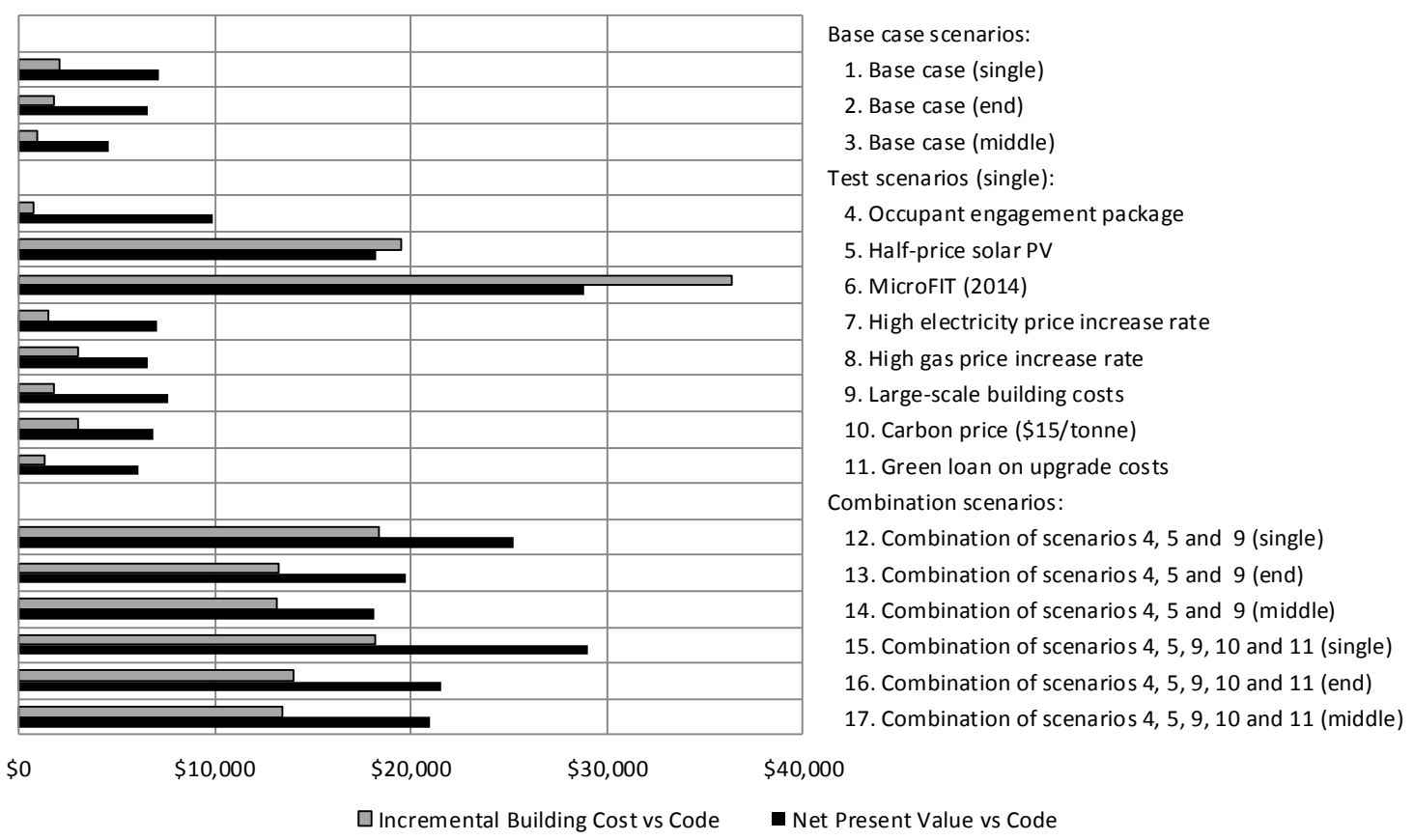

Figure 4.4: Optimization scenario cost results for $\mathrm{COHs}$

As can be seen in Figure 4.3, the NZEH for scenarios 12 has a positive NPV and is costeffective. Looking at the Pareto-optimal curves for scenarios 12-14 in Figure 4.5 and 
comparing these to the base case scenarios, it can be seen that only the single detached house's curve has shifted entirely above the x-axis, meaning that all of the resulting Pareto-optimal designs from this scenarios are cost-effective compared to code-built house. For the townhouses in scenarios 13 and 14, it can be seen that the Pareto optimal curves are cost-effective until a steep drop-off, which occurs as the curves approach $100 \%$ energy savings.
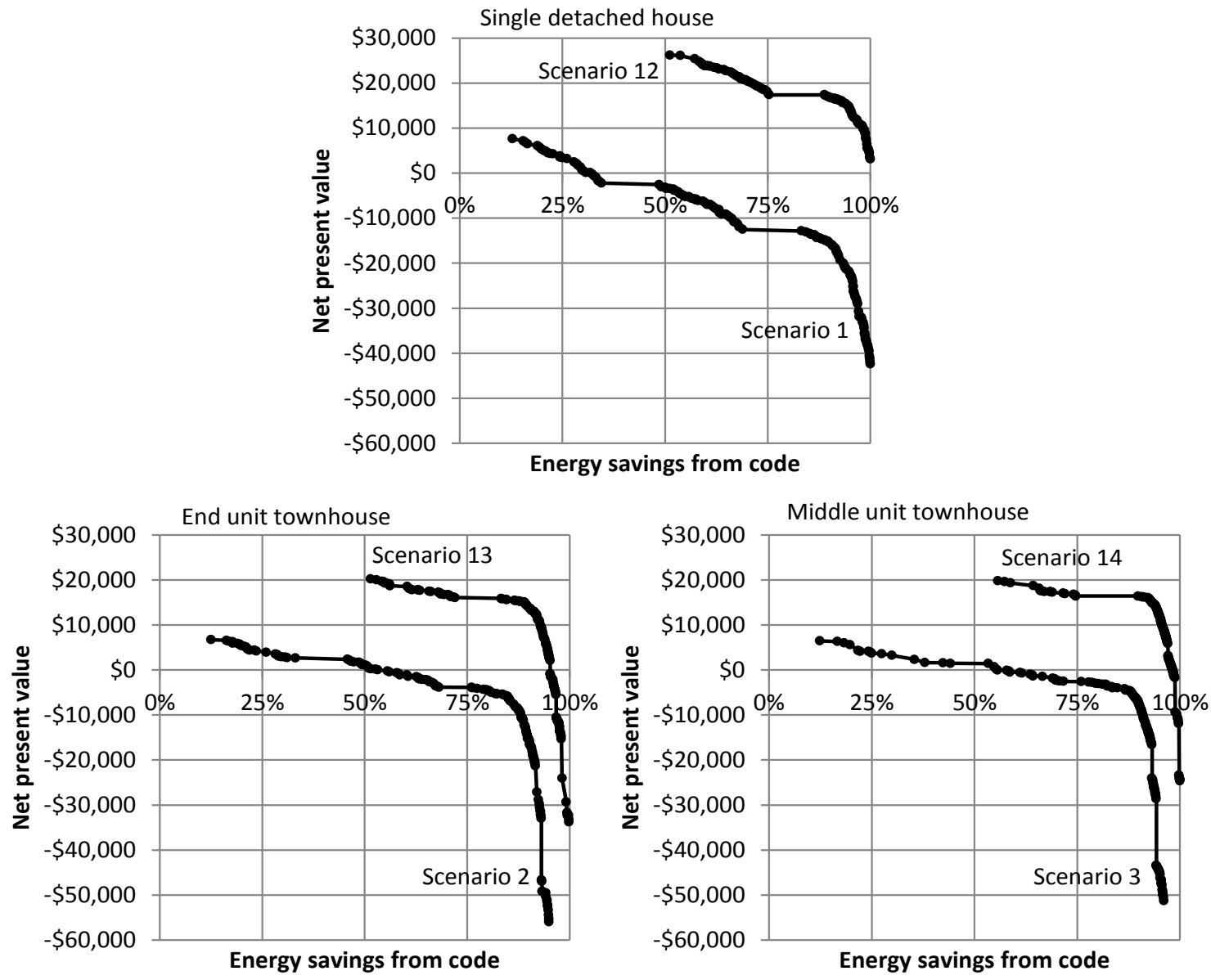

Figure 4.5: Pareto-optimal curves of scenarios 1-3 and 12-14

Table 4.2 shows the design and cost information for the NZEHs and NNZEH from scenarios 12-14, and it includes the cost-effective NZEH house from scenario 12. Table 
4.3 shows the $\mathrm{COH}$ designs from scenarios $12-14$ as well. The design information, IBC, NPV and energy performance of these designs is listed in these tables. The rest of the resulting NZEH, NNZEH and $\mathrm{COH}$ designs from the other scenarios are in Appendix $\mathrm{H}$ in code form to save space. The codes from Table H.1 and Table H.2 can be translated using Table 3.2.

Table 4.2: NZEH designs found by scenarios 12-14

\begin{tabular}{|c|c|c|c|}
\hline \multirow{2}{*}{ Category } & \multicolumn{3}{|c|}{$\begin{array}{l}\text { NZEH designs found by combination occupant engagement, half-price solar PV, } \\
\text { large-scale building costs scenarios }\end{array}$} \\
\hline & Single & End & Middle \\
\hline Heating and Cooling & ASHP & GSHP (COP 3.7) & GSHP (COP 3.7) \\
\hline Hot Water & $\operatorname{SDHW}\left(5.95 \mathrm{~m}^{2}\right)$ & $\operatorname{SDHW}\left(5.95 \mathrm{~m}^{2}\right)$ & HPWH \\
\hline Ventilation & $75 \% \mathrm{HRV}$ & $75 \% \mathrm{HRV}$ & $75 \% \mathrm{HRV}$ \\
\hline Exterior wall type & $\begin{array}{c}5.64 \text { RSI (R32) batt }+ \\
\text { XPS }\end{array}$ & $\begin{array}{c}\text { 7.40 RSI (R42) batt }+ \\
\text { XPS }\end{array}$ & $\begin{array}{l}\text { 6.52 RSI (R37) batt }+ \\
\text { XPS }\end{array}$ \\
\hline $\mathbf{A C H}$ & 0.6 ACH50 & $0.6 \mathrm{ACH} 50$ & $0.6 \mathrm{ACH} 50$ \\
\hline Ceiling insulation & $\begin{array}{l}\text { 14.09 RSI (R80) blown-in } \\
\text { fibreglass }\end{array}$ & $\begin{array}{l}\text { 14.09 RSI (R80) blown-in } \\
\text { fibreglass }\end{array}$ & $\begin{array}{l}\text { 12.33 RSI (R70) blown-in } \\
\text { fibreglass }\end{array}$ \\
\hline $\begin{array}{l}\text { Basement wall } \\
\text { insulation }\end{array}$ & $\begin{array}{l}\text { 4.40 RSI (R25) batt }+ \\
\text { XPS }\end{array}$ & $\begin{array}{l}\text { 6.16 RSI (R35) batt }+ \\
\text { XPS }\end{array}$ & $\begin{array}{l}\text { 6.16 RSI (R35) batt }+ \\
\text { XPS }\end{array}$ \\
\hline Under-slab & No under-slab insulation & 1.76 RSI (R10) XPS & 0.88 RSI (R5) XPS \\
\hline Window type & $\begin{array}{l}\text { Triple glazed (USI } 1.08 \\
\text { SHGC 0.44) }\end{array}$ & $\begin{array}{l}\text { Triple glazed (USI } 1.08 \\
\text { SHGC 0.44) }\end{array}$ & $\begin{array}{l}\text { Triple glazed (USI } 1.08 \\
\text { SHGC 0.44) }\end{array}$ \\
\hline DWHR & $\begin{array}{l}54 \% \text { DWHR on both } \\
\text { showers }\end{array}$ & $\begin{array}{l}54 \% \text { DWHR on both } \\
\text { showers }\end{array}$ & $\begin{array}{l}54 \% \text { DWHR on both } \\
\text { showers }\end{array}$ \\
\hline Lighting & All fluorescent lighting & All fluorescent lighting & All fluorescent lighting \\
\hline Blinds & Dark blinds & Dark blinds & Dark blinds \\
\hline Siding & Dark vinyl exterior & Dark vinyl exterior & Dark vinyl exterior \\
\hline Water fixtures & $\begin{array}{c}\text { HE water fixtures }+\mathrm{HE} \\
\text { toilet }\end{array}$ & $\begin{array}{l}\text { HE water fixtures }+\mathrm{HE} \\
\text { toilet }\end{array}$ & $\begin{array}{l}\text { HE water fixtures }+\mathrm{HE} \\
\text { toilet }\end{array}$ \\
\hline Thermostat & Smart thermostat & Smart thermostat & Smart thermostat \\
\hline $\begin{array}{l}\text { Real-time energy } \\
\text { monitoring }\end{array}$ & $\begin{array}{l}\text { Energy monitor with } \\
\text { breakdown by appliance }\end{array}$ & $\begin{array}{c}\text { Energy monitor with } \\
\text { breakdown by appliance }\end{array}$ & $\begin{array}{l}\text { Energy monitor with } \\
\text { breakdown by appliance }\end{array}$ \\
\hline Appliances & $\begin{array}{l}\text { High efficiency } \\
\text { appliances }\end{array}$ & Best in class appliances & Best in class appliances \\
\hline Solar PV & $9.5 \mathrm{~kW}$ & $6.2 \mathrm{~kW}$ & $6.2 \mathrm{~kW}$ \\
\hline $\begin{array}{l}\text { Total incremental } \\
\text { building costs }\end{array}$ & $\$ 38,190$ & $\$ 53,200$ & $\$ 43,150$ \\
\hline $\begin{array}{c}\text { Net present value (25 } \\
\text { yrs) }\end{array}$ & $\$ 3,100$ & $-\$ 33,700$ & $-\$ 24,700$ \\
\hline $\begin{array}{c}\text { Total energy savings } \\
\text { over baseline }\end{array}$ & $100 \%$ & $99.8 \%$ & $100 \%$ \\
\hline
\end{tabular}


Table 4.3: Cost-optimized houses found by scenarios 12-14

\begin{tabular}{|c|c|c|c|}
\hline \multirow{2}{*}{ Category } & \multicolumn{3}{|c|}{$\begin{array}{c}\text { COH designs found by combination occupant engagement, half-price solar PV, } \\
\text { large-scale building costs scenarios }\end{array}$} \\
\hline & Single & End & Middle \\
\hline Heating and Cooling & Gas furnace $+\mathrm{AC}$ & Gas furnace $+\mathrm{AC}$ & Gas furnace $+\mathrm{AC}$ \\
\hline Hot Water & $\begin{array}{l}\text { Gas hot water tank }(0.67 \\
\text { EF) }\end{array}$ & $\begin{array}{l}\text { Gas hot water tank }(0.67 \\
\text { EF) }\end{array}$ & $\begin{array}{l}\text { Gas hot water tank }(0.67 \\
\text { EF) }\end{array}$ \\
\hline Ventilation & Exhaust fan & Exhaust fan & $60 \% \mathrm{HRV}$ \\
\hline Exterior wall type & 3.87 RSI (R22) batt & 3.87 RSI (R22) batt & 3.87 RSI (R22) batt \\
\hline $\mathbf{A C H}$ & $2.3 \mathrm{ACH} 50$ & $1.5 \mathrm{ACH} 50$ & $2.3 \mathrm{ACH} 50$ \\
\hline Ceiling insulation & $\begin{array}{l}\text { 10.57 RSI (R60) blown-in } \\
\text { fibreglass }\end{array}$ & $\begin{array}{l}\text { 8.81 RSI (R50) blown-in } \\
\text { fibreglass }\end{array}$ & $\begin{array}{l}\text { 8.81 RSI (R50) blown-in } \\
\text { fibreglass }\end{array}$ \\
\hline Basement wall insulation & 2.11 RSI (R12) batt & 2.11 RSI (R12) batt & 2.11 RSI (R12) batt \\
\hline Under-slab & No under-slab insulation & No under-slab insulation & No under-slab insulation \\
\hline Window type & $\begin{array}{l}\text { Triple glazed (USI } 1.08 \\
\text { SHGC 0.44) }\end{array}$ & $\begin{array}{l}\text { Triple glazed (USI } 1.08 \\
\text { SHGC 0.44) }\end{array}$ & $\begin{array}{l}\text { Triple glazed (USI } 1.08 \\
\text { SHGC 0.44) }\end{array}$ \\
\hline DWHR & $\begin{array}{l}\text { 37\% DWHR on one } \\
\text { shower }\end{array}$ & No DWHR & No DWHR \\
\hline Lighting & All fluorescent lighting & All fluorescent lighting & All fluorescent lighting \\
\hline Blinds & Dark blinds & Dark blinds & Dark blinds \\
\hline Siding & Dark vinyl exterior & Dark vinyl exterior & Dark vinyl exterior \\
\hline Water fixtures & $\begin{array}{l}\text { HE water fixtures }+\mathrm{HE} \\
\text { toilet }\end{array}$ & $\begin{array}{l}\text { HE water fixtures }+\mathrm{HE} \\
\text { toilet }\end{array}$ & $\begin{array}{l}\text { HE water fixtures }+\mathrm{HE} \\
\text { toilet }\end{array}$ \\
\hline Thermostat & Smart thermostat & Smart thermostat & Smart thermostat \\
\hline $\begin{array}{l}\text { Real-time energy } \\
\text { monitoring }\end{array}$ & $\begin{array}{l}\text { Energy monitor with } \\
\text { breakdown by appliance }\end{array}$ & $\begin{array}{l}\text { Energy monitor with } \\
\text { breakdown by appliance }\end{array}$ & $\begin{array}{l}\text { Energy monitor with } \\
\text { breakdown by appliance }\end{array}$ \\
\hline Appliances & High efficiency appliances & High efficiency appliances & High efficiency appliances \\
\hline Solar PV & $9.5 \mathrm{~kW}$ & $6.2 \mathrm{~kW}$ & $6.2 \mathrm{~kW}$ \\
\hline $\begin{array}{c}\text { Total incremental } \\
\text { building costs }\end{array}$ & $\$ 18,390$ & $\$ 13,310$ & $\$ 13,120$ \\
\hline Net present value (25 yrs) & $\$ 25,200$ & $\$ 19,700$ & $\$ 18,200$ \\
\hline $\begin{array}{c}\text { Total energy savings over } \\
\text { baseline }\end{array}$ & $55 \%$ & $54 \%$ & $58 \%$ \\
\hline
\end{tabular}

Lastly it was found that there is a significant amount of overlap between the house designs across the seventeen scenarios. The most commonly observed systems for all of the NZEHs/NNZEHs and COHs are listed in Table 4.4. Many systems were chosen almost universally across all optimization scenarios, since many systems are observed close to the maximum of seventeen times. 
Table 4.4: Most commonly observed systems across optimization scenarios

\begin{tabular}{|c|c|c|c|c|}
\hline \multirow{2}{*}{ Category } & \multicolumn{4}{|c|}{ Most commonly observed systems and their count } \\
\hline & NZEH/NNZEH & Count & $\mathrm{COH}$ & Count \\
\hline Heating and Cooling & $\begin{array}{c}\text { CCASHP (HSPF 9.3 SEER } \\
15 \text { ) }\end{array}$ & 8 & $\begin{array}{l}95 \text { AFUE Gas furnace + } \\
\text { SEER } 15 \text { AC }\end{array}$ & 17 \\
\hline Hot Water & SDHW (5.95 m2) & 15 & $\begin{array}{c}\text { Gas hot water tank (0.67 } \\
\text { EF) }\end{array}$ & 14 \\
\hline Ventilation & HRV (75\% efficient) & 17 & Exhaust fan & 10 \\
\hline Exterior wall type & 5.64 RSI (R32) batt + XPS & 11 & 3.87 RSI (R22) batt & 17 \\
\hline ACH & $0.6 \mathrm{ACH} 50$ & 17 & $2.3 \mathrm{ACH} 50$ & 14 \\
\hline Ceiling insulation & $\begin{array}{l}\text { 14.09 RSI (R80) blown-in } \\
\text { fibreglass }\end{array}$ & 13 & $\begin{array}{l}\text { 8.81 RSI (R50) blown-in } \\
\text { fibreglass }\end{array}$ & 16 \\
\hline $\begin{array}{l}\text { Basement wall } \\
\text { insulation }\end{array}$ & 5.28 RSI (R30) batt + XPS & 7 & 2.11 RSI (R12) batt & 17 \\
\hline Under-slab & No under-slab insulation & 9 & No under-slab insulation & 17 \\
\hline Window type & $\begin{array}{l}\text { Triple glazed (USI } 1.08 \\
\text { SHGC 0.44) }\end{array}$ & 17 & $\begin{array}{l}\text { Triple glazed (USI } 1.08 \\
\text { SHGC 0.44) }\end{array}$ & 17 \\
\hline DWHR & $\begin{array}{l}54 \% \text { DWHR on both } \\
\text { showers }\end{array}$ & 17 & No DWHR & 16 \\
\hline Lighting & All fluorescent lighting & 17 & All fluorescent lighting & 17 \\
\hline Blinds & \multicolumn{4}{|c|}{ For all scenarios where dark blinds were available, dark blinds were selected } \\
\hline Siding & \multicolumn{4}{|c|}{ For all scenarios where dark exterior siding was available, dark exterior siding was selected } \\
\hline Water fixtures & $\begin{array}{l}\text { HE water fixtures }+\mathrm{HE} \\
\text { toilet }\end{array}$ & 17 & $\begin{array}{l}\text { HE water fixtures }+\mathrm{HE} \\
\text { toilet }\end{array}$ & 17 \\
\hline Thermostat & Smart thermostat & 17 & Smart thermostat & 17 \\
\hline $\begin{array}{l}\text { Real-time energy } \\
\text { monitoring }\end{array}$ & \multicolumn{4}{|c|}{ For all scenarios where energy monitoring was available, energy monitoring was selected } \\
\hline Appliances & High efficiency appliances & 13 & High efficiency appliances & 12 \\
\hline Solar PV & $\begin{array}{l}\text { Necessary solar PV to } \\
\text { achieve NZE }\end{array}$ & 17 & \multicolumn{2}{|c|}{$\begin{array}{l}\text { For all scenarios with half-price solar PV or } \\
\text { MicroFIT, full solar PV was selected }\end{array}$} \\
\hline
\end{tabular}

This chapter compares the optimization algorithms and shows the results of the seventeen optimization scenarios. It shows the cost and energy performance of these design as well as what systems would be used in NZEHs and COHs. Chapter 5 discusses these results and looks at their implications and limitations. 


\section{Chapter 5: Discussion}

Chapter 4 showed the performance comparison of the Non-domination Sorting Genetic Algorithm II with active Pareto-archiving (aNSGA-II) and the Iterated Sequential Search (ISS) algorithms, and showed the results of seventeen optimization scenarios. It showed the incremental costs of NZEHs/NNZEHs and cost-optimized houses (COHs) compared to code, and their resulting designs. This chapter discusses the implications of these results, emphasizing that cost-effective NZEHs may be possible in the future. It discusses the limitations and applicability of these results, as well as what these results mean for the greater NZEH research community.

\subsection{Comparison of aNSGA-II and ISS algorithms}

Testing the optimization algorithm showed favourable results. Figure 3.6 shows the NZEH and $\mathrm{COH}$ results from the ten test runs compared to the ISS test run. Eight of the ten runs found the best NZEH design and the difference in net present value (NPV) between the best and worst NZEH was $\$ 3,200$. The difference between the best and worst $\mathrm{COH}$ design was $\$ 5,900$, so this represents the maximum variability in the ten test runs. Although the tests of the aNSGA-II algorithm showed favourable results, the ISS algorithm had better results in many of the optimization scenarios and was more efficient overall. In one case (scenario 10) the aNSGA-II NPV result was \$11,900 worse than the ISS design, which shows the aNSGA-II does not always produce near optimal results. This is likely due to the fact that the aNSGA-II spreads the simulation time too evenly across the entire Pareto front, when the points of interest are only at either ends. An 
additional function could be added to the aNSGA-II optimization that would encourage the selection of parents closer to the NZEH and $\mathrm{COH}$ points of the Pareto front. A function like this would likely reduce optimization time and improve the resulting NZEH and $\mathrm{COH}$ designs.

In certain cases the aNSGA-II provided a better result than the ISS, which shows that certain interactions between systems were not capitalized on by the rule based ISS algorithm. However, the advantage given by a randomized algorithm for the NZEH optimization problem appears to be small. The greatest NPV discrepancy that favoured the aNSGA-II for NZEHs was about $\$ 300$ in scenario 6.

In fact, the greatest advantage the aNSGA-II has over the ISS is the very detailed Pareto-optimal curve. Producing this curve can allow designers to see what advantages can be gained by shifting the curve in different directions. The result from the ISS is sparser than the result from the aNSGA-II. Figure 4.1 and Figure 4.2 show all the simulated points from the aNSGA-II and the ISS for scenario 1.

It can be seen that the Pareto-optimal curve from Figure 4.1 has some unusual discontinuities. It seems the designs have distinct groupings that are based on the major systems selection. The grouping to the left contains designs with gas furnaces but without solar PV, the grouping in the middle contains designs with air source heat pumps (ASHPs) without solar PV or gas furnaces with solar PV, and the grouping to the right contains designs with ASHPs with solar PV and cold climate air source heat pumps (CCASHPs) with solar PV. Since the optimization does not allow intermediate levels of solar PV, there is a sharp gap between houses with and without solar PV. Also there are no intermediate systems in terms of efficiency between the conventional systems with an 
efficiency of about $100 \%$ and the ASHP which has a heating seasonal COP of about $200 \%$. Because these groups are spatially separate in terms of cost and energy, there are discontinuities in the Pareto-optimal curves observed in the scenarios.

Since it was found that the ISS algorithm was better at finding the NZEHs with the best NPV, and the aNSGA-II algorithm was better at producing Pareto-optimal curves, the results from both optimizations were combined together, and the best results from either algorithm was selected for the outputted results. For instance, the Paretooptimal curves in Figure 4.5 are made from combining all the simulated points from both the aNSGA-II and the ISS algorithms and finding the overall Pareto-optimal points.

\subsection{Test scenarios}

It can be seen in Figure 4.3 the effects that changes in the scenarios have on NZEH costs. The base case scenarios showed the how much the NPV needs to be improved in order to achieve cost-effectiveness. The NZEH NPV for the base case was $-\$ 42,400$ for the single detached, $-\$ 56,000$ for the townhouse end unit, and $-\$ 51,200$ for the townhouse middle unit. So the NPVs would have to be increased by this amount for each case if the NZEHs are to be cost-effective.

The addition of occupant engagement options in scenario 4 substantially reduces the costs of the NZEH. The NZEH without the occupant engagement options needed more expensive upgrades like CCASHP and increased wall insulation. Exchanging these upgrades for lower cost occupant engagement options decreased the incremental building cost (IBC) by $\$ 7,170$ over the scenario 1 NZEH, and the NPV increased by $\$ 14,700$, 
making this option very advantageous. Scenario 4 shows the necessity of occupant engagement in order to reduce the cost of NZEHs by avoiding more expensive upgrades.

Scenarios 5 and 6 show that reducing the solar PV price or adding MicroFIT increased the NPV of the house substantially, with the reduction in solar PV price increasing the NPV by $\$ 21,500$, and the MicroFIT increasing the NPV by $\$ 31,600$, compared to the NZEH from scenario 1. The MicroFIT scenario is the most cost-effective test scenario that was found, with a total NPV of $-\$ 10,800$ compared to code. However the MicroFIT was not used in any of the combination scenarios for two reasons. One, developers cannot preregister for a MicroFIT before the house has been bought, meaning there is risk that the buyer may buy a house expecting MicroFIT, and may not obtain it. Two, the intention of the MicroFIT program is to give the owner a good return on investment, so as the price of solar decreases, there is a higher likelihood that the MicroFIT program will be phased out.

Scenarios 7 and 8 show that both electric and natural gas utility price increases have a positive impact on the cost-effectiveness of NZEHs. It was found that electricity and natural gas price increases of $1 \%$ higher than nominal result in an increase of NPV by about $\$ 3,600$ for both cases. The increase in utility rate was also not used in the combination scenarios, since one cannot count that the utility prices will increase at higher rates in the future, and it would be politically unpopular for governments to artificially increase utility prices.

Scenario 9 shows the magnitude of the effect of reducing building costs by $15 \%$ by using large-scale developer costs. Since the optimized house design was exactly the same as scenario 1 , the reduction in IBC is exactly $15 \%$ of the scenario $1 \mathrm{IBC}$, at 
$\$ 10,210$. This decrease in the incremental building cost results in an increase in NPV by $\$ 14,600$.

Scenario 10 shows that adding a carbon tax slightly improves the costeffectiveness of NZEHs, with no change to IBC. With the carbon tax the NPV is increased by $\$ 4,300$. The incremental building cost is neutral because the house design is the same as the scenario $1 \mathrm{NZEH}$.

Scenario 11 shows that having a green loan that covers $100 \%$ of the upgrade costs and reduces the interest rate by $1 \%$ slightly improves the cost-effectiveness of NZEHs. Therefore, decreasing the interest rate by $1 \%$ has more of an impact on cost than reducing down payment on upgrades from $20 \%$ to $0 \%$, which on its own would slightly increase costs. However, the main goal of the green loan is to make the upgrades more accessible. By having the green loan pay for $100 \%$ of the upgrade costs, the down payment of the house is not increased, which increases the accessibility of the upgrades. Between the carbon tax and the green loan, the green loan is a more cost-effective policy measure, since it has approximately twice the impact on NPV with an increase of $\$ 9,700$.

\subsection{Combination scenarios and cost-effective NZEHs}

Since the previous scenarios (scenarios 1-11) do not yield a cost-effective NZEH result, combination scenarios were added that combined multiple scenarios with the goal of finding a cost-effective NZEH. The first level of combination scenarios (scenarios 12-14) combine scenarios 4, 5 and 9, meaning that occupant engagement, half-price installed solar PV, and large-scale developer costs were used. The second level of combination scenarios (scenarios 15-17) combine scenarios 4, 5, 9, 10 and 11, meaning that a carbon 
tax and green loan are added to the first level. There are a few reasons why the first level was chosen as the combination of scenarios 4, 5 and 9. Firstly, occupant engagement was selected as it is a low cost option to which substantially improves NPV, and makes it easier for houses to reach NZE. All that is necessary for occupant engagement is a motivated occupant, and it is likely that the amount of effort and cost needed to motivate an occupant to select dark blinds, dark exterior siding, and best in class appliances and to use an energy monitor will be low. Secondly, the price of solar PV is on a steep decline; the DOE SunShot target aims to try and reduce residential installed solar PV prices to $1.75 \$ / \mathrm{kW}$ by 2020 [31]. In this thesis, half of the solar PV price is $\$ 1.688 / \mathrm{kW}$

(\$1.434/kW for large-scale developers), which is not much lower than the SunShot target, meaning that this solar PV price will likely occur in the near future. Thirdly, large-scale developer costs were selected since large-scale developers interested in building NZEHs already exist. The industry partner on this thesis, Minto Communities, is a good example of a large-scale developer. Since these three options represent a likely scenario that does not rely on additional policy instruments, they were combined together and run on all three house types in scenarios 12-14.

Only the single detached house type (scenario 12) is cost-effective under the first level combination scenario conditions. The end unit townhouse (scenario 13) was not able to reach NZE even with the maximum energy savings possible and the mid unit townhouse is not cost-effective, with a NPV of $-\$ 24,700$. The single detached house, on the other hand, accomplishes the goal of this thesis, which is to find a realistic pathway to costeffective NZEHs. The single detached NZEH in scenario 12 has an incremental building cost of $\$ 38,190$ and a NPV of $\$ 3,100$. Since the NPV is not very high above zero, all 
three factors: the large-scale developer costs, occupant engagement, and lower solar PV prices are necessary to achieve cost-effectiveness. If the NPV was significantly greater than zero, it may be possible that one of the factors would not be necessary.

The second level of combination scenarios adds two policy measures to the first level combination scenarios. The two policy measures are a carbon tax of $\$ 30 /$ tonne $\mathrm{CO}_{2}$ equivalent and a green loan of $100 \%$ of the upgrade cost, with an interest rate $1 \%$ lower than the mortgage interest rate $(3 \%)$. These were selected because they are cost neutral options for the government, unlike a MicroFIT incentive [88], [90]. However these measures are not enough to improve the case for the townhouses. These measures improve the NPV by $\$ 9,800$ for the single detached house type, $\$ 9,800$ for the end unit townhouse and $\$ 8,000$ for the middle unit townhouse. This NPV increase makes the single detached house even more cost-effective, but the middle unit townhouse still does not reach NZEH, and the end unit townhouse is still not cost-effective. This thesis then focusses more on the first level of combination scenarios (scenarios 12-14), because it is a more likely future scenario, and because there is no advantage in terms of finding costeffective NZEHs in the second level of combination scenarios (scenarios 15-17).

So it was found that NZEHs can be cost-effective under certain conditions. Occupant engagement, combined with half-price solar PV, as well as large-scale developer costs allows the single detached NZEH to be cost-effective compared to code. This result accomplishes the goal of this thesis, which is to find a viable pathway to costeffective NZEHs.

The output designs for the first level of combinations scenarios (scenarios 12-14) are shown in Table 4.2. Because the townhouses are at or near the limit of maximum 
energy savings their designs are much more aggressive than the single detached house. All houses had the maximum solar PV possible on the roof, and out of the eighteen different systems, eleven are the same across all three house types. However, the townhouses have GSHP heating instead of the ASHP, and have much higher envelope insulation. Figure 4.5 can be used to illustrate why the designs and costs are so different between the single detached house and the townhouses. The Pareto-optimal curves for the townhouses have a steep drop-off as the curves approach the $100 \%$ energy savings mark. It can be seen that for combination scenarios $12-14$, the curves are shifted up significantly and to the right slightly. What causes the shift upwards is the reduction in price of solar, and the large-scale developer costs. However what is needed for the townhouses is a further shift to the right. The occupant engagement package creates a small shift, through low cost energy savings, but it can be seen that a slightly greater shift would allow both the townhouse types to be not only NZE but cost-effective as well. It is likely that the designs of these cost-effective NZEHs, when the curves are shifted more to the right, would be similar to the single detached house design.

What is needed to shift the townhouse Pareto-optimal curves in Figure 4.5 to the right is more emphasis on occupant energy load savings. There is one type of energy consumption that is decreased only marginally in this optimization. Occupant lighting can be reduced by upgrading lights, large appliances can be upgraded as well, but miscellaneous appliances cannot be upgraded. The miscellaneous appliance load of 9.7 $\mathrm{kWh} /$ day (about $12 \%$ of the total energy load in the code-built case) can only be reduced by the addition of an energy monitor. This energy, even when the energy monitor is applied, makes up $43 \%$ of the energy of a NZE townhouse. It is very likely that there are 
energy saving miscellaneous appliances (including TVs, stereos, computers, and small kitchen appliances), that can be used to reduce this load further. For the end unit townhouse in scenario 13, an addition energy savings of only $3.2 \mathrm{kWh} /$ day is needed to achieve cost-effectiveness. This makes up $38 \%$ of the existing miscellaneous appliance load. It is likely that the miscellaneous load may be reduced through the purchase of high efficiency miscellaneous appliances. However, this energy savings may even be possible at no additional costs. Figure 2.1 shows that some households use about $50 \%$ less electricity than the average consistently and voluntarily. Perhaps there are energy saving techniques that can be taught, which could be considered as a second level of occupant engagement and would produce additional miscellaneous load savings. If either more efficient miscellaneous appliances or voluntary miscellaneous load savings could achieve an additional energy savings of $3.2 \mathrm{kWh}$ /day, both types of NZE townhouses would be able to be cost-effective, and the single detached NZEH would become even more costeffective.

It should also be noted that this research takes place in a specific financial environment (see Table 3.4), and changes to this environment would affect the costeffectiveness of both NZEHs and COHs. It has already been mentioned that increasing electricity or natural gas rates would improve cost-effectiveness of these houses. The only other constant in Table 3.4 that improves cost-effectiveness if increased would be the down payment percentage. Increases in inflation, interest rate, mortgage term length, and markup would result in lower cost-effectiveness. Increasing the base price of the houses also reduces cost-effectiveness since the tax rates are higher for more expensive houses [91]. 
Although the price of solar PV will likely decrease to where NZEHs become costeffective, it is important that NZEHs continue to be built in the meantime in order to reduce carbon emissions. One way to do this would be to build single detached houses to the specifications in Table 4.2, but instead make the houses solar PV ready, so that solar $\mathrm{PV}$ can be installed later once the price reduces sufficiently or if MicroFIT is available. Higher efficiency $\mathrm{COHs}$ are also valuable, since they save both energy and cost simultaneously, as shown in Table 4.3. Again these houses could be built solar PV ready, so that when it is financially favourable solar PV can be installed.

\subsection{Cost-optimized houses (COHs)}

Cost-optimized houses (COHs) are also compared across the different scenarios (see Figure 4.4). The most striking result from this figure is that for half of the cases, the incremental building cost is much higher than the other half. These houses with much higher incremental building costs are ones that have solar PV selected (scenarios 5, 6 and 12-17). If a MicroFIT contract is applied or the price of solar PV is reduced by $50 \%$, it becomes financially attractive to have solar PV installed. In these scenarios the houses with solar PV had much higher NPVs, meaning the houses were generating more money from solar PV than was lost in the price of installed solar PV. In the other scenarios where solar PV was not as cost-effective, the incremental building costs were low, demonstrating that only low cost upgrades were installed. It was found that in the base case scenario that the $\mathrm{COH}$ would save the owner $\$ 7,200$ over a code-built house (over 25 years) and would save $15 \%$ of the energy. These numbers change to an NPV increase 
of $\$ 18,300$ and an energy savings of $49 \%$ when the price of solar is reduced by half, since it becomes cost-effective to incorporate solar PV.

To see why some COH designs have PV others do not can be seen in Figure 4.5. Comparing the Pareto-optimal curves of the base case optimizations to the first level of combination scenarios (scenarios 12-14) it can be seen how the curves have been shifted. In Figure 4.5 the curves are shifted up significantly, due to the reduction in solar PV price and building costs, and they have been shifted slightly to the right, because of the occupant engagement options. Because of how the curves have been shifted, the solutions with solar PV are significantly higher than the designs without solar PV, so the designs without solar PV are no longer on the Pareto-optimal curve. Therefore all designs in these scenarios can improve their cost-effectiveness with the addition of solar PV.

The output designs for the COHs for the first level combination scenarios (scenarios 12-14) are shown in Table 4.3. All the COHs for these scenarios have solar PV, and save large amounts of energy and cost compared to code. As can be seen in Figure 4.5, when the costs of solar PV reduce enough so that solar PV is cost-effective, the COHs (the leftmost tips of the curves) shift much further to the right, meaning that these COHs have high energy savings. On the other hand, the incremental building costs increase substantially for these cases, which make them less accessible options. The case with the highest return for investment is from scenario 4 , the occupant engagement package case, which provides a $\$ 9,900$ NPV for an increased down payment of only $\$ 230$. Alternatively, the $\mathrm{COH}$ in scenario 12 has a NPV of $\$ 25,200$ for an increased down payment of $\$ 18,390$. 
The systems that were most commonly found in the NZEHs and COHs across all scenarios are found in Table 4.4. The NZEH column shows that the optimal NZEH designs are fairly stable across different scenarios, meaning that if the scenario were to change, the house would likely still perform relatively well, or would only need minor changes in order to retain its performance. For the NZEHs, there were two types of parameters that had more variability than the rest, heating and cooling, and the building envelope. These parameters were less stable because these were the systems that varied between house types. For COHs the least stable system was the ventilation system, likely because this variable made little difference in cost-effectiveness, i.e. a $\mathrm{COH}$ with an $\mathrm{HRV}$ would have a similar NPV as a $\mathrm{COH}$ with an exhaust fan. It should be noted that for the cases with the occupant engagement package, the designs contain dark blinds, dark siding, and the energy monitor in all cases, whereas the best-in-class appliances are only selected for the NZE townhouse in the combination scenarios. Therefore, all the occupant engagement options other than the best-in-class appliances would likely be selected for all other optimization scenarios if those options were made available

\subsection{Comparison with other literature}

There are five studies mentioned in Section 2.2.2 that perform similar NZEH optimizations to the optimizations performed in this thesis. It can be difficult to compare the house designs produced by the different studies, as many of them have optimized different variables and have different assumptions about the houses being optimized. However, one can conceptually compare different houses based on their exterior wall insulation level, their primary heating system, and their solar PV size to get an impression 
of the design strategy output by the optimization. Table 5.1 lists the NZEH or NNZEH designs from these studies, as well as the NZEHs from scenario 1 and scenario 12 in this thesis. Note that the research by CanmetENERGY found three different design strategies with similar affordability.

The NZEHs in scenario 1 and scenario 12 are most similar to the CanmetENERGY 2 case. The upgrade cost of the CanmetENERGY 2 NZEH was $\$ 79,700$ and the electric utility costs are $\$ 450$ /year, whereas the scenario 1 NZEH has an incremental building cost of $\$ 68,100$ and electric utility costs of $\$ 188 /$ year. The reason the costs are lower in the scenario 1 case is likely due to lower solar PV price, since the study by CanmetENERGY was performed in 2012 when the price of solar PV was higher.

Table 5.1: Conceptual comparison of previously optimized NZEHs or NNZEHs

\begin{tabular}{cccc}
\hline Case & $\begin{array}{c}\text { Exterior Wall - RSI } \\
\text { (R-value) }\end{array}$ & Primary heating system & Solar PV size - kW \\
\hline Remi [56] & $8.6(49)$ & Solar thermal assisted heat pump & 4.8 \\
Verbeek [92] & $5.3(30)$ & GSHP & 4.8 \\
CanmetENERGY 1 [15] & $9.2(52)$ & Electric baseboard heaters & 11.3 \\
CanmetENERGY 2 [15] & $4.9(28)$ & CCASHP & 10 \\
CanmetENERGY 3 [15] & $9.2(52)$ & Gas furnace & 13.9 \\
Hamdy [58] & PH $\approx 11.8(67)$ & GSHP combi-system & 0.95 (wind turbine) \\
Bucking [14] & $8.6(49)$ & GSHP combi-system with PV/T & 9 \\
Scenario 1 & $5.6(32)$ & CCASHP & 9.5 \\
Scenario 12 & $5.6(32)$ & ASHP & 9.5 \\
\hline
\end{tabular}

Unfortunately characterizing the costs of the house by building upgrade and utility cost does not encompass all the relevant costs since it does not show the savings from the base case house design, and therefore the cost-effectiveness of the house. Out of the previous studies, only the work by Bucking [14] found a cost-effective house design, under a time- 
of-use MicroFIT of $\$ 0.366 / \mathrm{kWh}$ for off-peak, $\$ 0.549 / \mathrm{kWh}$ for mid-peak, and $\$ 0.722 / \mathrm{kWh}$. While this presents an alternative means of achieving cost-effective NZEHs, a time-of-use MicroFIT is an unlikely case for Ontario as the MicroFIT in Ontario is $\$ 0.396 / \mathrm{kWh}$ and is decreasing. Also as the price of solar PV panels decreases, the purpose of the MicroFIT, to give solar PV owners a good return on investment, becomes less necessary [87].

The scenario 12 NZEH is a more feasible option for achieving cost-effectiveness. This scenario includes the reduction in solar PV price by half, occupant engagement, and the construction of the house by a large-scale developer. This is deemed a realistic future possibility because it is likely the solar PV price will halve in the near future [31], because it is likely that NZEH buyers can be convinced to select and use certain technologies, and because houses are already being built by large-scale developers. The combination of these three factors allowed this research to find a viable pathway to costeffective NZEHs.

\subsection{Limitations}

There are three main limitations with this study. First, the analysis was only performed on the current orientations of the lots where the houses are to be built, so the resulting designs may not be widely applicable to different orientations. Best practice would be to run optimizations for multiple orientations. The optimizations were only run in one climate, so optimizations would have to be run for other locations to extend the conclusions to the entire Canadian climate. 
Second, some promising NZEH systems were not included in the optimization due to modelling complexity. In the future, more powerful optimizations will be able to include more systems, hopefully leading to even more cost-effective NZEHs.

Third, the optimization assumes certain parameters as constants in the modelling and cost evaluation of the house, in spite of high variability in the actual values likely experienced by developers. An example of an uncertain modelling parameter is the occupant energy usage. As shown in Section 2.1.4 there is approximately $50 \%$ variability in actual occupant energy usage. The occupant energy usage is critical to the achievement of a cost-effective NZEH. If the occupant is a high consumer of electricity, the house will not meet its targets. Alternatively, if the occupant is a low consumer, it is possible that some expensive systems could be avoided in order to reach a cost-effective NZEH. System costs also vary from business to business and location to location. The costs of energy, the cost of water, and the carbon intensity per unit of energy also change depending on the province and municipality. Changes in these costs greatly impact the feasibility of the cost-effective NZEH designs produced by this thesis. This is shown by the impact of Scenario 9 in Section 4.2.

There are a few additional considerations that are worth mentioning. First, the optimization scenario that yielded the cost-effective NZEH uses current building code and future solar PV prices, so it is possible that these results may not be valid since other changes that impact cost-effectiveness may occur in the future. Some examples of these are changes to building energy codes and to mortgage rates. Alternatively, it is possible that system prices will decrease, which would improve cost-effectiveness. 
Second, grid connections may not be available with or without the MicroFIT in Ontario due to lack of grid infrastructure or other reasons [32]. For large-scale penetration of NZEHs, solar PV access to the grid must be available. One option might be to add smart controls to solar electricity generation, similar to the peaksaver PLUS ${ }^{\circledR}$ demand side management program [93]. In fact adding demand side management to the heat pump systems in the NZEHs as well as the solar PV would allow much more penetration of solar PV, since the peak generation and consumption could be better controlled.

Third, the $12 \%$ occupant energy usage savings due to the home energy monitor is not recognized by the pilot R2000 NZEH standard. This means that the NZEH house designs from scenarios $4,12,14,15$, and 17 might not be able to achieve this certification, or would need additional efficiency measures in order to achieve it. It is also possible that given the houses here are modelled in EnergyPlus, and the modelling software used for certification is HOT2000, there may be differences between the energy model outputs of EnergyPlus and HOT2000. The differences between these two modelling tools should be checked if NZEH certification is desired.

\subsection{Relevance of results}

This thesis has shown a potential pathway for NZEHs to become cost-effective. With large developer prices, occupant engagement, and reductions in solar PV price a costeffective NZEH is possible. More research could be focused on occupant engagement, as this is one of the most cost-effective ways to reduce energy. The thesis shows the sensitivity of NZEH costs across seventeen different scenarios, which gives insight to 
decision-makers on what strategies might be used to help improve the cost-effectiveness of NZEHs and also houses in general. The thesis displays $\mathrm{COH}$ designs that are more cost-effective and save energy compared to current building code and therefore could be incorporated into future changes to the code. The most common technologies for NZEHs/NNZEHs and COHs selected by the optimization are displayed, which shows designers what technologies are more useful for reaching certain energy targets. Research insights into useful technologies and ones that might be improved also helps researchers focus on technologies that show the most promise for creating more cost-effective houses in the future. The most important result of this thesis, though, is that cost-effective NZEHs will likely be possible in the future under certain circumstances. This means that in the future NZEHs may be much more common, allowing potential owners to substantially lower their carbon emissions. 


\section{Chapter 6: Conclusions}

The goal of this research was to determine if cost-effective NZEHs are possible, and if so, what strategies would be necessary to achieve them. Single detached NZEH designs resulting from different optimization scenarios had significantly different prices, but in most cases the design was not substantially affected. From the optimization scenarios the following results were found. Adding the occupant engagement options had a significantly positive cost impact, reducing the need to compensate with much more advanced systems. Incremental building cost (IBC) decreased by $\$ 7,170$ and net present value (NPV) increased by $\$ 14,700$ on the scenario where the occupant engagement options were added. Reducing the price of solar PV or adding a MicroFIT was very beneficial. Reducing the price of solar PV to half of the current price increased NPV by $\$ 21,500$. However, the MicroFIT was more cost-effective, and increased NPV by $\$ 31,600$. Increasing either electricity or natural gas prices was shown to increase the NPV of NZEHs. Using large-scale building costs with a $15 \%$ reduction in system price gave an improvement in NPV of $\$ 14,600$. Adding a carbon tax of $\$ 30 /$ tonne $\mathrm{CO}_{2} \mathrm{e}$ only improved the NPV by $\$ 4,300$. Adding a $100 \%$ green loan (with an interest rate $1 \%$ lower than the mortgage) to the house upgrades, allows the house down payment to remain unchanged, making the upgrades more accessible. However, the loan structure also improves long term cost-effectiveness by improving NPV by $\$ 9,700$.

Using this information a combination of occupant engagement options, half-price solar PV and large-scale developer costs led to a viable cost-effective NZEH path. This 
combination scenario represents a more likely future possibility because it does not require MicroFIT or any other government intervention.

The occupant engagement options, half-price solar PV and large-scale developer costs combination scenario was also used to find NZE townhouses. The NZE townhouses were not able to reach a cost-effective NZEH state. Only the single detached NZEH was found to be cost-effective. The major design strategy of the cost-effective single detached NZEH design is: an air source heat pump with solar domestic hot water, a moderately insulated envelope, and maximum solar PV. The single detached NZEH has an IBC of $\$ 38,190$ and an NPV of $\$ 3,100$. A positive NPV indicates that the single detached NZEH is more cost-effective over a 25 year period than a code-built house. The end unit townhouse approaches NZE because an energy savings of $99.8 \%$ is the maximum energy savings possible in that case. The middle unit townhouse is able to reach NZE, but needs more expensive upgrades than the single detached and is not cost-effective. It is proposed that increased occupant energy savings would improve the likelihood of achieving costeffective NZE townhouses.

Additionally, as a result of the optimization, cost-optimized houses $(\mathrm{COH})$ (nonNZE) were generated that maximized cost savings. These houses represent an option that performs between minimum building code and NZE. These COHs save money and energy; thus they have the potential to be implemented immediately as a carbon emissions reduction strategy.

There are three limitations with this study. First, sensitivity studies were not performed on house orientation or location. Second, some promising NZEH systems 
were not included in the optimization due to modelling complexity. Third, there is a high level of uncertainty in the costs inputs and some of the modelling inputs.

There is the potential for cost-effective NZEHs in the near future, which could be implemented on a mass scale to reduce carbon emissions of the housing sector.

This research found that viable cost-effective single detached NZEH designs may be possible when three conditions are met:

1. Building prices are similar to that of a large-scale developer

2. Occupant engagement is pursued, i.e. occupants choose dark blinds, dark exterior siding and an energy monitor

3. The price of installed solar PV decreases to half of the 2014 price $(\$ 1.434 / \mathrm{W}$ for large-scale developers)

Furthermore, with continued decreases in system prices and increases in efficiency on solar PV panels and other technologies, the cost-effectiveness of NZEHs is expected to improve. 


\subsection{Future work}

For this thesis only three different house types with two different orientations were optimized, since these were the specifics of the proposed ecoEII houses that are to be built by Minto Communities. For more generalized results, optimizations could be run for different designs, for different orientations, and in different locations. For a larger community of NZEHs the most value would come from optimizing the worst orientation for each particular design. By doing so, if all houses in a community were built with the same systems, they would all be NZE. No special considerations would have to be made for houses with less than ideal orientations. Similarly, it would be convenient to have a consistent design across townhouse types as well. Conceivably, an optimization method could optimize the combined performance of more than one house type with the same systems package. An optimization method like this would yield NZEH system designs that could be used across many house types. Both seeking out of the worst orientations and optimizing different house types with the same systems would allow for consistent systems design across larger communities of NZEHs and would allow construction to be more streamlined. On the other hand, this would have to be balanced against energy and cost advantages of having more optimal designs for each orientation or house type.

There are possible further improvements to the optimization algorithm that would potentially yield more favourable results. In this thesis the entire Pareto-archive was randomly accessed to provide parents for the next generation. While tournament selection was used pick points that were generally less crowded than other points, the Paretoarchive becomes quite large, meaning that key points might be skipped, and less attention is given to the NZEH and $\mathrm{COH}$ ends of the Pareto-optimal curve. The easiest fix would 
be to force the optimization to select solutions nearer to the desired points and put them into the parent population, like the nearest NZE and cost-optimized points. This would improve the resolution of the optimal points in those areas, and would reduce the number of simulations.

Continued work on industry level optimization tools with quick turnaround times, like BEopt, will help empower industry to be able to optimize NZEHs more quickly and easily. It is suggested that a Canadian version of BEopt be created. This program would have tailored options and modelling for a Canadian climate and would include Canadian building prices, making it a more relevant and effective tool for Canadian developers. 


\section{References}

[1] Environment Canada, “Canada's emissions trends," 2013.

[2] P. Torcellini, S. Pless, and M. Deru, "Zero energy buildings : A critical look at the definition," ACEEE Summer Study, 2006.

[3] F. Wolfgang, "What is a Passive House?," 2007.

[4] Canadian Morgage and Housing Corporation, "Approaching net-zero energy in existing housing," 2008.

[5] J. Gusdorf, R. Charron, and K. Winder, "Canada's EQuilibrium housing demonstration initiative: Net-zero energy houses in cold climates," ACEEE Summer Study Energy Effic. Build., vol. 2, pp. 88-102, 2010.

[6] D. Ürge-Vorsatz and A. Novikova, "Potentials and costs of carbon dioxide mitigation in the world's buildings," Energy Policy, vol. 36, pp. 642-661, 2008.

[7] D. Crawley, S. Pless, and P. Torcellini, "Getting to net zero," ASHRAE J., vol. 51, pp. 18-25, 2009.

[8] S. Schimschar, K. Blok, T. Boermans, and A. Hermelink, “Germany's path towards nearly zero-energy buildings-Enabling the greenhouse gas mitigation potential in the building stock," Energy Policy, vol. 39, pp. 3346-3360, 2011.

[9] G. Proskiw and A. Parekh, "Optimization of net zero energy houses," in BEST 2 Conference, 2010, pp. 1-15.

[10] S. Attia, M. Hamdy, W. O’Brien, and S. Carlucci, “Assessing gaps and needs for integrating building performance optimization tools in net zero energy buildings design," Energy Build., vol. 60, pp. 110-124, 2013.

[11] P. Amerongen and D. Richardson, "Learning from NZE houses: extending design approaches to larger structures," ASHRAE Trans., pp. 141-149, 2011.

[12] A. Athienitis, P. Torcellini, A. Hirsch, W. O’Brien, M. Cellura, R. Klein, V. Delisle, S. Attia, P. Bourdoukan, and S. Carlucci, "Design, optimization, and modelling issues of net-zero energy solar buildings," EuroSun 2010, vol. 1, 2010.

[13] R. Charron, "A review of design processes for low energy solar homes," Open House Int., vol. 33, pp. 7-16, 2008. 
[14] S. Bucking, "Pathways to net-zero energy buildings: An optimization methodology." Concordia University, 2013.

[15] M. Carver and A. Ferguson, "Affordable net-zero energy housing pathways," CanmetENERGY, 2012.

[16] Natural Resources Canada, "Integrating renewables and conservation measures in a net-zero energy low-rise residential subdivision." [Online]. Available: http://www.nrcan.gc.ca/energy/funding/current-funding-programs/eii/16140.

[17] W. O. Brien, A. Athienitis, and T. Kesik, "The development of a solar house design tool," Elev. Int. IBPSA Conf., pp. 1397-1404, 2009.

[18] Lockheed Martin Energy Solutions Group, "Impact evaluation of the U.S. Department of Energy's Solar Decathlon program,” Rockville, 2012.

[19] Canadian Mortgage and Housing Corporation, "EQuilibrium ${ }^{\mathrm{TM}}$ housing InSights and resources." [Online]. Available: http://www.cmhcschl.gc.ca/en/inpr/su/eqho/eqho_007.cfm.

[20] ASHRAE, "Energy standard for buildings except low-rise residential buildings." ANSI/ASHRAE/IESNA 90.1-2004, Atlanta, 2004.

[21] G. Proskiw, "Identifying affordable net zero energy housing solutions," Proskiw Eng. Ltd, A Rep. Prep. CanmetENERGY, 2010.

[22] C. Mahaffy, "No furnace, no car, no problem," Tech Life, 2009.

[23] R. S. Dumont, "The Factor 9 home: A new prairie approach: Monitoring final report," Saskatoon, 2008.

[24] Passivhaus, "The rainbow passive house: Project data sheet." [Online]. Available: http://www.passivhausprojekte.de/projecte.php?detail=2752.

[25] US Department of Energy, “DOE Solar Decathlon 2013: Team Ontario: Queen's University, Carleton University, and Algonquin College,” 2013. [Online]. Available: http://www.solardecathlon.gov/past/2013/team_ontario.html.

[26] US Department of Energy, "DOE Solar Decathlon 2013: Norwich University," 2013. [Online]. Available:

http://www.solardecathlon.gov/past/2013/team_norwich.html.

[27] P. Norton and C. Christensen, "A cold-climate case study for affordable zero energy homes," Natl. Renew. Energy Lab., vol. NREL/CP-55, p. 7, 2006. 
[28] US Department of Energy, "DOE Solar Decathlon 2011: University of Illinois at Urbana-Champaign," 2011. [Online]. Available:

http://www.solardecathlon.gov/past/2011/team_illinois.html.

[29] US Department of Energy, "DOE Solar Decathlon 2011: Purdue University," 2011. [Online]. Available:

http://www.solardecathlon.gov/past/2011/team_purdue.html.

[30] US Department of Energy, "DOE Solar Decathlon 2009: University of Illinois at Urbana-Champaign," 2009. [Online]. Available:

http://www.solardecathlon.gov/past/2009/team_illinois.html.

[31] D. Feldman and G. Barbose, "Photovoltaic system pricing trends: Historical, recent, and near-term projections - 2013 edition," Golden, CO, 2013.

[32] O. Temby, K. Kapsis, H. Berton, D. Rosenbloom, G. Gibson, A. Athienitis, and J. Meadowcroft, "Building-integrated photovoltaics : Distributed energy development for urban sustainability," Environ. Sci. Policy Sustain. Dev., vol. 56:6, no. November, pp. 4-17, 2014.

[33] National Renewable Energy Laboratory, "National residential efficiency measures database: Development document, v3.0." Golden, CO, 2012.

[34] Mitsubishi Electric, "Zuba-Central ${ }^{\mathrm{TM}}$," 2011.

[35] EERE, "Technical support document: Energy efficiency program for consumer products: Residential central air conditioners, heat pumps, and furnaces," Energy Effic. Renew. Energy Off., 2011.

[36] B. Sparn, K. Hudon, and D. Christensen, "Laboratory performance evaluation of residential integrated heat pump water heaters," NREL, no. September, 2011.

[37] R. Aldrich and G. Vijayakumar, "Cost, design and performance of solar hot water in cold-climate homes," Steven Winter Assoc. Inc., 2005.

[38] NRCan, Heat recovery ventilators. 2012.

[39] R. A. Aldrich, L. Arena, and W. Zoeller, "Practical residential wall systems : R-30 and beyond," Res. Rep. Prep. by Steven Winter Assoc. Inc Consort. Adv. Resid. Build., 2010.

[40] R. Jacobson, "Performance of 8 Passive House envelopes in cold climates," Passiv. Nord., 2012.

[41] Government of Ontario, "Supplementary standard SB-12: Energy efficiency for housing," Minist. Munic. Aff. Housing, Build. Dev. Branch, 2013. 
[42] R. Charron, "EQuilibrium ${ }^{\mathrm{TM}}$ : Demonstrating a vision for sustainable housing in canada." Canadian Mortgage and Housing Corporation, Ottawa, 2010.

[43] J. Harris, "Air leakage in Ontario housing," DSG Home Insp. Inc./Aubrey LeBlanc Consult., 2009.

[44] CanmetENERGY, "NZEH_CostData_ARCH1_for_sharing." Ottawa, 2013.

[45] R. Hendron and C. Engebrecht, "Building America house simulation protocols," National Renewable Energy Laboratory, 2010.

[46] Canadian Mortgage and Housing Corporation, Tap the sun: passive solar techniques and home design. 1989.

[47] Natural Resources Canada, "MINTO NZE-Calculation-Spreadsheet_v3 1.xls." R2000 Net Zero Energy Pilot Project, 2015.

[48] Hydro Ottawa, "Minto - Consumption - Energy efficient townhome data - 2013." 2013.

[49] Hydro Ottawa, "Minto singles - 2014 - Latest request - Hydro Ottawa data." 2014.

[50] K. Ehrhardt-Martinez, K. Donnelly, and S. Laitner, "Advanced metering initiatives and residential feedback programs: a meta-review for household electricity-saving opportunities," ACEEE, 2010.

[51] A. Meier, C. Aragon, B. Hurwitz, D. Mujumdar, T. Peffer, D. Perry, and M. Pritoni, "How people actually use thermostats," Control. Inf. Technol., vol. 2, pp. 193-206, 2010.

[52] A. Selvig, W. O. Brien, and C. G. Merrett, "2013 Solar Decathlon: Technologies, modelling tools and Canadian applications," Proc. eSim 2014, 2014.

[53] Habitat Studio \& Workshop Ltd., "Designing for net zero energy.” 2012.

[54] W. O'Brien, A. Athienitis, S. Bucking, M. Doiron, and T. Kesik, "A study of design tools and processes through a near net-zero energy house redesign," Proc. EuroSun 2010, pp. 1-8, 2010.

[55] J. W. Chinneck, Practical optimization: a gentle introduction. 2006.

[56] R. Charron, "Development of a genetic algorithm optimisation tool for the early stage design of low and net-zero energy solar homes," Concordia University, 2007.

[57] G. Verbeeck and H. Hens, "Optimization of extremely low energy residential buildings," in Proceedings of Clima 2007 Wellbeing indoors, 2007. 
[58] M. Hamdy, M. Palonen, and A. Hasan, "Implementation of pareto-archive NSGAII algorithms to a nearly-zero-energy building optimisation problem," First Build. Simul. Optim. Conf., no. September, pp. 181-188, 2012.

[59] S. Horowitz, C. Christensen, M. Brandemuehl, and M. Krarti, "Enhanced sequential search methodology for identifying cost-optimal building pathways," in Proceedings of SimBuild 2008: 3rd conference of IBPSA-USA, 2008, pp. 1-11.

[60] D. Tuhus-Dubrow and M. Krarti, "Comparative analysis of optimization approaches to design building envelope for residential buildings," ASHRAE Trans., vol. 115.2, 2009 .

[61] Minto Communities, "Arcadia - Killarney model - Kanata new homes, Ottawa." [Online]. Available: http://www.minto.com/ottawa/Kanata-newhomes/Arcadia/The-Killarney 1396ht.html.

[62] Minto Communities, "Arcadia - Hampton model - Kanata new homes, Ottawa." [Online]. Available: http://www.minto.com/ottawa/Kanata-newhomes/Arcadia/Hampton-II 781ht.html.

[63] C. Christensen and S. Horowitz, "BEopt training videos," National Renewable Energy Laboratory. [Online]. Available: https://beopt.nrel.gov/videos.

[64] D. B. Crawley, L. K. Lawrie, C. O. Pedersen, F. C. Winkelmann, M. J. Witte, R. K. Strand, R. J. Liesen, W. F. Buhl, Y. J. Huang, R. H. Henninger, J. Glazer, D. E. Fisher, D. B. Shirey, B. T. Griffith, P. G. Ellis, and L. Gu, "EnergyPlus Structure," SimBuild 2004, 2004.

[65] US Department of Energy, "EnergyPlus engineering reference: The reference to EnergyPlus calculations," p. 1375, 2010.

[66] I. Beausoleil-Morrison and B. P. Kemery, "Analysis of basement insulation alternatives," 2009.

[67] I. S. Walker and D. J. Wilson, "Field validation of algebraic equations for stack and wind driven air infiltration calculations," ASHRAE HVAC\&R Res. J., vol. 4, no. 2, 1998.

[68] Dublin Energy Lab, "A reference model for ground coupled heat transfer," Dublin Institute of Technology. [Online]. Available:

http://dit.ie/dublinenergylab/researchthemes/zeroemissonsbuilding/areferencemode lforgroundcoupledheattransfer/.

[69] I. Bennet, W. O'Brien, and H. B. Gunay, "Effect of window blind use in residential buildings: Observation and simulation study," in eSim 2014, 2014. 
[70] Office of Energy Efficiency and National Resources Canada, "2011 Survey of household energy use - Detailed statistical report," 2011.

[71] CanmetENERGY, “LEEP_COSTING_ottawa_V1.2.” Ottawa, 2014.

[72] Jeld-Wen Ltd., "Natural Resources Canada Local Energy Efficiency Partnership (LEEP) meeting presentation." September 12, 2014, Ottawa.

[73] “Amazon.ca: Online shopping.” [Online]. Available: http://www.amazon.ca/.

[74] Ontario Power Authority, "Cost of electricity service 2013 LTEP: Module 4," no. January, 2014.

[75] U.S. Energy Information Administration, “Annual energy outlook 2015," U.S. Dep. Energy, 2015.

[76] "Canadian Mortgage and Housing Corporation." [Online]. Available: http://www.cmhc-schl.gc.ca/.

[77] “Bank of Canada." [Online]. Available: http://www.bankofcanada.ca/.

[78] Hydro Ottawa, "Rates and conditions." [Online]. Available: https://hydroottawa.com/residential/rates-and-conditions/.

[79] Enbridge Gas Distribution, "Purchasing gas from enbridge." [Online]. Available: https://www.enbridgegas.com/homes/accounts-billing/residential-gasrates/purchasing-gas-from-enbridge.aspx.

[80] City of Ottawa, "Water and sewer bills," 2014. [Online]. Available: http://ottawa.ca/en/residents/water-and-environment/water-and-sewer-bills.

[81] Environment Canada, "Municipal water and wastewater survey: Municipal water use 2009 summary tables," Sustain. Water Manag. Div., 2009.

[82] G. Keoleian, S. Blanchard, and P. Reppe, "Life-cycle energy, costs, and strategies for improving a single-family house," J. Ind. Ecol., vol. 4, no. 2, pp. 135-156, 2001.

[83] Minto Communities, "Arcadia - Greenwich model - Kanata new homes, Ottawa." [Online]. Available: http://www.minto.com/ottawa/Kanata-newhomes/Arcadia/Greenwich-II 780ht.html.

[84] A. Seshadri, "NSGA-II: A multi-objective optimization algorithm, MATLAB Central." [Online]. Available:

http://www.mathworks.com/matlabcentral/fileexchange/10429-nsga-ii-a-multi- 
objective-optimization-algorithm/content/NSGA-

II/html/non_domination_sort_mod.html.

[85] T. Goel and N. Stander, "A study on the convergence of multiobjective evolutionary algorithms," Prepr. Submitt. to 13th AIAA/ISSMO Conf. Multidiscip. Anal. Optim., pp. 1-18, 2010.

[86] S. W. Mahfoud and D. E. Goldberg, "Parallel recombinative simulated annealing: A genetic algorithm," Parallel Comput., vol. 21, no. 94, pp. 1-28, 1995.

[87] Ontario Power Authority, "FIT/microFIT price schedule (January 1, 2014).” 2014.

[88] Province of British Columbia, "Carbon tax." [Online]. Available: http://www.fin.gov.bc.ca/tbs/tp/climate/carbon_tax.htm.

[89] “Bullfrog Power," 2013. [Online]. Available: www.bullfrogpower.com.

[90] H. Berton, D. Rosenbloom, O. Temby, and J. Meadowcroft, "Using local improvement charges to finance solar photovoltaic systems in Canada," Energy Transitions Sustain.

[91] Government of Ontario, "What's taxable under the HST and what's not?," pp. 1$10,2010$.

[92] G. Verbeeck, Optimisation of extremely low energy residential buildings. 2007.

[93] Independent Electricity System Operator, "Save on energy," 2015. [Online]. Available: saveonenergy.ca. 


\section{Appendix A House floorplans}

The floorplans of the houses that Minto plans to build to NZEH specifications for the EcoEII [16] are shown in Figure A.1 and Figure A.2. The dimensions of the floorplans were used to create the house forms in BEopt, for conversion into EnergyPlus input file templates.
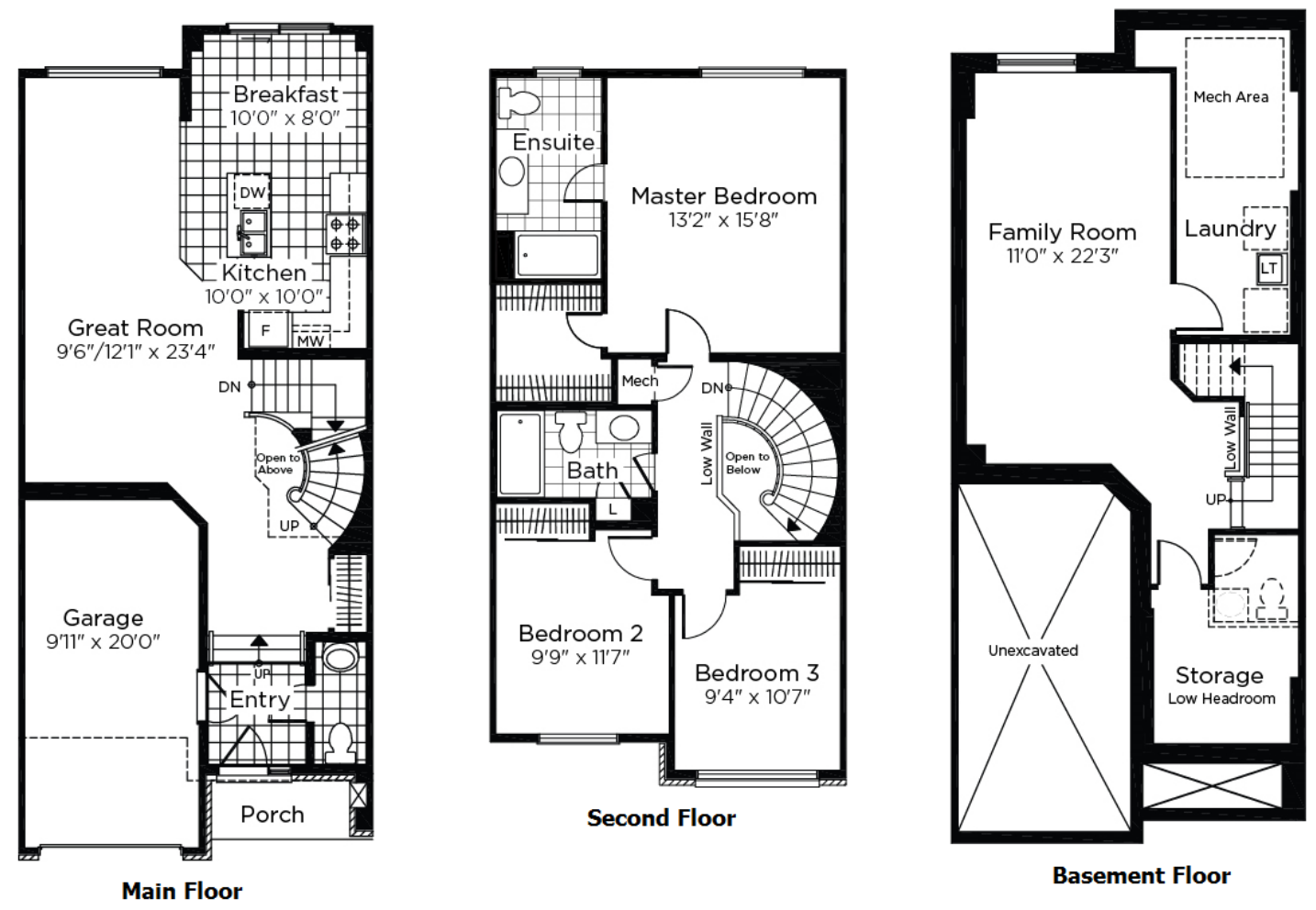

Figure A.1: Townhouse (end and middle unit) floorplans [62] 

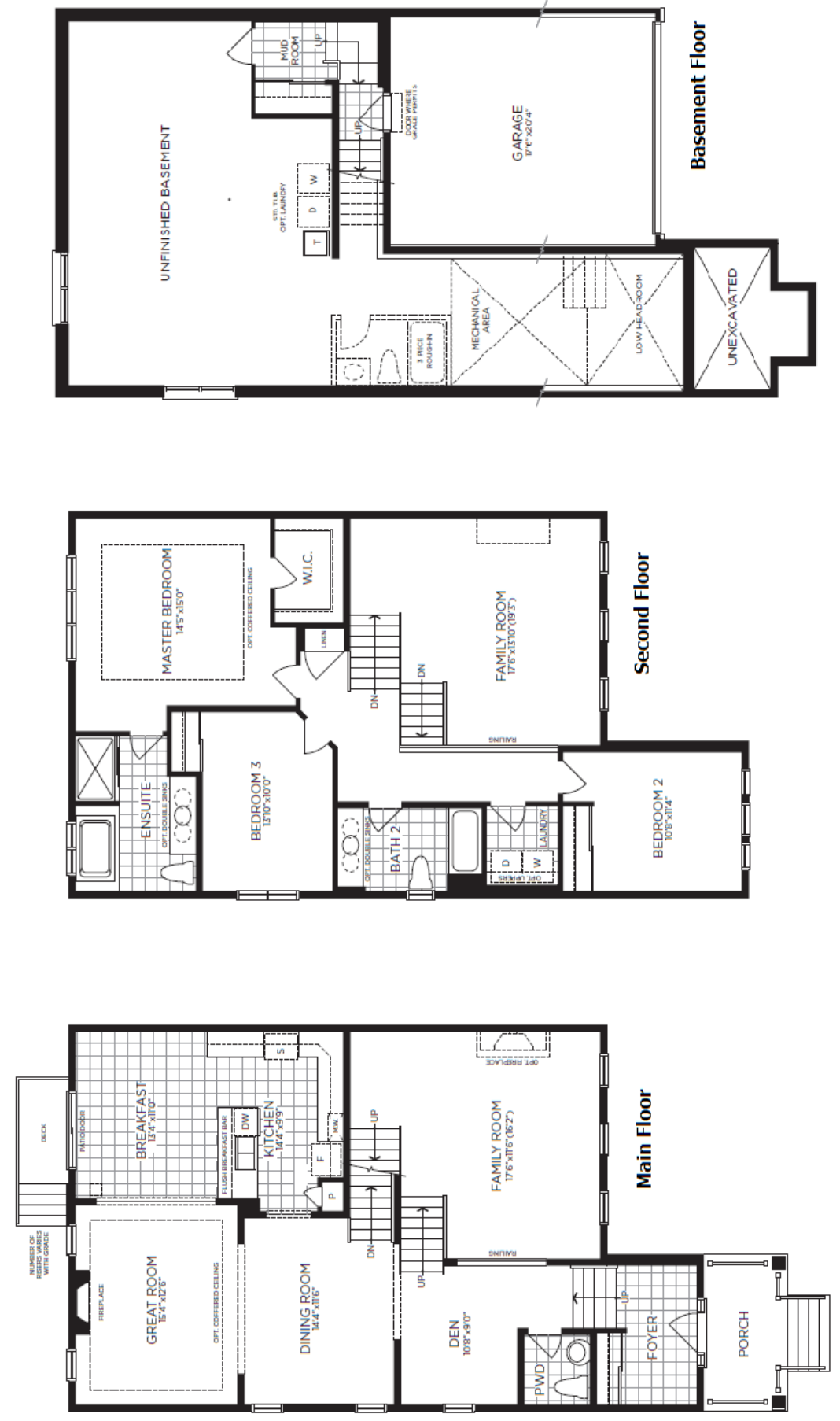

Figure A.2: Single detached house floor plans [61] 


\section{Appendix B Systems not used in optimization}

Section 3.2 describes the different reasons why systems were not selected for the optimization. Table B.1 lists the different systems that were not used in the optimization and categorizes the systems by reason not selected. One system that was not selected for the optimization that does not fall into these categories is structurally insulated panel (SIP) construction. SIP construction was not selected because it would require significant training for builders and trades people. It was decided to try to stay within the existing skill sets of the builders and minimize the additional training needed as much as possible. 


\section{Table B.1: Systems not used in optimization}

\section{Preliminary analysis of systems showed unfavourable costs relative to efficiency gains}

Solar air heaters

Interior thermal mass upgrades

Photovoltaic thermal

Micro combined heat and power system

Absorption heat pump

Radiant floor heating

Natural ventilation cooling

Demand controlled ventilation

Double stud wall construction

Insulated concrete form construction

Spray foam insulation

Vacuum insulation panels

Quadruple glazed windows

Vacuum windows

Thermally resistive cladding

Thermally massive cladding

Programmable thermostats

Phantom load switch

Building integrated photovoltaic

Light tubes

Light louvers

Occupancy sensors

Daylight sensors

Ceiling fan

2. A system or combination of systems with similar performance were already selected

ASHP combi-systems

GSHP combi systems

Integrated mechanical system

Expanded polystyrene insulation

Polyisocyanurate insulation

Blown-in cellulose insulation

Energy recover ventilator

3. The system was not in the BEopt database and could not be easily adapted

Solar thermal combi-systems

Solar thermal assisted heat pumps

Motorized shading

Home automation system 


\section{Appendix C Parameter sensitivity study}

Table C. 1 shows the impact of each system on the code built single detached house. The table show the design change in code form, the incremental building cost (IBC), the net present value (NPV), and the total site energy savings. The designs can be decoded using Table 3.2. 
Table C.1: Sensitivity study of all system options (from code-built design)

\begin{tabular}{|c|c|c|c|c|c|c|c|c|c|c|c|c|c|c|c|c|c|c|c|c|c|}
\hline \multirow{2}{*}{ Design } & \multicolumn{18}{|c|}{ Parameter selection } & \multirow{2}{*}{$B C$} & \multirow{2}{*}{ NPV } & \multirow{2}{*}{$\begin{array}{l}\text { Energy } \\
\text { savings }\end{array}$} \\
\hline & 1 & 2 & 3 & 4 & 5 & 6 & 7 & 8 & 9 & 10 & 11 & 12 & 13 & 14 & 15 & 16 & 17 & 18 & & & \\
\hline Code-built & 1 & 1 & 2 & 1 & 1 & 1 & 1 & 1 & 1 & 1 & 1 & 1 & 1 & 1 & 1 & 1 & 1 & 1 & $\$ 0$ & $\$ 0$ & $0.0 \%$ \\
\hline 2 & 2 & 1 & 2 & 1 & 1 & 1 & 1 & 1 & 1 & 1 & 1 & 1 & 1 & 1 & 1 & 1 & 1 & 1 & $\$ 1,240$ & $-\$ 47,700$ & $3.1 \%$ \\
\hline 3 & 3 & 1 & 2 & 1 & 1 & 1 & 1 & 1 & 1 & 1 & 1 & 1 & 1 & 1 & 1 & 1 & 1 & 1 & $\$ 420$ & $-\$ 15,300$ & $33.1 \%$ \\
\hline 4 & 4 & 1 & 2 & 1 & 1 & 1 & 1 & 1 & 1 & 1 & 1 & 1 & 1 & 1 & 1 & 1 & 1 & 1 & $\$ 6,810$ & $-\$ 23,700$ & $38.2 \%$ \\
\hline 5 & 5 & 1 & 2 & 1 & 1 & 1 & 1 & 1 & 1 & 1 & 1 & 1 & 1 & 1 & 1 & 1 & 1 & 1 & $\$ 18,560$ & $-\$ 46,000$ & $41.0 \%$ \\
\hline 6 & 1 & 2 & 2 & 1 & 1 & 1 & 1 & 1 & 1 & 1 & 1 & 1 & 1 & 1 & 1 & 1 & 1 & 1 & $\$ 1,000$ & $-\$ 1,000$ & $3.6 \%$ \\
\hline 7 & 1 & 3 & 2 & 1 & 1 & 1 & 1 & 1 & 1 & 1 & 1 & 1 & 1 & 1 & 1 & 1 & 1 & 1 & $-\$ 610$ & $-\$ 5,200$ & $4.2 \%$ \\
\hline 8 & 1 & 4 & 2 & 1 & 1 & 1 & 1 & 1 & 1 & 1 & 1 & 1 & 1 & 1 & 1 & 1 & 1 & 1 & $\$ 710$ & $-\$ 5,600$ & $6.3 \%$ \\
\hline 9 & 1 & 5 & 2 & 1 & 1 & 1 & 1 & 1 & 1 & 1 & 1 & 1 & 1 & 1 & 1 & 1 & 1 & 1 & $\$ 6,510$ & $-\$ 9,200$ & $9.9 \%$ \\
\hline 10 & 1 & 1 & 1 & 1 & 1 & 1 & 1 & 1 & 1 & 1 & 1 & 1 & 1 & 1 & 1 & 1 & 1 & 1 & $-\$ 800$ & $\$ 1,700$ & $-3.4 \%$ \\
\hline 11 & 1 & 1 & 3 & 1 & 1 & 1 & 1 & 1 & 1 & 1 & 1 & 1 & 1 & 1 & 1 & 1 & 1 & 1 & $\$ 570$ & $-\$ 500$ & $2.6 \%$ \\
\hline 12 & 1 & 1 & 2 & 2 & 1 & 1 & 1 & 1 & 1 & 1 & 1 & 1 & 1 & 1 & 1 & 1 & 1 & 1 & $\$ 4,120$ & $-\$ 4,400$ & $5.6 \%$ \\
\hline 13 & 1 & 1 & 2 & 3 & 1 & 1 & 1 & 1 & 1 & 1 & 1 & 1 & 1 & 1 & 1 & 1 & 1 & 1 & $\$ 6,440$ & $-\$ 6,700$ & $9.2 \%$ \\
\hline 14 & 1 & 1 & 2 & 4 & 1 & 1 & 1 & 1 & 1 & 1 & 1 & 1 & 1 & 1 & 1 & 1 & 1 & 1 & $\$ 11,000$ & $-\$ 12,500$ & $11.8 \%$ \\
\hline 15 & 1 & 1 & 2 & 5 & 1 & 1 & 1 & 1 & 1 & 1 & 1 & 1 & 1 & 1 & 1 & 1 & 1 & 1 & $\$ 15,290$ & $-\$ 18,100$ & $13.8 \%$ \\
\hline 16 & 1 & 1 & 2 & 1 & 2 & 1 & 1 & 1 & 1 & 1 & 1 & 1 & 1 & 1 & 1 & 1 & 1 & 1 & $\$ 720$ & $-\$ 500$ & $2.0 \%$ \\
\hline 17 & 1 & 1 & 2 & 1 & 3 & 1 & 1 & 1 & 1 & 1 & 1 & 1 & 1 & 1 & 1 & 1 & 1 & 1 & $\$ 1,580$ & $-\$ 1,200$ & $3.9 \%$ \\
\hline 18 & 1 & 1 & 2 & 1 & 4 & 1 & 1 & 1 & 1 & 1 & 1 & 1 & 1 & 1 & 1 & 1 & 1 & 1 & $\$ 2,880$ & $-\$ 2,400$ & $6.4 \%$ \\
\hline 19 & 1 & 1 & 2 & 1 & 5 & 1 & 1 & 1 & 1 & 1 & 1 & 1 & 1 & 1 & 1 & 1 & 1 & 1 & $\$ 3,950$ & $-\$ 3,400$ & $8.3 \%$ \\
\hline 20 & 1 & 1 & 2 & 1 & 1 & 2 & 1 & 1 & 1 & 1 & 1 & 1 & 1 & 1 & 1 & 1 & 1 & 1 & $\$ 360$ & $-\$ 300$ & $0.6 \%$ \\
\hline 21 & 1 & 1 & 2 & 1 & 1 & 3 & 1 & 1 & 1 & 1 & 1 & 1 & 1 & 1 & 1 & 1 & 1 & 1 & $\$ 920$ & $-\$ 1,000$ & $1.1 \%$ \\
\hline 22 & 1 & 1 & 2 & 1 & 1 & 4 & 1 & 1 & 1 & 1 & 1 & 1 & 1 & 1 & 1 & 1 & 1 & 1 & $\$ 1,410$ & $-\$ 1,600$ & $1.4 \%$ \\
\hline 23 & 1 & 1 & 2 & 1 & 1 & 1 & 2 & 1 & 1 & 1 & 1 & 1 & 1 & 1 & 1 & 1 & 1 & 1 & 1,110 & $-\$ 1,200$ & $1.3 \%$ \\
\hline 24 & 1 & 1 & 2 & 1 & 1 & 1 & 3 & 1 & 1 & 1 & 1 & 1 & 1 & 1 & 1 & 1 & 1 & 1 & $\$ 2,510$ & $-\$ 3,000$ & $2.0 \%$ \\
\hline 25 & 1 & 1 & 2 & 1 & 1 & 1 & 4 & 1 & 1 & 1 & 1 & 1 & 1 & 1 & 1 & 1 & 1 & 1 & $\$ 3,560$ & $-\$ 4,400$ & $2.5 \%$ \\
\hline 26 & 1 & 1 & 2 & 1 & 1 & 1 & 5 & 1 & 1 & 1 & 1 & 1 & 1 & 1 & 1 & 1 & 1 & 1 & $\$ 4,620$ & $-\$ 5,800$ & $2.9 \%$ \\
\hline 27 & 1 & 1 & 2 & 1 & 1 & 1 & 1 & 2 & 1 & 1 & 1 & 1 & 1 & 1 & 1 & 1 & 1 & 1 & $\$ 1,350$ & $-\$ 1,500$ & $1.7 \%$ \\
\hline 28 & 1 & 1 & 2 & 1 & 1 & 1 & 1 & 3 & 1 & 1 & 1 & 1 & 1 & 1 & 1 & 1 & 1 & 1 & $\$ 2,200$ & $-\$ 2,600$ & $2.5 \%$ \\
\hline 29 & 1 & 1 & 2 & 1 & 1 & 1 & 1 & 1 & 2 & 1 & 1 & 1 & 1 & 1 & 1 & 1 & 1 & 1 & $\$ 20$ & $-\$ 700$ & $-3.2 \%$ \\
\hline 30 & 1 & 1 & 2 & 1 & 1 & 1 & 1 & 1 & 3 & 1 & 1 & 1 & 1 & 1 & 1 & 1 & 1 & 1 & $\$ 680$ & $\$ 600$ & $5.6 \%$ \\
\hline 31 & 1 & 1 & 2 & 1 & 1 & 1 & 1 & 1 & 4 & 1 & 1 & 1 & 1 & 1 & 1 & 1 & 1 & 1 & $\$ 1,270$ & $-\$ 1,100$ & $2.2 \%$ \\
\hline 32 & 1 & 1 & 2 & 1 & 1 & 1 & 1 & 1 & 1 & 2 & 1 & 1 & 1 & 1 & 1 & 1 & 1 & 1 & $\$ 710$ & $-\$ 700$ & $1.3 \%$ \\
\hline 33 & 1 & 1 & 2 & 1 & 1 & 1 & 1 & 1 & 1 & 3 & 1 & 1 & 1 & 1 & 1 & 1 & 1 & 1 & $\$ 1,780$ & $-\$ 1,800$ & $2.9 \%$ \\
\hline 34 & 1 & 1 & 2 & 1 & 1 & 1 & 1 & 1 & 1 & 1 & 2 & 1 & 1 & 1 & 1 & 1 & 1 & 1 & $\$ 110$ & $\$ 2,300$ & $1.0 \%$ \\
\hline 35 & 1 & 1 & 2 & 1 & 1 & 1 & 1 & 1 & 1 & 1 & 3 & 1 & 1 & 1 & 1 & 1 & 1 & 1 & $\$ 640$ & $\$ 1,700$ & $1.0 \%$ \\
\hline 36 & 1 & 1 & 2 & 1 & 1 & 1 & 1 & 1 & 1 & 1 & 1 & 2 & 1 & 1 & 1 & 1 & 1 & 1 & $\$ 0$ & $\$ 600$ & $3.3 \%$ \\
\hline 37 & 1 & 1 & 2 & 1 & 1 & 1 & 1 & 1 & 1 & 1 & 1 & 1 & 2 & 1 & 1 & 1 & 1 & 1 & $\$ 0$ & $\$ 300$ & $1.5 \%$ \\
\hline 38 & 1 & 1 & 2 & 1 & 1 & 1 & 1 & 1 & 1 & 1 & 1 & 1 & 1 & 2 & 1 & 1 & 1 & 1 & $\$ 70$ & $\$ 1,300$ & $1.5 \%$ \\
\hline 39 & 1 & 1 & 2 & 1 & 1 & 1 & 1 & 1 & 1 & 1 & 1 & 1 & 1 & 3 & 1 & 1 & 1 & 1 & $\$ 320$ & $\$ 1,300$ & $1.5 \%$ \\
\hline 40 & 1 & 1 & 2 & 1 & 1 & 1 & 1 & 1 & 1 & 1 & 1 & 1 & 1 & 1 & 2 & 1 & 1 & 1 & $\$ 230$ & $\$ 1,800$ & $8.5 \%$ \\
\hline 41 & 1 & 1 & 2 & 1 & 1 & 1 & 1 & 1 & 1 & 1 & 1 & 1 & 1 & 1 & 1 & 2 & 1 & 1 & $\$ 260$ & $\$ 1,800$ & $1.4 \%$ \\
\hline 42 & 1 & 1 & 2 & 1 & 1 & 1 & 1 & 1 & 1 & 1 & 1 & 1 & 1 & 1 & 1 & 1 & 2 & 1 & $\$ 1,550$ & $-\$ 400$ & $2.6 \%$ \\
\hline 43 & 1 & 1 & 2 & 1 & 1 & 1 & 1 & 1 & 1 & 1 & 1 & 1 & 1 & 1 & 1 & 1 & 3 & 1 & $\$ 6,640$ & $-\$ 10,300$ & $3.4 \%$ \\
\hline 44 & 1 & 1 & 2 & 1 & 1 & 1 & 1 & 1 & 1 & 1 & 1 & 1 & 1 & 1 & 1 & 1 & 1 & 2 & $\$ 34,240$ & $-\$ 9,900$ & $33.1 \%$ \\
\hline
\end{tabular}




\section{Appendix D EnergyPlus input file generation}

The main way the house design codes were converted into EnergyPlus input files was through placeholders. Table D.1 shows the function of each placeholder and what type it is: actual value or a BEopt constant. There were separate templates for each HVAC, DHW and ventilation type, and solar PV was modeled only once for each house type so design parameters (found in Table 3.2) 1-3, and 18 are missing from this table.

Table D.1: Placeholders used in EnergyPlus input file templates and their functions

\begin{tabular}{|c|c|c|c|}
\hline Placeholder & $\begin{array}{l}\text { Design } \\
\text { Parameter }\end{array}$ & Type & Function \\
\hline \%EXWA\% & 4 & Actual value & Changes exterior wall insulation thickness \\
\hline$\%$ АСН\% & 5 & Scaled BEopt constant & Changes air-change rate constant \\
\hline$\%$ CEIL\% & 6 & Actual value & Changes ceiling insulation thickness \\
\hline \%BSWA\% & 7 & Actual value & Changes basement wall insulation thickness \\
\hline$\%$ BSFL $\%$ & 8 & Actual value & Changes basement floor thermal resistance \\
\hline$\%$ UFAC\% & 9 & Actual value & Changes simple window U-factor properties \\
\hline$\%$ SHGC\% & 9 & Actual value & Changes simple window SHGC properties \\
\hline$\%$ SHOW\% & 10,14 & Scaled BEopt constant & Changes shower demand constant \\
\hline$\%$ SINK\% & 10,14 & Scaled BEopt constant & Changes sink demand constant \\
\hline$\%$ LIG1\% & 11,16 & Scaled BEopt constant & Changes Light schedule 1 demand constant \\
\hline$\%$ LIG2\% & 11,16 & Scaled BEopt constant & Changes Light schedule 2 demand constant \\
\hline$\%$ LIG3\% & 11,16 & Scaled BEopt constant & Changes Light schedule 3 demand constant \\
\hline$\%$ LIG4\% & 11,16 & Scaled BEopt constant & Changes Light schedule 4 demand constant \\
\hline$\%$ MISL\% & 16 & Scaled BEopt constant & Changes living zone miscellaneous electric load \\
\hline$\%$ MISB \% & 16 & Scaled BEopt constant & Changes basement zone miscellaneous electric load \\
\hline$\%$ FRIG\% & 16,17 & Scaled BEopt constant & Changes fridge demand constant \\
\hline$\%$ RANG\% & 16,17 & Scaled BEopt constant & Changes electric range demand constant \\
\hline$\%$ WASH\% & 16,17 & Scaled BEopt constant & Changes washing machine demand constant \\
\hline$\%$ DRY\% & 16,17 & Scaled BEopt constant & Changes dryer demand constant \\
\hline$\%$ DISH\% & 16,17 & Scaled BEopt constant & Changes dishwasher demand constant \\
\hline$\%$ SHAD \% & 12 & Actual value & Changes shade solar reflectivity \\
\hline$\%$ SIDE \% & 13 & Actual value & Changes siding solar absorptivity \\
\hline$\%$ НЕАТ\% & 15 & Actual value & Changes heating set-point (smart thermostat) \\
\hline$\%$ COOL \% & 15 & Actual value & Changes cooling midday weekday setpoint \\
\hline
\end{tabular}




\section{Appendix E Basement preprocessor settings in EnergyPlus}

The basement preprocessor was run in order to improve the accuracy of the basement model, since the BEopt model assumes no heat transfer through the basement slab. The

EnergyPlus code for the basement preprocessor, which generated the temperatures in

Table 3.3, is shown below:

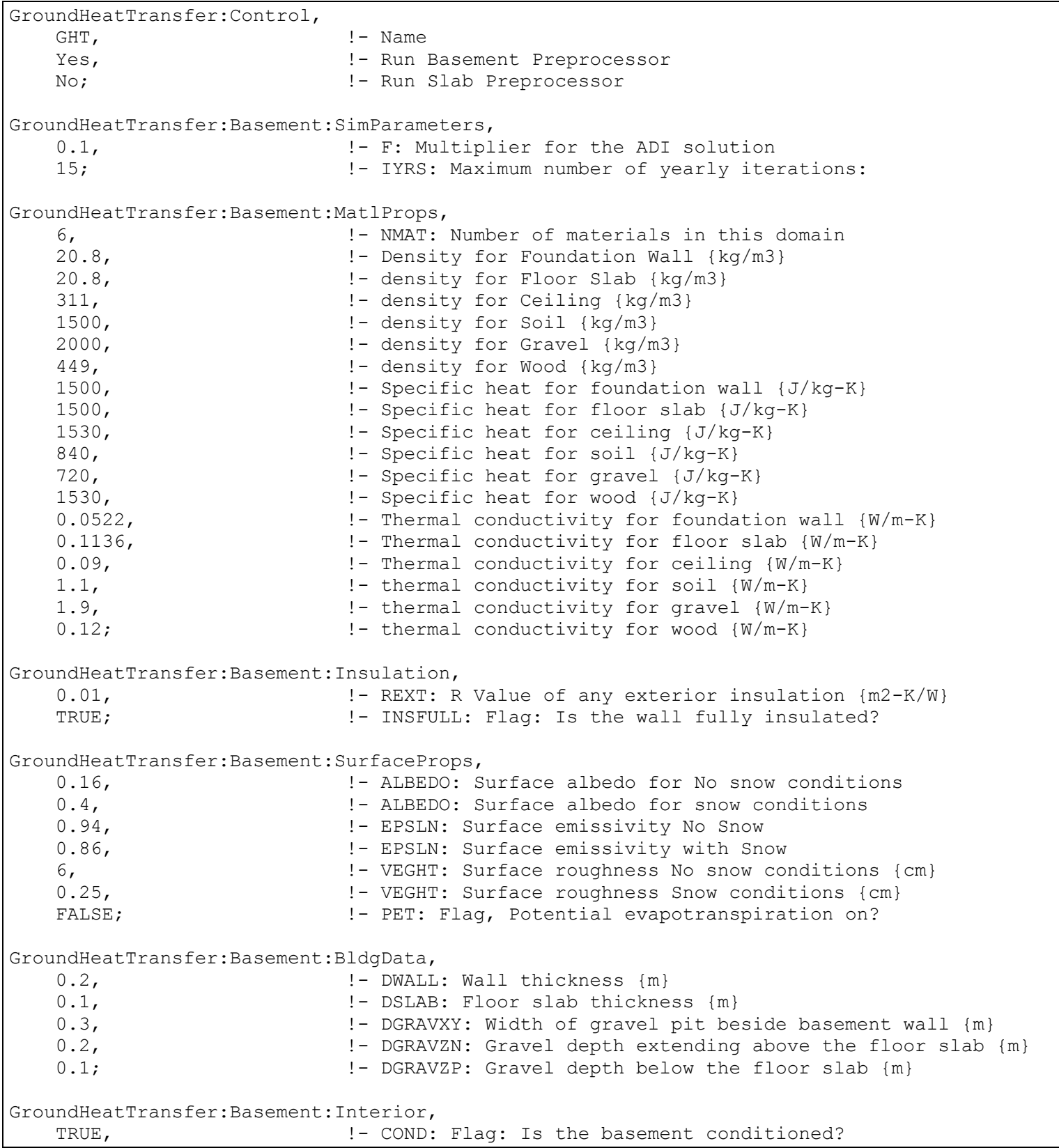




\begin{tabular}{|c|c|}
\hline $\begin{array}{l}0.92, \\
\{\mathrm{~W} / \mathrm{m} 2-\mathrm{K}\}\end{array}$ & !- HIN: Downward convection only heat transfer coefficient \\
\hline $\begin{array}{l}4.04, \\
\{\mathrm{~W} / \mathrm{m} 2-\mathrm{K}\}\end{array}$ & !- HIN: Upward convection only heat transfer coefficient \\
\hline $\begin{array}{l}3.08 \\
\{\mathrm{~W} / \mathrm{m} 2-\mathrm{K}\}\end{array}$ & !- HIN: Horizontal convection only heat transfer coefficient \\
\hline $\begin{array}{l}\text { 6.13, } \\
\text { transfer coefficient }\{\mathrm{W} / \mathrm{m} 2-\mathrm{K}\}\end{array}$ & !- HIN: Downward combined (convection and radiation) heat \\
\hline $\begin{array}{l}9.26, \\
\text { transfer coefficient }\{\mathrm{W} / \mathrm{m} 2-\mathrm{K}\} \\
\quad 8.29 ; \\
\text { transfer coefficient }\{\mathrm{W} / \mathrm{m} 2-\mathrm{K}\}\end{array}$ & $\begin{array}{l}\text { !- HIN : Upward combined (convection and radiation) heat } \\
\text { !- HIN: Horizontal combined (convection and radiation) heat }\end{array}$ \\
\hline $\begin{array}{l}\text { roundHeatTransfer: Basement: Cc } \\
\text { 18, } \\
18, \\
18, \\
18, \\
18, \\
18, \\
18, \\
18, \\
18, \\
18, \\
18, \\
18, \\
0 ;\end{array}$ & $\begin{array}{l}\text { ombldg, } \\
\text { !- January average temperature }\{\mathrm{C}\} \\
\text { !- February average temperature }\{\mathrm{C}\} \\
\text { !- March average temperature }\{\mathrm{C}\} \\
\text { !- April average temperature }\{\mathrm{C}\} \\
\text { - May average temperature }\{\mathrm{C}\} \\
\text { - June average temperature }\{\mathrm{C}\} \\
\text { - July average temperature }\{\mathrm{C}\} \\
\text { - - August average temperature }\{\mathrm{C}\} \\
\text { - September average temperature }\{\mathrm{C}\} \\
\text { - - October average temperature }\{\mathrm{C}\} \\
\text { !- November average temperature }\{\mathrm{C}\} \\
\text { !- December average temperature }\{\mathrm{C}\} \\
\text { - Daily variation sine wave amplitude \{deltaC }\end{array}$ \\
\hline $\begin{array}{l}\text { GroundHeatTransfer: Basement: Ec } \\
6.5, \\
\text { TRUE; }\end{array}$ & $\begin{array}{l}\text { quivslab, } \\
\text { !- APRatio: The area to perimeter ratio for this slab }\{\mathrm{m}\} \\
\text { - EquivSizing: Flag }\end{array}$ \\
\hline $\begin{array}{l}\text { GroundHeatTransfer: Basement: Ec } \\
\text { 15, } \\
\text { ground domain }\{\mathrm{m}\} \\
0.0508, \\
2 ;\end{array}$ & $\begin{array}{l}\text { quivAutoGrid, } \\
\text { !- CLEARANCE: Distance from outside of wall to edge of } 3-\mathrm{D} \\
\text { !- SlabDepth: Thickness of the floor slab }\{\mathrm{m}\} \\
\text { !- BaseDepth: Depth of the basement wall below grade }\{\mathrm{m}\}\end{array}$ \\
\hline
\end{tabular}




\section{Appendix F Costs of technologies}

The cost data used in this optimization comes from a number of different sources, but the majority of it is made up of costs from the Affordable Net-Zero Energy Housing cost database [44], provided by CanmetENERGY. More detail on the cost sources and cost calculations can be found in Section 3.4. Table F.1 shows the cost data for each system type used in the optimization, and the lifespan if applicable. The lifespans come from the NREL Measures Database version 3.0.0 [33].

Table F.1: Costs for technologies used in optimization [44], [71], [73], [31], [33]

\begin{tabular}{|c|c|c|c|c|c|}
\hline Variable & $\begin{array}{c}\text { Category and } \\
\text { unit }\end{array}$ & Option & $\begin{array}{c}\text { Lifespan } \\
\text { (yrs) }\end{array}$ & \multicolumn{2}{|c|}{ Cost per unit } \\
\hline \multirow{5}{*}{1} & \multirow{5}{*}{ Heating - each } & $\mathrm{Gas}+\mathrm{AC}$ & 20 & & $\$ 8,609$ \\
\hline & & Elec + AC & 20 & & $\$ 9,848$ \\
\hline & & ASHP & 16 & & $\$ 9,030$ \\
\hline & & CCASHP & 16 & & $\$ 15,414$ \\
\hline & & GSHP & 16 & & $\$ 27,170$ \\
\hline \multirow{5}{*}{2} & \multirow{5}{*}{ Hot water - each } & 0.67 Gas & 13 & & $\$ 1,280$ \\
\hline & & $0.96 \mathrm{Gas}$ & 20 & & $\$ 2,275$ \\
\hline & & 0.95 Elec & 13 & & $\$ 675$ \\
\hline & & HPWH & 13 & & $\$ 1,994$ \\
\hline & & SDHW & 30 & & $\$ 7,792$ \\
\hline \multirow{3}{*}{3} & \multirow{3}{*}{ HRV - each } & Exhaust fan & 18 & & $\$ 460$ \\
\hline & & $60 \%$ & 18 & & $\$ 1,260$ \\
\hline & & $75 \%$ & 18 & & $\$ 1,825$ \\
\hline \multirow{6}{*}{4} & \multirow{6}{*}{$\begin{array}{l}\text { Exterior wall - m2 } \\
\text { applied (sq ft) }\end{array}$} & & & Single & Town \\
\hline & & 3.87 RSI batt & - & $\$ 0.00(\$ 0.00)$ & $\$ 0.00(\$ 0.00)$ \\
\hline & & + 0.88 RSI XPS & - & $\$ 17.10(\$ 1.59)$ & $\$ 17.10(\$ 1.59)$ \\
\hline & & + 1.76 RSI XPS & - & $\$ 26.75(\$ 2.48)$ & $\$ 26.75(\$ 2.48)$ \\
\hline & & + 2.64 RSI XPS* & - & $\$ 45.66(\$ 4.24)$ & $\$ 40.64(\$ 3.78)$ \\
\hline & & +3.52 RSI XPS* & - & $\$ 63.49(\$ 5.90)$ & $\$ 53.44(\$ 4.97)$ \\
\hline \multirow{5}{*}{5} & \multirow{5}{*}{$\begin{array}{c}\mathrm{ACH}-\mathrm{m} 2 \text { floor } \\
(\mathrm{sq} \mathrm{ft})\end{array}$} & $3 \mathrm{ACH} 50$ & - & & $\$ 4.63(\$ 0.43)$ \\
\hline & & $2.5 \mathrm{ACH} 50$ & - & & $\$ 6.89(\$ 0.64)$ \\
\hline & & $2 \mathrm{ACH} 50$ & - & & $\$ 9.58(\$ 0.89)$ \\
\hline & & $1.5 \mathrm{ACH} 50$ & - & & $\$ 13.67(\$ 1.27)$ \\
\hline & & $1 \mathrm{ACH} 50$ & - & & $\$ 17.01(\$ 1.58)$ \\
\hline
\end{tabular}




\begin{tabular}{|c|c|c|c|c|}
\hline Variable & $\begin{array}{c}\text { Category and } \\
\text { unit }\end{array}$ & Option & Lifespan & Cost per unit \\
\hline \multirow{4}{*}{6} & \multirow{4}{*}{$\begin{array}{l}\text { Ceiling insulation } \\
\text { - m2 applied (sq } \\
\mathrm{ft})\end{array}$} & 8.81 RSI blown-in & - & $\$ 19.16(\$ 1.78)$ \\
\hline & & 10.57 RSI blown-in & - & $\$ 21.96(\$ 2.04)$ \\
\hline & & 12.33 RSI blown-in & - & $\$ 26.26(\$ 2.44)$ \\
\hline & & 14.09 RSI blown-in & - & $\$ 30.03(\$ 2.79)$ \\
\hline \multirow{5}{*}{7} & \multirow{5}{*}{$\begin{array}{c}\text { Basement } \\
\text { insulation - m2 } \\
\text { applied (sq ft) }\end{array}$} & 2.11 RSI batt & - & $\$ 0.00(\$ 0.00)$ \\
\hline & & 3.52 RSI batt & - & $\$ 9.46(\$ 0.88)$ \\
\hline & & +0.88 RSI XPS & - & $\$ 21.37(\$ 1.98)$ \\
\hline & & +1.76 RSI XPS & - & $\$ 30.30(\$ 2.81)$ \\
\hline & & +2.64 RSI XPS & - & $\$ 39.34(\$ 3.65)$ \\
\hline \multirow{3}{*}{8} & \multirow{3}{*}{$\begin{array}{l}\text { Under slab - m2 } \\
\text { applied (sq ft) }\end{array}$} & Code double & - & $\$ 0.00(\$ 0.00)$ \\
\hline & & TG high gain & - & $\$ 14.27(\$ 1.33)$ \\
\hline & & TG low gain & - & $\$ 23.21(\$ 2.16)$ \\
\hline \multirow{4}{*}{9} & \multirow{4}{*}{$\begin{array}{l}\text { Windows - m2 } \\
\text { applied (sq ft) }\end{array}$} & DG high gain & 30 & $\$ 247.35(\$ 22.98)$ \\
\hline & & DG low gain & 30 & $\$ 248.00(\$ 23.04)$ \\
\hline & & TG high gain & 30 & $\$ 268.88(\$ 24.98)$ \\
\hline & & TG low gain & 30 & $\$ 287.18(\$ 26.68)$ \\
\hline \multirow{3}{*}{10} & \multirow{3}{*}{ DWHR - each } & None & - & $\$ 0$ \\
\hline & & $37 \%$ & - & $\$ 706$ \\
\hline & & $54 \% \times 2$ & - & $\$ 1,784$ \\
\hline \multirow{3}{*}{11} & \multirow{3}{*}{$\begin{array}{l}\text { Lighting - m2 } \\
\text { applied (sq ft) }\end{array}$} & Halogen & 1.2 & $\$ 0.13(\$ 0.01)$ \\
\hline & & $\mathrm{CFL}$ & 14 & $\$ 0.46(\$ 0.04)$ \\
\hline & & LED & - & $\$ 2.12(\$ 0.20)$ \\
\hline \multirow{2}{*}{12} & \multirow{2}{*}{ Blinds - set } & Light & 30 & $\$ 0$ \\
\hline & & Dark & 30 & $\$ 0$ \\
\hline \multirow{2}{*}{13} & \multirow{2}{*}{ Siding - set } & Light & 30 & $\$ 0$ \\
\hline & & Dark & 30 & $\$ 0$ \\
\hline \multirow{3}{*}{14} & \multirow{3}{*}{$\begin{array}{c}\text { Water fixtures - } \\
\text { set }\end{array}$} & Code & - & $\$ 408$ \\
\hline & & High efficiency & - & $\$ 473$ \\
\hline & & HE with HE Toilets & - & $\$ 728$ \\
\hline \multirow{2}{*}{15} & \multirow{2}{*}{ Thermostat - each } & Regular & 14 & $\$ 20$ \\
\hline & & Smart & 14 & $\$ 250$ \\
\hline \multirow{2}{*}{16} & \multirow{2}{*}{$\begin{array}{c}\text { Energy monitoring } \\
\text { - each }\end{array}$} & None & - & $\$ 0$ \\
\hline & & Energy monitor & 14 & $\$ 260$ \\
\hline \multirow{3}{*}{17} & \multirow{3}{*}{ Appliances - set } & Regular & 14 & $\$ 2,239$ \\
\hline & & High efficiency & 14 & $\$ 3,791$ \\
\hline & & Best in class & 14 & $\$ 8,876$ \\
\hline \multirow[t]{2}{*}{18} & \multirow[t]{2}{*}{ Solar** - each } & $\begin{array}{l}\text { None / Solar PV } \\
\text { Ready }\end{array}$ & - & $\$ 0$ or $\$ 2,180$ \\
\hline & & Full solar PV & 30 & $\$ 2,180+\$ 3,375 * \mathrm{~kW}$ \\
\hline
\end{tabular}

* Additional cost added due to lost square footage. ** If the house could be net-zero but solar is not selected, the house becomes NZE ready, and if a house does not need full solar to be NZE, then only the amount of solar necessary is added 


\section{Appendix G Electricity rate increase}

Table G.1 shows the electricity rate increases calculated from the Ontario Power Authority's Long Term Energy Plan [74], which contains long term predictions of the electricity rate. The rate increase from years 2015 to 2032 are taken from the Long Term Energy Plan, and the rest of the years are extrapolated. For optimization scenario 7 the electricity rate is made to increase by an extra $1 \%$ in order to assess the impact of higher electricity costs. The second column in Table G.1 shows the rates used for scenario 7.

Table G.1: Electricity rate increases over time

\begin{tabular}{c|cc}
\hline \multirow{2}{*}{ Year } & \multicolumn{2}{|c}{ Electricity increase rate } \\
\cline { 2 - 3 } & Nominal & $\begin{array}{c}\text { Additional } 1 \% \\
\text { used in Scenario } 7\end{array}$ \\
\hline $\mathbf{2 0 1 5}$ & $6.6 \%$ & $7.6 \%$ \\
$\mathbf{2 0 1 6}$ & $3.1 \%$ & $4.1 \%$ \\
$\mathbf{2 0 1 7}$ & $1.8 \%$ & $2.8 \%$ \\
$\mathbf{2 0 1 8}$ & $4.7 \%$ & $5.7 \%$ \\
$\mathbf{2 0 2 0}$ & $-0.6 \%$ & $0.4 \%$ \\
$\mathbf{2 0 2 1}$ & $2.3 \%$ & $3.3 \%$ \\
$\mathbf{2 0 2 2}$ & $3.3 \%$ & $4.3 \%$ \\
$\mathbf{2 0 2 3}$ & $3.2 \%$ & $4.2 \%$ \\
$\mathbf{2 0 2 4}$ & $-2.6 \%$ & $-1.6 \%$ \\
$\mathbf{2 0 2 5}$ & $1.6 \%$ & $2.6 \%$ \\
$\mathbf{2 0 2 6}$ & $1.6 \%$ & $2.6 \%$ \\
$\mathbf{2 0 2 7}$ & $2.1 \%$ & $3.1 \%$ \\
$\mathbf{2 0 2 8}$ & $1.0 \%$ & $2.0 \%$ \\
$\mathbf{2 0 2 9}$ & $1.0 \%$ & $2.0 \%$ \\
$\mathbf{2 0 3 0}$ & $1.0 \%$ & $2.0 \%$ \\
$\mathbf{2 0 3 1}$ & $0.5 \%$ & $1.5 \%$ \\
$\mathbf{2 0 3 2}$ & $1.0 \%$ & $2.0 \%$ \\
$\mathbf{2 0 3 3}$ & $1.4 \%$ & $2.4 \%$ \\
$\mathbf{2 0 3 4}$ & $1.8 \%$ & $2.8 \%$ \\
$\mathbf{2 0 3 5}$ & $1.8 \%$ & $2.8 \%$ \\
$\mathbf{2 0 3 6}$ & $1.8 \%$ & $2.8 \%$ \\
$\mathbf{2 0 3 7}$ & $1.8 \%$ & $2.8 \%$ \\
$\mathbf{2 0 3 8}$ & $1.8 \%$ & $2.8 \%$ \\
$\mathbf{2 0 3 9}$ & $1.8 \%$ & $2.8 \%$ \\
\hline & $1.8 \%$ & $2.8 \%$ \\
\hline
\end{tabular}




\section{Appendix H NZEH and COH results from optimization scenarios}

Table H.1 shows the best net-zero energy house (NZEH) or near net-zero energy house (NNZEH) results from the optimization scenarios. Table H.2 shows the best cost-

optimized house $(\mathrm{COH})$ results. The tables show the design in code form, the incremental building cost (IBC), the net present value (NPV), and the total site energy savings. The listing of the scenarios can be found in Table 3.5, and the designs can be decoded using

Table 3.2. Note that for the optimization scenarios where a NZEH was not found, the closest NNZEH was chosen.

Table H.1: NZEH design and cost results from optimization scenarios

\begin{tabular}{|c|c|c|c|c|c|c|c|c|c|c|c|c|c|c|c|c|c|c|c|c|c|}
\hline \multirow{2}{*}{ Scenario } & \multicolumn{18}{|c|}{ NZEH parameter selection } & \multirow{2}{*}{ IBC } & \multirow{2}{*}{ NPV } & \multirow{2}{*}{$\begin{array}{l}\text { Energy } \\
\text { savings }\end{array}$} \\
\hline & 1 & 2 & 3 & 4 & 5 & 6 & 7 & 8 & 9 & 10 & 11 & 12 & 13 & 14 & 15 & 16 & 17 & 18 & & & \\
\hline 1 & 4 & 5 & 3 & 3 & 5 & 4 & 4 & 1 & 3 & 3 & 2 & 1 & 1 & 3 & 2 & 1 & 2 & 2 & $\$ 68,120$ & $-\$ 42,400$ & $100 \%$ \\
\hline 2 & 5 & 5 & 3 & 5 & 5 & 4 & 5 & 3 & 3 & 3 & 2 & 1 & 1 & 3 & 2 & 1 & 2 & 2 & $\$ 67,600$ & $-\$ 56,000$ & $95 \%$ \\
\hline 3 & 5 & 5 & 3 & 5 & 5 & 4 & 5 & 3 & 3 & 3 & 2 & 1 & 1 & 3 & 2 & 1 & 2 & 2 & $\$ 63,470$ & $-\$ 51,200$ & $96 \%$ \\
\hline 4 & 3 & 5 & 3 & 3 & 5 & 4 & 3 & 1 & 3 & 3 & 2 & 2 & 2 & 3 & 2 & 2 & 2 & 2 & $\$ 60,950$ & $-\$ 27,700$ & $100 \%$ \\
\hline 5 & 4 & 5 & 3 & 3 & 5 & 4 & 4 & 1 & 3 & 3 & 2 & 1 & 1 & 3 & 2 & 1 & 2 & 2 & $\$ 52,110$ & $-\$ 20,900$ & $100 \%$ \\
\hline 6 & 4 & 5 & 3 & 3 & 5 & 3 & 3 & 2 & 3 & 3 & 2 & 1 & 1 & 3 & 2 & 1 & 2 & 2 & $\$ 67,930$ & $-\$ 10,800$ & $100 \%$ \\
\hline 7 & 4 & 5 & 3 & 3 & 5 & 4 & 4 & 1 & 3 & 3 & 2 & 1 & 1 & 3 & 2 & 1 & 2 & 2 & $\$ 68,120$ & $-\$ 38,800$ & $100 \%$ \\
\hline 8 & 4 & 5 & 3 & 3 & 5 & 3 & 3 & 2 & 3 & 3 & 2 & 1 & 1 & 3 & 2 & 1 & 2 & 2 & $\$ 67,930$ & $-\$ 38,800$ & $00 \%$ \\
\hline 9 & 4 & 5 & 3 & 3 & 5 & 4 & 4 & 1 & 3 & 3 & 2 & 1 & 1 & 3 & 2 & 1 & 2 & 2 & $\$ 57,910$ & $-\$ 27,800$ & $100 \%$ \\
\hline 10 & 4 & 5 & 3 & 3 & 5 & 4 & 4 & 1 & 3 & 3 & 2 & 1 & 1 & 3 & 2 & 1 & 2 & 2 & $\$ 68,120$ & $-\$ 38,100$ & $100 \%$ \\
\hline 11 & 4 & 5 & 3 & 3 & 5 & 4 & 4 & 1 & 3 & 3 & 2 & 1 & 1 & 3 & 2 & 1 & 2 & 2 & $\$ 68,120$ & $-\$ 32,700$ & $100 \%$ \\
\hline 12 & 3 & 5 & 3 & 3 & 5 & 4 & 3 & 1 & 3 & 3 & 2 & 2 & 2 & 3 & 2 & 2 & 2 & 2 & $\$ 38,190$ & $\$ 3,100$ & $100 \%$ \\
\hline 13 & 5 & 5 & 3 & 5 & 5 & 4 & 5 & 3 & 3 & 3 & 2 & 2 & 2 & 3 & 2 & 2 & 3 & 2 & $\$ 53,200$ & $-\$ 33,700$ & $99.8 \%$ \\
\hline 14 & 5 & 4 & 3 & 4 & 5 & 3 & 5 & 2 & 3 & 3 & 2 & 2 & 2 & 3 & 2 & 2 & 3 & 2 & $\$ 43,150$ & $-\$ 24,700$ & $100 \%$ \\
\hline 15 & 3 & 5 & 3 & 3 & 5 & 4 & 3 & 1 & 3 & 3 & 2 & 2 & 2 & 3 & 2 & 2 & 2 & 2 & $\$ 38,190$ & $\$ 12,900$ & $100 \%$ \\
\hline 16 & 5 & 5 & 3 & 5 & 5 & 4 & 5 & 3 & 3 & 3 & 2 & 2 & 2 & 3 & 2 & 2 & 3 & 2 & $\$ 53,200$ & $-\$ 23,900$ & $99.8 \%$ \\
\hline 17 & 5 & 4 & 3 & 4 & 5 & 3 & 4 & 3 & 3 & 3 & 2 & 2 & 2 & 3 & 2 & 2 & 3 & 2 & $\$ 43,290$ & $-\$ 16,700$ & $100 \%$ \\
\hline
\end{tabular}


Table H.2: COH design and cost results from optimization scenarios

\begin{tabular}{|c|c|c|c|c|c|c|c|c|c|c|c|c|c|c|c|c|c|c|c|c|c|}
\hline \multirow{2}{*}{ Scenario } & \multicolumn{10}{|c|}{ IBC } & \multirow{2}{*}{ NPV } & $\begin{array}{c}\text { Energy } \\
\text { savings }\end{array}$ \\
\cline { 2 - 3 } & 1 & 2 & 3 & 4 & 5 & 6 & 7 & 8 & 9 & 10 & 11 & 12 & 13 & 14 & 15 & 16 & 17 & 18 & & \\
\hline 1 & 1 & 1 & 1 & 1 & 1 & 1 & 1 & 1 & 3 & 1 & 2 & 1 & 1 & 3 & 2 & 1 & 2 & 1 & $\$ 2,090$ & $\$ 7,200$ & $15 \%$ \\
\hline 2 & 1 & 1 & 1 & 1 & 1 & 1 & 1 & 1 & 3 & 1 & 2 & 1 & 1 & 3 & 2 & 1 & 2 & 1 & $\$ 1,790$ & $\$ 6,600$ & $16 \%$ \\
\hline 3 & 1 & 1 & 2 & 1 & 1 & 1 & 1 & 1 & 3 & 1 & 2 & 1 & 1 & 3 & 2 & 1 & 1 & 1 & $\$ 990$ & $\$ 4,600$ & $15 \%$ \\
\hline 4 & 1 & 1 & 1 & 1 & 1 & 1 & 1 & 1 & 3 & 1 & 2 & 2 & 2 & 3 & 2 & 2 & 1 & 1 & $\$ 800$ & $\$ 9,900$ & $18 \%$ \\
\hline 5 & 1 & 1 & 2 & 1 & 1 & 1 & 1 & 1 & 3 & 1 & 2 & 1 & 1 & 3 & 2 & 1 & 1 & 2 & $\$ 19,560$ & $\$ 18,300$ & $49 \%$ \\
\hline 6 & 1 & 1 & 1 & 1 & 1 & 1 & 1 & 1 & 3 & 1 & 2 & 1 & 1 & 3 & 2 & 1 & 2 & 2 & $\$ 36,330$ & $\$ 28,800$ & $49 \%$ \\
\hline 7 & 1 & 2 & 1 & 1 & 1 & 1 & 1 & 1 & 3 & 1 & 2 & 1 & 1 & 3 & 2 & 1 & 1 & 1 & $\$ 1,530$ & $\$ 7,000$ & $16 \%$ \\
\hline 8 & 1 & 2 & 1 & 1 & 1 & 1 & 1 & 1 & 3 & 1 & 2 & 1 & 1 & 3 & 2 & 1 & 2 & 1 & $\$ 3,090$ & $\$ 6,600$ & $19 \%$ \\
\hline 9 & 1 & 1 & 1 & 1 & 1 & 1 & 1 & 1 & 3 & 1 & 2 & 1 & 1 & 3 & 2 & 1 & 2 & 1 & $\$ 1,780$ & $\$ 7,700$ & $15 \%$ \\
\hline 10 & 1 & 2 & 1 & 1 & 1 & 1 & 1 & 1 & 3 & 1 & 2 & 1 & 1 & 3 & 2 & 1 & 2 & 1 & $\$ 3,090$ & $\$ 6,900$ & $19 \%$ \\
\hline 11 & 1 & 1 & 2 & 1 & 1 & 1 & 1 & 1 & 3 & 1 & 2 & 1 & 1 & 3 & 2 & 1 & 1 & 1 & $\$ 1,340$ & $\$ 6,100$ & $16 \%$ \\
\hline 12 & 1 & 1 & 1 & 1 & 1 & 2 & 1 & 1 & 3 & 2 & 2 & 2 & 2 & 3 & 2 & 2 & 2 & 2 & $\$ 18,390$ & $\$ 25,200$ & $55 \%$ \\
\hline 13 & 1 & 1 & 1 & 1 & 3 & 1 & 1 & 1 & 3 & 1 & 2 & 2 & 2 & 3 & 2 & 2 & 2 & 2 & $\$ 13,310$ & $\$ 19,700$ & $54 \%$ \\
\hline 14 & 1 & 1 & 2 & 1 & 1 & 1 & 1 & 1 & 3 & 1 & 2 & 2 & 2 & 3 & 2 & 2 & 2 & 2 & $\$ 13,120$ & $\$ 18,200$ & $58 \%$ \\
\hline 15 & 1 & 1 & 2 & 1 & 1 & 1 & 1 & 1 & 3 & 1 & 2 & 2 & 2 & 3 & 2 & 2 & 2 & 2 & $\$ 18,160$ & $\$ 29,000$ & $57 \%$ \\
\hline 16 & 1 & 1 & 2 & 1 & 3 & 1 & 1 & 1 & 3 & 1 & 2 & 2 & 2 & 3 & 2 & 2 & 2 & 2 & $\$ 13,990$ & $\$ 21,600$ & $58 \%$ \\
\hline 17 & 1 & 1 & 2 & 1 & 2 & 1 & 1 & 1 & 3 & 1 & 2 & 2 & 2 & 3 & 2 & 2 & 2 & 2 & $\$ 13,500$ & $\$ 21,000$ & $60 \%$ \\
\hline
\end{tabular}

